\title{
Regulating Retinoic Acid Availability during Development and Regeneration: The Role of the CYP26 Enzymes
}

\author{
Catherine Roberts ${ }^{1,2}$ \\ 1 Developmental Biology of Birth Defects, UCL-GOS Institute of Child Health, 30 Guilford St, \\ London WC1N 1EH, UK; catherine.roberts@ucl.ac.uk \\ 2 Institute of Medical and Biomedical Education St George's, University of London, Cranmer Terrace, Tooting, \\ London SW17 0RE, UK
}

Received: 27 September 2019; Accepted: 17 February 2020; Published: 5 March 2020

\begin{abstract}
This review focuses on the role of the Cytochrome p450 subfamily 26 (CYP26) retinoic acid (RA) degrading enzymes during development and regeneration. Cyp26 enzymes, along with retinoic acid synthesising enzymes, are absolutely required for RA homeostasis in these processes by regulating availability of RA for receptor binding and signalling. Cyp26 enzymes are necessary to generate RA gradients and to protect specific tissues from RA signalling. Disruption of RA homeostasis leads to a wide variety of embryonic defects affecting many tissues. Here, the function of CYP26 enzymes is discussed in the context of the RA signalling pathway, enzymatic structure and biochemistry, human genetic disease, and function in development and regeneration as elucidated from animal model studies.
\end{abstract}

Keywords: CYP26; retinoic acid; embryonic development

\section{Introduction}

Retinoic acid (RA) signalling is required in postnatal and adult life where it has various roles which include: neurogenesis, synaptic plasticity, learning and memory (reviewed [1,2]) and circadian rhythms and seasonality [3]; retinal gap-junction neuromodulation and rod and cone cell function, (reviewed [4]); immune response for T-cell differentiation, immunoglobulin production, homing of innate immune cells to the gut and production of pro-inflammatory cytokines, (reviewed [5]); roles in lipid/fatty acid formation/breakdown, adipocyte differentiation and remodelling and energy metabolism (reviewed [6]) and postnatal skeletal growth and homeostasis (reviewed [7,8]).

RA homeostasis to regulate signalling by controlling available RA levels is absolutely required in the developing embryo. Both reduced and excessive RA levels are injurious to embryonic development, producing similar embryonic defects, usually leading to embryonic lethality [9], (reviewed [10,11]). Availability of RA is regulated by a balance between synthesizing enzymes (retinaldehyde dehydrogenases-RALDHs) and metabolizing enzymes (Cytochrome p450 family 26-CYP26s). Whilst substantial progress has been made regarding the function of RALDHs during development, much less is known about the CYP26s. This review gives a brief overview of the RA pathway and function in development, already well-described in numerous reviews, for example [10-16] and then focusses upon the role of the RA-degrading CYP26 enzymes during embryonic development and in regenerative processes.

\section{Retinoic Acid Synthesis and Receptor Signalling}

The retinoic acid pathway is characterised by a number of cytoplasmic oxidative enzymatic reactions, some of which are required to synthesise RA from dietary precursors including Vitamin 
A and others which are required to metabolise RA to less biologically active forms. RA can act cell autonomously (autocrine) entering the nucleus to bind to hetero-dimeric receptors at target gene promoters altering transcriptional activity of the promoter. It also acts non-cell autonomously, functioning as a classic morphogen, diffusing across cell membranes establishing retinoic acid gradients within and across tissues (paracrine).

RA is a lipophilic molecule, manufactured during embryogenesis from maternal retinol (vitamin A) in placental species and carotenoids in the yolk of oviparous species [17]. This process (summarised in Figure 1) begins with circulating retinol being taken up by embryonic retinol binding protein 4 (RBP4). This complex then binds to STRA6 (stimulated in retinoic acid 6) and is transported across the plasma membrane in the cell. Stra6 is expressed in many tissues in the developing embryo, including the epithelia of the pharyngeal arches and facial mesenchyme. Human mutations in Stra6 produce a complex phenotype including anophthalmia, lung hypoplasia, mental retardation and craniofacial and heart defects reminiscent of 22q11 Deletion Syndrome [18].

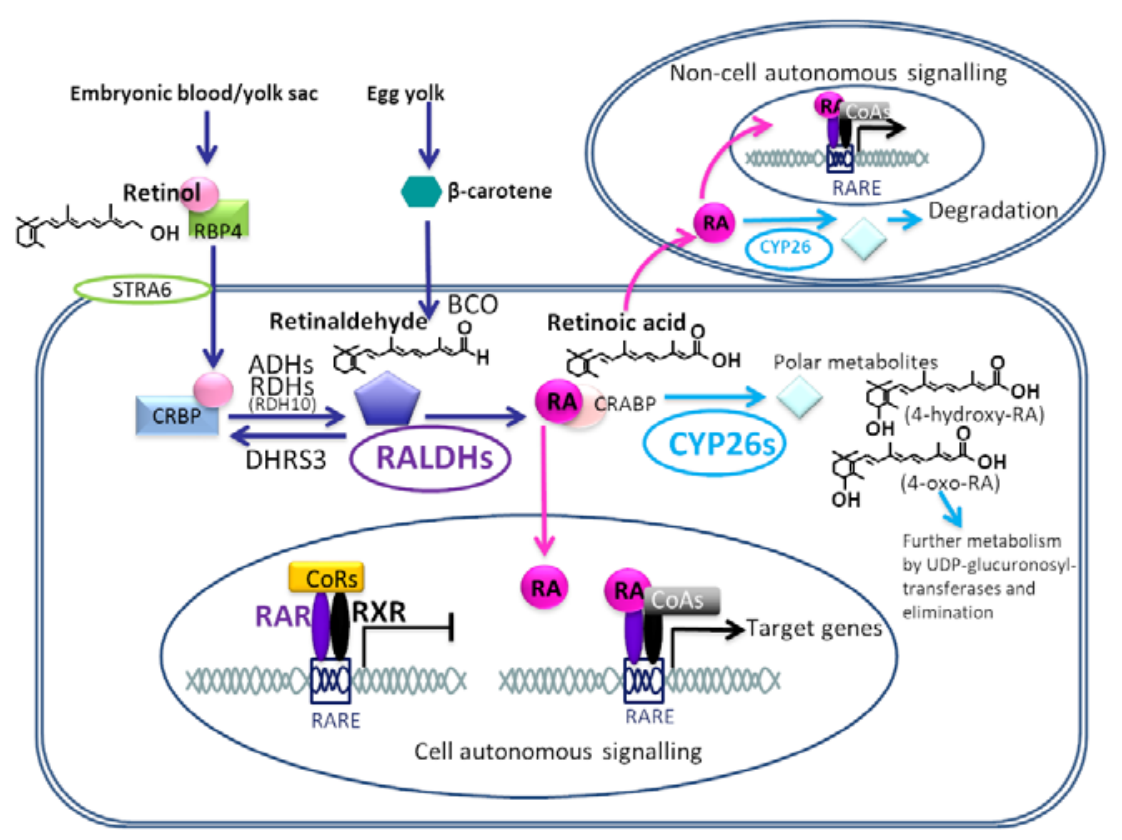

Figure 1. Schematic of the retinoic acid signalling pathway during development. Maternal diet-derived retinol/ in blood/yolk sac/yolk of embryo bound to retinol binding protein 4 (RBP4) enter cellular cytoplasm via binding to membrane bound RBP/RA complex receptor STRA6 (Stimulated by Retinoic Acid 6). Retinol is then bound to cellular retinol binding protein (CRBP) and reversibly oxidised to the intermediate form retinaldehyde (also known as retinal) by alcohol dehydrogenase and retinol dehydrogenase (particularly RDH10) enzymes. The reverse reaction, retinaldehyde to retinol is catalysed by the dehydrogenase/reductase 3 (DHRS3) enzyme. Retinaldehyde can also be generated from $\beta$-carotene by $\beta$-carotene 15,15'-monooxygenase (BCO). Retinaldehyde is then irreversibly converted to retinoic acid (RA) by retinaldehyde dehydrogenase (RALDH) enzymes, particularly RALDH2. RA can then undergo three different processes: (1.) RA bound to cellular retinoic acid binding proteins which shuttle RA to the nucleus. Hetero-dimerised RAR-RXR complexes (retinoic acid receptor-retinoid-X-receptor) are bound to conserved retinoic acid responsive elements (RARE) within the promotors of target genes. Most frequently, in the absence of RA co-repressor complexes (e.g. NCoR/SMRT) are bound to the RAR-RXRs, preventing transcription. Upon RA binding, the receptors undergo a conformational change, releasing co-repressor complexes and recruiting co-activator proteins (e.g. SWI/SNF, pCIP/p300, PolII) as replacements, thus triggering transcription activation of target genes. 
(2.) RA produced in one cells can also signal in a paracrine fashion to neighbouring cells, mediating non-cell autonomous effects. (3.) If Cytochrome P450 subfamily 26 (CYP26) enzymes are present in the cell, RA is hydroxylised in the cytoplasm to more polar metabolites with less biological activity, which are further processed by UDP-gluconyl transferases and eventually eliminated from the cell. Adapted from Niederreither and Dolle 2008 [10].

Retinol then must be converted by oxidation into the intermediate form of retinaldehyde which is accomplished by two enzyme families, the cytosolic alcohol dehydrogenases (ADHs) and microsomal retinol dehydrogenases (RDHs).

Adh1, Adh3 (also known as Adh5) and Adh4 (also known as Adh7) null mutations in mice are viable post-natally on a standard diet. When challenged by administration of retinol, levels of RA in the test tissue of the kidney increased in wild type mice. Lesser increases were seen for $A d h 1^{-/-}$and $A d h 4^{-/-}$ animals. Further examination of $A d h 3^{-/-}$mice revealed slightly smaller litter sizes and reduced growth compared to wild type. On a vitamin A deficient (VAD) diet $100 \%$ of $A d h 3^{-/-}$eventually died, with $80 \%$ lethality between P0 and P3. For $A d h 1^{-/-}$mice $40 \%$ lethality by P40 was observed whereas $A d h 4^{-/}$ mice all died by P15. Growth deficiency was observed for all Adh mutations on a VAD diet but was more severe in $A d h 3$ and $A d h 4$ null mutant mice. Interestingly, double null mutants for Adh1/4 exhibited a slightly milder phenotype than $A d h 4^{-/-}$animals alone, surviving slightly longer into the postnatal period with $100 \%$ penetrant lethality by P24. The VAD diet also affected embryonic viability. Live-born mice were seen in only $15 \%$ of $A d h 1^{-/-}$pups compared to $49 \%$ for wild-type and the reabsorption rate at e12.5 was $69 \%$ compared to $30 \%$ for wild type. When these mice were fed on retinol supplemented diets, $A d h 3^{-/-}$and Adh $4^{-/-}$displayed high levels (95\%) of postnatal survival, whereas for $A d h 1^{-/}$mice, only $36 \%$ survived to adulthood, with $64 \%$ lethality between P0 and P3 [19-24]. Therefore, the ADHs may be variously, and possibly redundantly, involved in RA synthesis from retinol and play protective roles against the effects of excess or reduced retinol.

Work in the chick embryo also suggests that Cyp1b1 a p450 cytochrome enzyme may be able to convert retinol to retinaldehyde and retinoic acid during neural development [25]. Whilst mouse null mutations appear normal during embryogenesis [26], human mutations are associated with congenital glaucoma, Peters anomaly [27,28] and Axel-Riegers Syndrome [29,30].

Various RDH genes coding for retinol dehydrogenase enzymes have also been implicated in the oxidative conversion of retinol to retinaldehyde. $R d h 5$ and $R d h 8$ mutations are associated with mild night blindness in humans and individual knockout mice for these genes also display delayed dark adaption phenotypes [31]. $\mathrm{Rdh}^{-/-} ; \mathrm{Abca}^{-/-}$double mutants also exhibit progressive retinal degeneration from 4-6 weeks of age [32]. Rdh12 function in photoreceptors is essential for the visual cycle and mutations have been linked to Leber congenital amaurosis and autosomal dominant retinitis pigmentosa $[33,34]$ and childhood onset severe retinal dystrophy. $R d h 12^{-/-}$mice are prone to light-induced photoreceptor apoptosis. $R d h 8^{-/-} ; R d h 12^{-/-}$double mutants have a slowly progressing rod cone dystrophy phenotype. Thus, these enzymes appear to be important in the clearance of trans-retinal, which otherwise produces $N$-retinylidene- $N$-retinylethanolamine (A2E), a toxic substance known to contribute to retinal degeneration and photoreceptor cell death [31]. Rdh13 is also important in retinal biology, as $R d h 13^{-/}$mice suffer from acute light-induced retinopathy via the mitochondrial apoptosis pathway [35]. It is also implicated in liver injury, apoptosis and fibrosis as mutant mice displayed fewer injurious responses in carbon-tetrachloride-induced liver injury compared to wild type [36,37].

Rdh1 mutant mice on a VAD diet show reduced Cyp26a1 levels combined with increased retinoid stores, suggesting compensation for the lack of retinaldehyde and therefore RA in these mice. They also display increased size and adiposity. Finally, double null mice of epidermal short-chain retinol dehydrogenases $S d r 16 c 5$ and $S d r 16 c 6$ have accelerated hair growth and enlarged meibomian glands, upregulated hair-follicle stem cell genes and $80 \%$ reduced $\mathrm{RDH}$ activity, consistent with these genes regulating $\mathrm{RDH}$ function in the skin [38]. 
RDH10 and DHRS3 have been shown to regulate this retinol/retinaldehyde conversion in a reversible fashion. $R d h 10$ is expressed in specific and dynamic fashion in early development, including lateral plate, paraxial and cardiac mesoderm. Mutations of Rdh10 produce phenotypes reminiscent of various Raldh 2 loss-of function mutations. Full loss-of-function alleles give rise to embryonic lethality at $\sim$ E10.5 with shortened anteroposterior axes, defects in embryo turning, dilated and un-looped hearts, small somites, and forelimb bud agenesis, similar to Raldh $2^{-/-}$. Point mutations of Rdh10 gave rise to an RA-deficiency-like phenotype lethal at E13.0 which included pharyngeal arch, vascular and cardiac malformations such as common arterial trunk (CAT), ventricular misalignment and

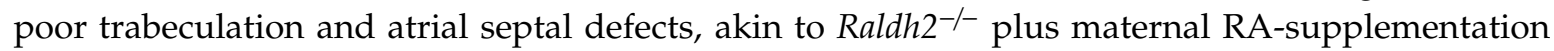
phenotypes. These defects can be partially rescued by the administration of maternal RA, although cardiac defects remain recalcitrant to this treatment. Maternal retinaldehyde supplementation, however, rescues all defects to a greater degree and allows the production of viable and fertile $R d h 10^{-/}$ adult mice. RDH10 is therefore thought to be the main enzyme involved in embryonic retinol to retinaldehyde conversion [16,39-43]. DHRS3, a short-chain dehydrogenase/reductase enzyme, reverses this reaction converting retinaldehyde back to retinol. Deletion of Dhrs3 leads to late embryonic lethality (E15.5/18.5) with abnormal axial, craniofacial (palatal) and cardiac (VSD, ASD, DORV) as a result of increased at RA activity development. A similar result is seen in zebrafish mutants and Xenopus morphants. Both Rdh10 and Dhsr3 are responsive to levels of RA, and each requires the other for full enzymatic activity ([15,44-47], reviewed [16]). Thus, the RDH10 and DHRS3 enzymes controlling the bi-directional retinol-retinaldehyde conversion act to regulate against retinoid deficiency and excess retinoid levels respectively.

The final step of the RA synthesis pathway requires the irreversible oxidation of retinaldehyde into all-trans retinoic acid ligand by the retinaldehyde dehydrogenase (RALDH) enzymes [48-50] (Figure 1). Three of these enzymes are active during development. All three genes are expressed around the developing eye. Raldh 3 is also expressed in the olfactory placodes, whereas Raldh 2 has a wider expression pattern encompassing domains in the head, somatic and splanchnic mesoderm and the limb [51-53]. Null mutations for Raldh1 and Raldh3 suggest that these two family members are only necessary for embryonic RA production in a minor fashion as mutant phenotypes affect only the development of the eye, ear, forebrain and frontonasal process [54-57] (Figure 2).

In contrast, Raldh2, expressed in caudal mesodermal tissues (Figure 2), provides RA to the majority

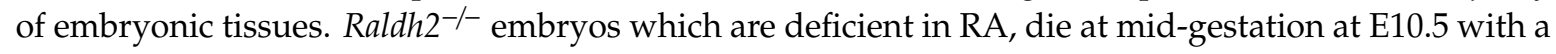
very severe phenotype encompassing failure of axial rotation, a shortened anteroposterior axis and frontonasal process, abnormal somitogenesis, small otocysts, lack of limb buds and a single medial un-looped dilated heart cavity with impaired atrial and sinus venosus formation, posteriorly expanded SHF markers and impaired ventricular cardiomyocyte differentiation. A similar set of malformations has been observed in the zebrafish raldh2 mutant neckless and recapitulated in morpholino knockdowns. Maternal/exogenous RA administration is able to rescue much of this phenotype such that embryos survive until E13.5-14.5 [58-67]. 'RA-rescued' Raldh2 null mouse embryos and hypomorphic null allele of Raldh2 display similar phenotypes including with early abnormalities of PAA1-3 and disorganized migration of the neural crest and later characteristic heart and thymus malformations similar to those described for 22q11DS and Tbx1 mutations [64,68,69].

Local control of available retinoic acid via expression of RALDH (synthesis) as described above and CYP26 (degradation) enzymes (addressed in detail below), is an important element in the regulation of RA distribution across the embryo and within specific tissues/cell types, particularly given that several retinoic acid receptors, (RAR $\alpha$ RXR $\alpha$ and $R X R \beta)$ have broad/ubiquitous expression patterns and can compensate for each other (reviewed by [70-72]). 


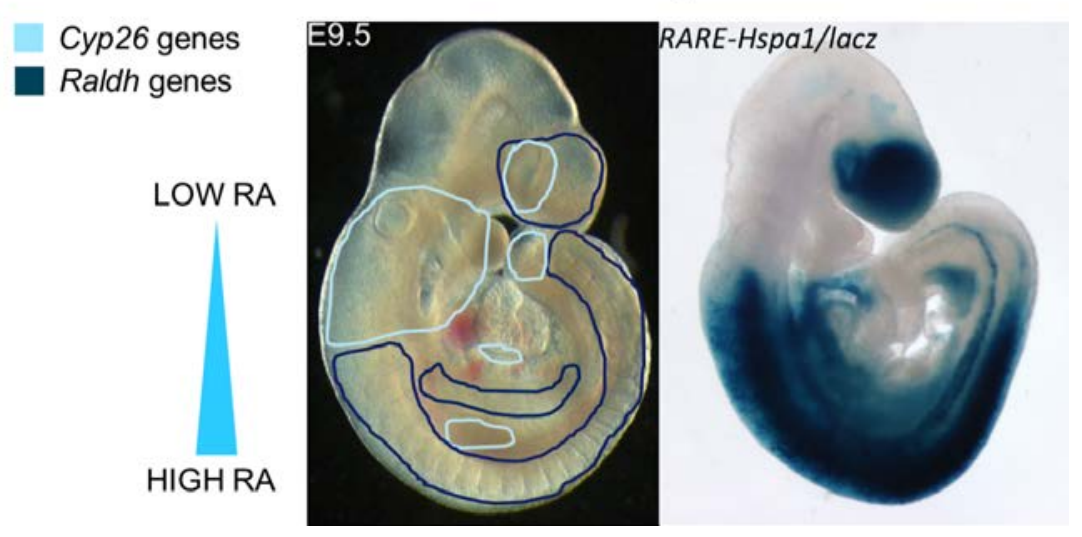

Figure 2. Overview of expression of retinoic acid regulating enzyme expression and retinoic acid signalling in mouse E9.5 embryos.(A). Combined expression domains of RALDH1-3 retinoic acid synthesising enzymes (dark blue lines) versus CYP26A1, B1 and C1 retinoic acid degrading enzymes (pale blue lines) depicted on an E9.5 embryo. RA synthesising activity is mostly localised in the caudal part of the embryo due to RALDH2 expression in the paraxial and splanchnic mesoderm. RALDH1 and 3 contribute to small domains of expression around the developing eye and forebrain. CYP26 expression is mostly localised to the pharyngeo-cardiovascular tissues and hindbrain, with small regions of expression in the tail-bud and eye. This establishes a high to low postero-anterior RA gradient across the embryo, with varying expression in specific tissues modulating the exposue to RA further. (B). Beta-galactosidase staining in a wild type E9.5 RARE-Hspa1b/lacz transgenic mouse, giving a read-out of regions of retinoic acid signalling at this stage of development. Overall, regions of active RA signalling correspond to regions expressing RALDH RA synthesising enzymes, whereas those tissues expressing RA-degrading CYP26 enzymes are negative for RA signalling.

Once RA has been generated in the cell by the synthesizing pathway, it binds cellular retinoic acid binding protein 2 (CRABP2) and is transported into the nucleus and delivered to the retinoic acid receptors (RARs) $[11,73,74]$ to facilitate autocrine signalling within the cell. RA can also signal in a paracrine fashion to neighbouring cells by diffusion, a function important for developmental patterning gradients (Figures 1 and 2).

The three conserved RARs $(\alpha, \beta$ and $\gamma$ ) are members of the nuclear receptor superfamily and bind RA in partnership with one of their three retinoid $X$ receptor $(R X R \alpha, \beta$ and $\gamma)$ heterodimer binding partners. Both RAR and RXR subtypes contain a number of different isoforms. The activity of RAR-RXR heterodimers is probably mediated via binding of all-trans-RA to the RAR partner $[75,76]$. Several retinoic acid receptors, (RAR $\alpha, R X R \alpha$ and $R X R \beta)$, have broad/ubiquitous expression patterns in general, with the others (RAR $\beta, R A R \gamma$ and $R X R \gamma$ ) showing more complex, tissue-specific expression. Different heterodimer combinations can transduce the RA signal in many tissues and there is a high degree of functional redundancy. Usually at least two receptors must be deleted in concert to ascertain any developmental defects. For example, compound receptor mutations which produce abnormalities of pharyngeal and outflow tract similar to 22q11DS include various compound mutants of $R A R \alpha / \beta, R A R \alpha / \gamma$ and $R A R \beta / \gamma$, compound mutants of RXR $\alpha$ with any of the RARs and $R X R \alpha$ mutants alone [71,72,77-82].

In the absence of ligand, the RAR/RXR heterodimers bind to specific motifs within the promoters of target genes, known as retinoic acid response elements (RAREs). These are repeats of consensus sequences $5^{\prime}-(\mathrm{A} / \mathrm{G}) \mathrm{G}(\mathrm{G} / \mathrm{T}) \mathrm{TCA}-3^{\prime}$ or $5^{\prime}-(\mathrm{A} / \mathrm{G}) \mathrm{G}(\mathrm{G} / \mathrm{T})(\mathrm{G} / \mathrm{C}) \mathrm{A}-3^{\prime}$ spaced at 1,2 or 5 bp intervals. Unliganded receptor binding allows recruitment of co-repressor complexes, e.g., Polycomb group complexes such as NCor/SMRT which make the DNA unavailable for transcription. When RA binds to the RAR, a conformational change is initiated in the RAR-ligand binding domain, which results in the co-repressor complexes being released. Transactivating complexes such as SWI/SNF, NF1, pCIP/p300 
and PolII are recruited instead, leading to the induction of chromatin remodelling and the activation of the transcriptional machinery. Alternatively, ligand-dependent repression can mediated by binding of proteins such as NRIP1, PRAME and TRIM24 (reviewed by $[10,11,83]$ (Figure 1).

Maternal diet-derived retinol/in blood/yolk sac/yolk of embryo bound to retinol binding protein 4 (RBP4) enters cellular cytoplasm via binding to membrane-bound RBP/RA complex receptor STRA6 (Stimulated by Retinoic Acid 6). Retinol is then bound to cellular retinol binding protein (CRBP) and reversibly oxidised to the intermediate form retinaldehyde (also known as retinal) by alcohol dehydrogenase and retinol dehydrogenase (particularly RDH10) enzymes. The reverse reaction, retinaldehyde to retinol, is catalysed by the dehydrogenase/reductase 3 (DHRS3) enzyme. Retinaldehyde can also be generated from $\beta$-carotene by $\beta$-carotene $15,15^{\prime}$-monooxygenase (BCO). Retinaldehyde is then irreversibly converted to retinoic acid (RA) by retinaldehyde dehydrogenase (RALDH) enzymes, particularly RALDH2. RA can then undergo three different processes: (1.) RA bound to cellular retinoic acid binding proteins which shuttle RA to the nucleus. Hetero-dimerised RAR-RXR complexes (retinoic acid receptor-retinoid-X-receptor) are bound to conserved retinoic acid responsive elements (RARE) within the promotors of target genes. Most frequently, in the absence of RA co-repressor complexes (e.g., NCoR/SMRT) are bound to the RAR-RXRs, preventing transcription. Upon RA binding, the receptors undergo a conformational change, releasing co-repressor complexes and recruiting co-activator proteins (e.g., SWI/SNF, pCIP/p300, PolII) as replacements, thus triggering transcription activation of target genes. (2.) RA produced in one cells can also signal in a paracrine fashion to neighbouring cells, mediating non-cell autonomous effects. (3.) If Cytochrome P450 subfamily 26 (CYP26) enzymes are present in the cell, RA is hydroxylised in the cytoplasm to more polar metabolites with less biological activity, which are further processed by UDP-gluconyl transferases and eventually eliminated from the cell. Adapted from Niederreither and Dolle 2008 [10].

\section{Embryonic Defects Arising from Dysregulated RA Signalling}

All-trans retinoic acid (RA) is one of the most important signalling molecules in embryogenesis, required for the development of a large number of tissues. RA homeostasis can be disrupted via maternal diet or genetic/chemical modification to either increase or decrease RA availability and/or signalling relative to normal endogenous levels. This leads to a wide range of developmental defects affecting many tissues. These include antero-posterior axis development (anterior and caudal truncations), CNS abnormalities (posteriorization of the hindbrain), abnormalities of limb, lung kidney and eye development $[9,60,62,84-104]$ reviewed $[84,85]$.

The development of the craniofacial/pharyngeal region can also be severely affected by dysregulation of the RA pathway. Observed defects include abnormal development of the pharyngeal arch/artery development, pharyngeal pouch endoderm segmentation and number/migration of neural crest. This produces craniofacial anomalies and cardiac defects affecting the great vessels and outflow tract. Craniofacial anomalies can include anterior pharyngeal arch fusion, defects of the cranial skeleton and teeth, reduction of the frontonasal process, cleft palate/lip, cranial gland, ocular and ear defects. Cardiac defects largely affect the formation/remodelling of the pharyngeal arch arteries into the great vessels and the development of the outflow and inflow tracts by addition of secondary heart field progenitors at the arterial and venous poles of the heart. Neural-crest driven septation of the outflow tract is also abnormal leading to CAT and aorticopulmonary windows [9,76-80,101,105-109], reviewed [10-14,110]. 
The pharyngeal anomalies and consequent craniofacial and cardiac defects produced by altered RA signalling are very like the abnormalities seen in human 22q11 Deletion Syndrome (22q11DS). This interstitial chromosomal deletion syndrome leads to haploinsufficiency of $1-3 \mathrm{Mb}$ regions of chromosome 22q11 and gives rise to a characteristic phenotype affecting craniofacial, thymus and great vessel/outflow tract development. Animal models for deletion of syntenic chromosomal regions reproduce these anomalies and led to the identification of TBX1 as the major candidate gene for the 22q11DS. Full and temporal or pharyngeal tissue-specific deletion mouse models for $T b x 1$ recapitulate much of the 22q11DS phenotype. Furthermore, ectopic expression of Raldh2 and down-regulated expression of Cyp26 genes in Tbx1 mutant mice indicate that RA levels are up-regulated, likely contributing to the early pharyngeal defects and resulting craniofacial and cardiac defects [69,111-130].

\section{Retinoic Acid Degradation: The CYP26 Enzymes}

The role of the degrading CYP26 enzymes is two-fold. Firstly CYP26-expressing cells act as retinoic acid sinks. Expression of Raldh2 which synthesises RA and one or more of the Cyp26 genes is often complementary within a tissue. This establishes a retinoic acid gradient between adjacent high and low RA-expressing regions (Figure 2). This gradient then establishes dose-dependent specific transcriptional readouts, which are important for embryonic patterning. Secondly, expression of CYP26 enzymes protects cells/tissues which are extremely sensitive to RA by preventing inappropriate RA-mediated transcription in these regions.

\section{CYP26 Structure, Biochemistry and Function}

There are three vertebrate Cyp26 genes, Cyp26a1, $b 1$ and $c 1$, which are active during development and later life. These enzymes are cytochrome P450s (CYPs), enzymes named for the $450 \mathrm{~nm}$ absorption band of their carbon-monoxide bound form. They are members of the membrane-anchored microsomal (endoplasmic reticulum-ER) p450 mixed function oxidase superfamily, which are important in the metabolism of both endogenous and exogenous biologically active molecules.

All CYP enzymes, including the CYP26s, contain several membrane-spanning domains and a conserved $C^{\prime}$-terminal haem-binding domain of amino acids surrounding a central cysteine residue, which binds the iron molecule required for enzymatic activity. This comprises a four-helix (D, E, I and $\mathrm{L}$ ) bundle, helices J and $\mathrm{K}$, two sets of $\beta$ sheets, and a coil region. The haem-binding loop contains the conserved consensus sequence Phe-X-X-Gly-X-Arg-X-Cys-X-Gly, which includes the absolutely conserved cysteine required for iron binding and is positioned on the proximal face of the haem just before the L helix. The Glu-X-X-Arg motif in helix K also on the proximal side of heme is also absolutely conserved and is predicted to stabilize the core structure. A final consensus sequence in central part of the I helix, Ala/Gly-Gly-X-Asp/Glu-Thr-Thr/Ser is also characteristic of p450 proteins (Figure 3C).

Substrate recognition and binding sites found near the catalytic site and substrate access region undergo flexible changes upon substrate binding which promote the catalytic reaction. These domains, along with those for targeting membrane-bound proteins and amino-terminal anchoring, have much less sequence conservation than the haem-binding domains where the highest structural conservation is to be found. There is however, a generally high reproducibility of overall topography and structural folding despite other sequence variations mirroring differences in catalytic reaction, electron donors and membrane localisation. Localisation at microsomal/ER membranes is frequently mediated by a proline group (Pro-Pro-X-Pro), which forms a hinge region between a basic residue domain and the hydrophobic domain of the amino-terminal region required for membrane anchoring [131-136] (Figure 3). 
CLUSTAL $0(1.2 .4)$ multiple sequence alignment

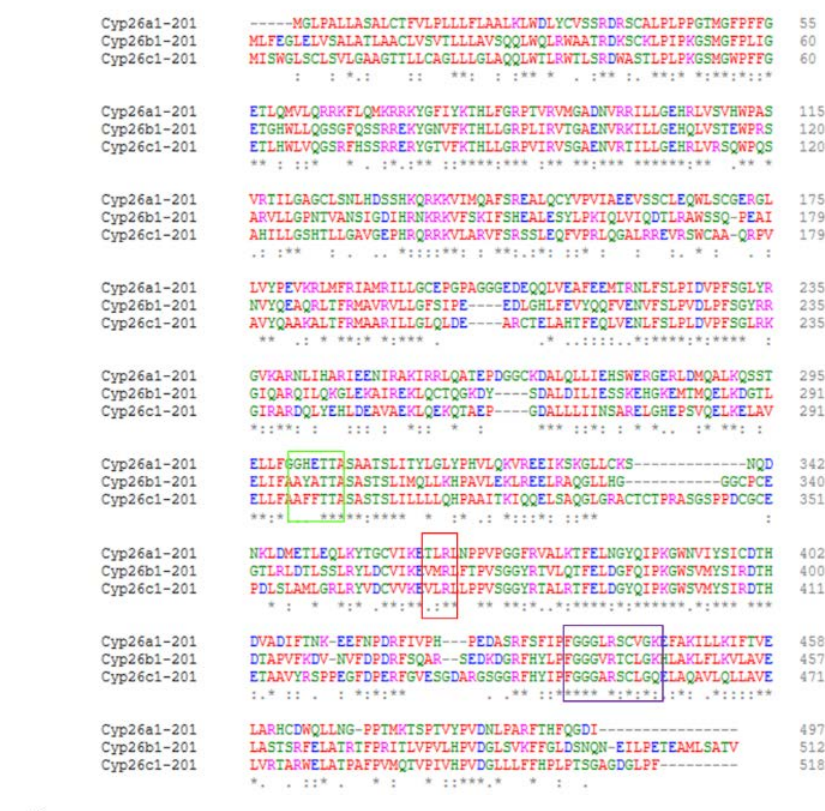

B CLUSTAL 0(1.2.4) multiple sequence alignment

\begin{tabular}{|c|c|}
\hline $\begin{array}{l}\text { cyp26b1-201 } \\
\text { CYP26B1-201 } \\
\text { Cyp26b1-201 }\end{array}$ & 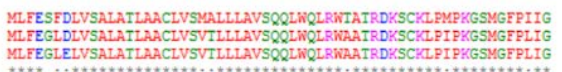 \\
\hline $\begin{array}{l}\text { cyp26b1-201 } \\
\text { CYP26B1-201 } \\
\text { Cyp26b1-201 }\end{array}$ & 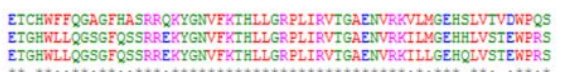 \\
\hline $\begin{array}{l}\text { cyp26b1-201 } \\
\text { CYP26B1-201 } \\
\text { Cyp26b1-201 }\end{array}$ & 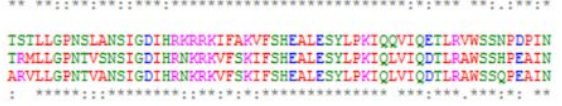 \\
\hline $\begin{array}{l}\text { cyp26b1-201 } \\
\text { CYP26B1-201 } \\
\text { Cyp26b1-201 }\end{array}$ & 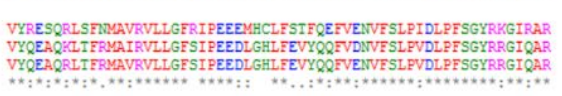 \\
\hline $\begin{array}{l}\text { cyp26b1-201 } \\
\text { CYP26B1-201 } \\
\text { Cyp26b1-201 }\end{array}$ & 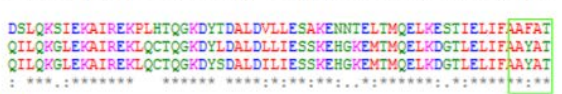 \\
\hline $\begin{array}{l}\text { cyp26b1-201 } \\
\text { CYP26B1-201 } \\
\text { Cyp26b1-201 }\end{array}$ & 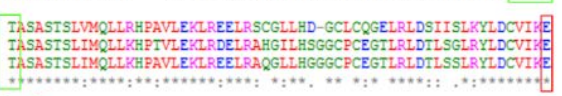 \\
\hline $\begin{array}{l}\text { cyp26b1-201 } \\
\text { CYP26B1-201 } \\
\text { Cyp26b1-201 }\end{array}$ & 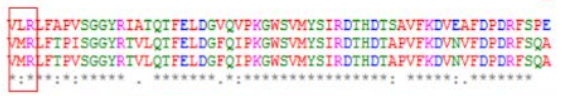 \\
\hline $\begin{array}{l}\text { cyp26b1-201 } \\
\text { CYP26B1-201 } \\
\text { Cyp26b1-201 }\end{array}$ & 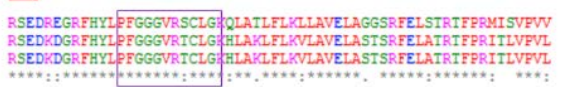 \\
\hline $\begin{array}{l}\text { CYp26b1-201 } \\
\text { CYP26B1-201 } \\
\text { CYp26b1-201 }\end{array}$ & $\begin{array}{l}\text { HPTDGLRVKFFGLDSNONQTMAKSDEVIDATV } \\
\text { HFVDGLSVKFELDSNQNEILPETEAMLSATV } \\
\text { HFVDGLSVKFFGLDSNQNEILPETENLSATV }\end{array}$ \\
\hline
\end{tabular}

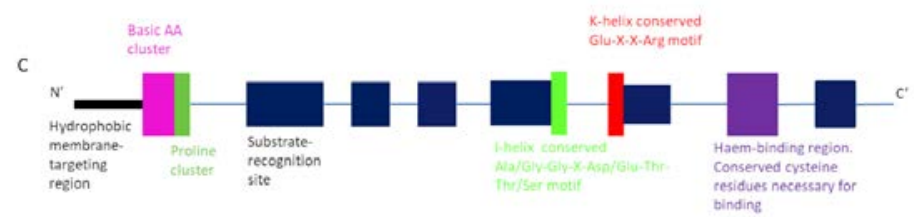

Figure 3. CYP26 protein amino acid sequences and protein schematic. (A). Clustal Omega alignment of mouse CYP26A1, B1 and C1 amino acid sequences showing the relatively low level of sequence conservation between the family members. (B). Clustal Omega alignment of amino acid sequence of CYP26B1 between zebrafish, mouse and human showing a high degree of conservation between species. (C). Schematic of CYP26 protein structure with conserved I (green box) and K (red box) helix regions and the conserved haem-binding domain (purple box). Same colour boxes denote these regions in $(\mathbf{A}, \mathbf{B})$. 
The haem-binding domain is essential for enzyme function. CYP26 enzymes are class II p450 enzymes, meaning that the catalysis reaction requires 2 electrons per cycle provided from NADPH via cytochrome 450 oxidoreductase (Por, also Cpr, Cypor), which is the obligate electron donor for the CYP26 enzymes. The proteins link via the ER membrane to which they are both bound. POR has two cofactors: flavin mononucleotide (FM) and flavin adenine dinucleotide (FAD). Electrons move from NADPH to FAD, then to FN which interacts with the CYP26 protein following a conformational change forming a redox chain. The two faces of the POR and CYP26 proteins carry opposite charge and the electron flow is enabled by the protein-protein interaction between them, causing them to act as dipoles with salt bridges forming once oppositely charged amino acids interact [135]. Similar substrate specificity was seen for all three CYP26 proteins, with high catalytic activity for RA, with affinity in the range of $\mathrm{Km}<100 \mathrm{nM}$ observed in experiments with COS-1 transfected cells. This Km value for RA is similar to the concentration of RA in a range of tissues and is roughly 1000 times higher than to other CYP enzymes. Enzyme turnover rate was around 1-10 pmol/min/pmol, similar to that of other mammalian p450 enzymes. Much lower levels of substrate specificity were seen with 9-cis-RA, retinaldehyde and other retinoids for CYP26A1 and B1, whereas CYP26C1 was able to catalyse 9-cis-RA oxidation at an equivalent rate to RA. CYP26C1 also cleared RA metabolite 4-oxo-atRA more efficiently than the other two CYP26 enzymes. Overall, the metabolisation of RA by the CYP26 enzymes is up to $10^{4}$-fold higher than for other CYP enzymes shown to hydroxylate RA in the liver, such as CYP3A4, CYP3A5, CYP3A7, CYP2C8 and CYP2C22 [135,137-150].

In experiments based on microsomal liver extractions and transfected cells, CYP26 enzymes can hydroxylate RA to three major metabolites 4-hydroxy, 4-oxo, 18-hydroxy plus 5, 8 epoxy all-trans RA and more polar products which include dihydroxy, mono-oxo and mono-hydroxy derivatives. These are thought to be produced from the $\beta$-ionone ring of RA following multiple hydroxylations. These chemical forms are less biologically active than RA and undergo further glucuronation by UDP-glucuronosyltransferases (e.g., UTP2B7) to 4-O- $\beta$-glucuronide and are eventually eliminated from the cell (Figure 1) [139,143,144,146,150-152].

It has been suggested that some metabolites of RA may still have biological activity within the embryo and some evidence has been put forward for this idea. All three CYP26-generated RA-metabolites can regulate Cyp26 expression in the chick and each is capable of rescuing the RA-deficient phenotype of the VAD quail embryo [153]. Furthermore, 4-oxo-RA causes anteroposterior defects and the induction of Hoxb4 and 9 in Xenopus embryos, and is a high-affinity activating ligand of RAR $\beta$ [154]. In zebrafish 4-oxo-RA produces the same range of development abnormalities as all-trans-RA but at a lower efficiency [155]. However, genetic experiments in the mouse suggest that this does not occur in vivo, since the majority of Cyp26a1 null embryos on a Raldh 2 heterozygous background survive well past birth. If part of the Cyp26a1 null phenotype is the result of impaired RA-metabolite signalling, then crossing on the Raldh2 haploinsufficient background should exacerbate the phenotype by decreasing the levels of substrate for the oxidizing enzymes, thus leading to lower levels of RA-metabolites. Additionally, Cyp26a1 can rescue excess RA phenotypes, whereas if the CYP26 metabolites were active it might be expected to potentiate the effect of excess RA. Therefore defects observed in Cyp26 loss-of-function models are thought to be the result of excess/ectopic RA and not absence of RA-metabolites. It has been suggested that in normal development, although the RA-derived CYP26 metabolites above can be biologically active, they are very rapidly conjugated, mainly as glucuronates, and eliminated by excretion before accumulating to levels at which they can exert a biological effect $[153,156]$.

Despite similar biochemical functions, the individual three CYP26s proteins have only approximately $55 \%$ amino acid identity to each other, mostly based around the $C^{\prime}$-haem domain (Figure 3A). However, each CYP26 protein is highly evolutionarily conserved between species (human, mouse and zebrafish) with the human to mouse amino acid identity being over $80 \%$ for each protein and CYP26B1 the most highly conserved and CYP26C1 the least conserved (Figure 3B). In amphioxus, three similar Cyp26 genes, Cyp261-3 have been identified which are clustered within the genome and 
possibly are the result of lineage specific duplication of an ancestral gene. Cyp261 and 3 are very responsive to RA levels and are induced to protect against teratogenic outcomes of inappropriate RA-mediated transcription. Cyp262 however, exhibits a complex developmental pattern, and is suggested to mediate developmental patterning in amphioxus $[157,158]$. An RA-inducible Cyp26 homologue has also been identified in ascidians expressed in the neural plate and tail-bud in a similar fashion to Cyp26a1 [141,146,159-163], reviewed [137,139,144,164].

Red letters: small hydrophobic residues, blue letters: acidic residues, magenta letters; basic residues, green letters: hydroxyl, sulfhydryl, amine, and glycine residues. Grey asterisk: single fully conserved residue, grey colon: conservation between residues of strongly similar properties, grey period: conservation between residues of weakly similar properties.

The individual Cyp26 genes have differing domains of expression within the developing embryo and in adults. Generally, expression of CYP26 is found in those tissues with particular sensitivity to RA (e.g., the tail-bud, limb, hindbrain and pharyngeal regions) and is often found in complementary domains to the RA-synthesising RALDH enzymes (Figure 2). There is some variation in the embryonic expression of each specific gene between different vertebrate species at specific developmental stages (mouse, rat, chick, zebrafish and Xenopus). However, the combined domain of expression of all three Cyp26 genes considered as a whole, is overall similar between the species. An excellent overview of the expression domain of all three Cyp26 genes during development in four different species can be found in White and Schilling 2008 [143,159-161,165-169].

Conclusions drawn from studies on the effect of expression of CYP26A1 have suggested that expression within a cell can deplete it completely of RA. As described above and in Figure 2, this allows CYP26-expressing tissues to act as RA sinks. When combined with adjacent RA-synthesising expression domains, this allows the generation of RA gradients across a tissue.

Furthermore, expression of CYP26 enzymes within specific tissues or cell types allows protection of these selected cells/tissues from RA signalling even when the overall RA availability across a region is high. This allows the CYP26-positive cells to adopt different cell fates compared unprotected neighbouring cells exposed to higher RA levels [103,151,169-172].

As yet, further studies examining the effect of relative levels of expression of RALDHs and CYP26s within the same cells/tissues on RA levels and transcriptional outcomes have not been undertaken in a systematic fashion. However, a study investigating complementary and cellular co-expression of RALDH and CYP26 enzymes in different regions of the adult human brain have been suggested to underlie differential paracrine and autocrine RA signalling respectively, although resulting functional differences remain to be explored [173].

This complex and dynamic expression of RALDH and CYP26 enzymes throughout development has been shown to be an important mechanism for regulating RA availability and thus RA autocrine and paracrine signalling and subsequent RA-mediated transcriptional outcomes during development and regeneration. These mechanisms are discussed in detail in a variety of tissue contexts in the sections below.

Expression of both Cyp26a1 and Cyp26b1 mRNA can be induced by exogenous RA in a dose-dependent manner in developmental and adult tissues. There is a clear response of both hepatic Cyp26 mRNA and total retinol concentration to both dietary Vitamin A and exogenous administration of RA, with the latter being a particularly strong response. In response to low, adequate and increased levels of dietary Vitamin A, rats showed dose-dependent increases in Cyp26a1. A study in which similar levels of dietary Vitamin A were fed to rats across their lifetime gave similar results at every time point examined, from young to old age [174,175]. In response to exogenous RA in Vitamin A-deficient rats, Cyp26a1 mRNA in the liver increased over $6 \mathrm{~h}$ to 2000 -fold, and then decreased to baseline by $72 \mathrm{~h}$. In other tissues including testis, lung, kidney and small intestine, RA treatment also led to increased Cyp26a1, albeit at lower levels with a 10-fold increase after $10 \mathrm{~h}$ [139,144,176-178]. Explants from embryonic E8.5 tail bud which expresses Cyp26a1 and somites, which do not, showed rapid upregulation of RA-induced RARE-lacz reporter levels $3.5 \mathrm{~h}$ after exogenous at RA treatment. 
In tail bud explants RARE-lacz reporter levels were reduced back to baseline by $6 \mathrm{~h}$ after treatment whereas somatic explants continued to show high levels of atRA-reporter expression. Ectopic RARE-lacz expression in tailbud and pharyngeal regions also shows increases levels of RA within Cyp26a1 ${ }^{-/}$ embryos. Furthermore, RA bead explant experiments/treatment with RA/RAR agonists in zebrafish, chick and Xenopus embryos induce local expression of Cyp26a1 [103,153,179-182]. This response appears to be mediated co-operatively by the three and a half RARE sites found within the $2.2 \mathrm{~kb}$ upstream sequence of the Cyp26a1 transcriptional start site (TSS), one close to the TSS and the remaining sites $2 \mathrm{~kb}$ more distal $[178,183-185]$. Additional more distant RARE sites, positioned more than $10 \mathrm{~kb}$ away from the Cyp26a1 TSS and conserved between six species including mouse and human which were further validated for functionality have also been identified using an in silico approach [186]. Obviously, other transcription factors will also act to regulate Cyp26a1 expression in addition to RA binding. For example, a known proximal SP1/SP3 binding site has been found to increase Cyp26a1 promoter activity in response to RA in co-operation with the nearby RARE binding site [183] and it has been shown that HOXA10V2 enhances induction of CYP26A1 by RAR $\alpha / R X R$ primed transcription in NB4 cells [187]. Epigenetic factors such as removal of repressive complexes, including PcG proteins (eg Suz12) and HDACs, recruitment of activators (e.g., pCIP/p300) and PolII, H3K27 acetylation, H3K9 methylation, differential chromatin regulation by RAR $\beta 2$ are all also linked to regulation of $C y p 26 a 1$ expression in different contexts [188-191].

The response of Cyp26b1 mRNA to RA in the liver is less than that of Cyp26a1. As for Cyp26a1, Cyp26b1 mRNA levels increased in a dose-dependent linear fashion, but overall up-regulation was not more than 10-5-fold and again reduction to baseline levels was accomplished by $72 \mathrm{~h}[144,192]$. In the neonatal rat lung when treated with Vitamin A/RA/Cyp26b1, mRNA increased at a rapid rate to a higher more persistent level than Cyp26a1 mRNA [193]. Cyp26b1 has also been reported to be induced in response to RA in aortic smooth muscle cells [194] and in response to local RA-bead implantation in chick embryos [153]. In naïve CD4+ T cells, Cyp26b1 is induced by 1-10 nm RA and this up-regulation was inhibited by TGF $\beta 1$, TGF $\beta 2$ and IL-12 [195]. TGF $\beta$ family member activin has also been shown to inhibit Cyp26b1 in telencephalic neural precursors and mouse granulosa cells [196,197]. Previously consensus RARE sites have not been reported within the Cyp26b1 promoter, however the in silico study above generated a number of DR5 RARE binding sites for both mouse and human Cyp26b1 [186]. However, these have not yet been functionally validated. In TM3 cells as a model for gonadal somatic cells Cyp26b1 has also been shown to be RA-independently activated by SOX9 and SF1-expressing constructs and repressed by FOXL2. In Sox9/Sf1- and Foxl2-deficient gonads, Cyp26b1 transcription was respectively decreased and increased approximately 20-fold compared to wild-type [198]. All three Cyp26 genes may be up-regulated by TBX1 as expression is down-regulated in Tbx1 null embryos. It is unknown if this is a direct or indirect transcriptional effect although putative conserved TBX1 binding sites have been found in Cyp26b1 upstream sequences (C. Roberts, P. Ataliotis unpublished data). Furthermore, activation of Cyp26b1 expression via PPAR agonists, presumably via promiscuous binding of PPAR receptors to RAREs have previously been reported [199]. Cyp26c1 has also been reported as being both up and down regulated by RA $[141,153]$ and in silico RARE sites have been predicted [186] but little information exists about other possible regulators of the Cyp26c1 promoter. Cyp26c1 is on the same chromosome as Cyp26a1 within $13 \mathrm{~kb}$ distance of each other, raising the possibility that there may be regulatory elements in common [141,161].

The function of the CYP26 enzymes can be chemically blocked by a variety of retinoic acid metabolism blocking agents (RAMBAs). These have been developed with possible clinical applications in mind: increasing RA levels by inhibiting CYP26 function could provide a more specific less toxic approach to RA treatment for a variety of conditions including cancer and dermatological diseases. The best known of these are R115866 (talarozole), R116010, ketocozanole and liarozole. These compounds, particularly R116010 and R115866, have also been useful in exploring CYP26 biological function in variety of animal models in vivo and in vitro. R115866 and R116010 contain imidazole and triazole and are more potent inhibitors of CYP26s with an IC 50 of 4-5 nM each compared to liarozole 
and ketoconazole with $\mathrm{IC}_{50}$ s of 2100 and $550 \mathrm{nM}$, respectively. Inhibition of CYP26B1 has also been demonstrated for these molecules. While no compound is totally specific, the selectivity for CYP26 in particular, is evidenced by trivial inhibition of other CYP-dependent synthesis of estradiol and testosterone (micromolar concentrations of R115866/R1160101 are required to inhibit CYP19, CYP 17, CYP 2C11, CYP3A and CYP2A1, CYP2B1/1).

Oral administration of R115866 to adult rats resulted in raised levels of RA in plasma, skin, fat, kidney and testis. R115866 also reproduces known retinoidal effects including vaginal keritanization, induction of epidermal hyperplasia and epidermal transformation and up-regulation of Cyp $26 \mathrm{mRNA}$ expression in rat liver. These effects can all be reversed by administration of retinoic acid receptor antagonists suggesting that R115866 inhibition of CYP26s results in an increased availability of endogenous RA and exposure of developing embryos to R115866 results in a range of developmental defects which phenocopy those of exogenous RA. Further compounds based on these four initial molecules are still in development [126,200-204], reviewed [205].

\section{CYP26 in Human Genetic Disease}

Various polymorphisms potentially affecting CYP26 activity have been reported in humans, along with some disease-causing mutations (see Table 1 for details) with additional silent polymorphic changes also reported (reviewed $[139,149])$. Polymorphism screens of CYP26A1 from healthy individuals of varying ethnicity identified at least 13 single nucleotide change polymorphisms (SNP). Reduced enzymatic functionality was confirmed for F186L, and C358R which were found to have reduced RA metabolising activity of between $40 \%$ and $80 \%$ compared to wild-type. Further silent changes have been reported for both CYP26A1 and CYP26B1 [206,207]. A further single nucleotide deletion polymorphism g.3116delT (premature stop) associated with spina bifida was also found to attenuate CYP26A1 RA metabolising activity [208]. Polymorphisms in both CYP26A1 (rs4411227 C/G genotype or C/C+C/G compared to G/G) and CYP26B1 (rs9309462 C/T genotype and C allele, rs138478634 G/A change in exon 5) alone or combined polymorphisms (CYP26A1 rs4411227 and CYP26B1 rs3768647/rs930946) have an increased risk of oral and pharyngeal cancer [209-212]. Raised levels of CYP26 enzymes have also been reported in a range of other cancers including breast, colorectal and head/neck cancers, reviewed [149]. Haploinsufficient microdeletions encompassing the CYP26A1 and CYP26C1-containing chromosomal region has also been reported with differing phenotypes of either optic nerve aplasia or premature skeletal and dental aging combined with retinal scarring and autism [213,214].

A variety of missense variants in CYP26B1 shown to abrogate protein function are associated with a range of human neural tube defects, craniofacial and skeletal defects and defects affecting other tissues including the heart (atrial septal defects and dextrocardia) [207]. An alternatively spliced CYP26B1 lacking exon 2 and has reduced metabolic functionality of $\sim 30 \%$ compared to full length CYP26B1 and is expressed at higher levels in vascular cells atherosclerotic lesions. This expression was further upregulated with exposure to RA. A polymorphic variation rs2241057C/C (minor allele) L264S is associated with larger macrophage-positive atherosclerotic lesions, whereas carries of the major allele rs2241057T/T have an increased risk of Crohn's disease, an autoimmune condition of the gut. Additionally, Cyp26b1 is upregulated in atheroschlerotic lesions and associated there with activated macrophages, suggesting that Cyp26b1 may be important in RA clearance in the arterial wall [215-217]. 
Table 1. Summary of Phenotype Causing Mutations in Human CYP26 genes.

\begin{tabular}{|c|c|c|c|c|}
\hline Gene & Nucleotide/AA Change & Change in Enzyme Function & Phenotype & Reference \\
\hline \multirow{3}{*}{ CYP26A1 } & R173S & ? & \multirow{3}{*}{ None reported } & \multirow{3}{*}{ [206] } \\
\hline & F186L & $\begin{array}{l}40-80 \% \text { reduced atRA metabolising } \\
\text { activity in COS cells }\end{array}$ & & \\
\hline & C358R & & & \\
\hline CYP26A1 & $\begin{array}{l}\text { g.3116delT } \\
\text { premature stop }\end{array}$ & reduced atRA metabolising activity & Associated with spina bifida & [208] \\
\hline CYP26A1 & rs4411227 C/G or C/C & $?$ & Increased risk oral and pharyngeal cancer & [209-211] \\
\hline $\begin{array}{l}\text { CYP26A1 and } \\
\text { CYP26C1 }\end{array}$ & $\begin{array}{l}\text { Microdeletion of up to } 249-363 \mathrm{~kb} \text { of chrs. } \\
10 \mathrm{q} 23.33\end{array}$ & $\begin{array}{c}\text { Haploinsufficiency } \\
\text { CYP26A1, CYP26C1, EXOC6 }\end{array}$ & Optic nerve aplasia & [213] \\
\hline $\begin{array}{l}\text { CYP26A1 and } \\
\text { CYP26C1 }\end{array}$ & $\begin{array}{l}\text { 8.3 Mb microdel. Chrs 10q23.2-23.33. The } 79 \\
\text { deleted genes included CYP26A1 and C1, }\end{array}$ & $\begin{array}{l}\text { Haploinsufficiency CYP26A1, } \\
\text { CYP26C1 + 79 other genes } \\
\text { Raised plasma RA levels }\end{array}$ & $\begin{array}{l}\text { Premature ageing skeletal and dental development, retinal } \\
\text { scarring, and autism-spectrum }\end{array}$ & [214] \\
\hline CYP26B1 & $\begin{array}{c}\text { Nine missense or splicing changes } \\
\text { (samples collected during gestation) } \\
583 \mathrm{C}>\text { T Arg195Met (1) } \\
589 \mathrm{c}>\text { A Leu197Met (3) } \\
704 \mathrm{G}>\text { A Arg235Gln (1) } \\
712 \mathrm{C}>\text { G Gln238Glu (1) } \\
715 \mathrm{G}>\text { A Ala237Thr (3) }\end{array}$ & $100 \%$ loss of function & $\begin{array}{c}\text { Neural tube, limb, craniofacial, skeletal, heart, kidney and } \\
\text { lung defects }\end{array}$ & [207] \\
\hline CYP26B1 & Splicing variant with loss of exon 2 & $30 \%$ loss of function & Expressed in atherosclerotic lesion vascular cells & [215] \\
\hline CYP26B1 & $\begin{array}{c}\text { rs3768647/9309462 } \\
\text { C/C or C/T } \\
\text { rs138478634 G/A change in exon } 5\end{array}$ & $?$ & Increased risk oral and pharyngeal cancer & [209-212] \\
\hline CYP26B1 & $\begin{array}{l}\text { rs2241057T/T (major allele } \\
\text { rs2241057C/C (minor allele) } \\
\text { L264S }\end{array}$ & $\begin{array}{l}\text { Lower CYP26B1 activity } \\
\text { Higher CYP26B1 activity }\end{array}$ & $\begin{array}{c}\text { Increased risk of Crohn's disease } \\
\text { Larger macrophage-rich atherosclerotic } \\
\text { lesions }\end{array}$ & $\begin{array}{l}{[217]} \\
{[216]}\end{array}$ \\
\hline CYP26B1 & $\begin{array}{c}3 \text { c.1088G }>\mathrm{T} \\
\text { homozygous } \\
\text { p.Arg363Leu } \\
1 \text { died in utero/2 terminations }\end{array}$ & $\begin{array}{l}100 \% \text { loss of function by affecting the } \\
\text { K-helix }\end{array}$ & Craniofacial, skull, pelvic, limb long bone skeletal defects & [202] \\
\hline
\end{tabular}


Table 1. Cont

\begin{tabular}{|c|c|c|c|c|}
\hline Gene & Nucleotide/AA Change & Change in Enzyme Function & Phenotype & Reference \\
\hline CYP26B1 & $\begin{array}{c}\text { c.436T }>C \\
\text { homozygous } \\
\text { p.Ser146Pro } \\
\text { Died at } 5 \text { months }\end{array}$ & $31 \%$ loss of function & $\begin{array}{l}\text { Defects similar to Antley-Bixler and Pfeiffer Syndromes } \\
\text { Skull, digit and joint skeletal defects }\end{array}$ & [202] \\
\hline CYP26B1 & $\begin{array}{c}\text { c.1303G > A } \\
\text { p.Gly435Ser } \\
\text { homozygous } \\
\text { (survived to adulthood) }\end{array}$ & Predicted loss of function & Skull and long bone skeletal defects, intellectual disability & [218] \\
\hline CYP26C1 & Missense p.Phe508Cys & Loss of function & $\begin{array}{l}\text { Confers increased severity of SHOX p.Val161Ala mutation } \\
\text { skeletal and short stature phenotype }\end{array}$ & [223] \\
\hline CYP26C1 & $\begin{array}{c}\text { Missense c.148C > T, Pro50Ser; } \\
\text { c.356A > C, p.Gln119Pro; c.910G > A, Ala304 } \\
\text { The } \\
\text { Splice variant truncation } \\
\text { c.706-A }>\text { C }\end{array}$ & Loss of function & Short stature phenotype & [224] \\
\hline POR & $\begin{array}{c}\text { Missense, nonsense, frameshift, splicing and } \\
\text { exon deletions }\end{array}$ & Loss of function & $\begin{array}{l}\text { Antley-Bixler like skeletal defects and deficient steroidal } \\
\text { profiles }\end{array}$ & [220-222] \\
\hline
\end{tabular}


Several papers have reported human skeletal abnormalities in patients with CYP26B1 mutations. Three siblings carried a homozygous CYP26B1 c.1088G > T transversion of CYP26B1, predicting a p.Arg363Leu substitution (one died in utero at 35 weeks and two terminations). All three displayed severe skeletal abnormalities including craniofacial malformations, radio-humeral fusions, hypoplastic pelvis, calvarial plate hypoplasia and mineralisation defects, oligo and arachnodactyly, narrow thorax, premature bone maturation and occipital encephalocele. The mutation affected the conserved core-stabilising K-helix region required for enzymatic catalysis and produced a similar reduction in ability to metabolise RA to that of a null truncation [202]. Furthermore, predicted loss of function mutations in CYP26B1 have produced skeletal phenotypes analogous to that of Antley-Bixler and Pfeiffer Syndromes as described in Table 1 [202,218]. Microdeletions of chromosome 2p13.2-13.3 leading to haploinsufficiency of CYP26B1 and EXOC6B have been associated with phenotypes of intellectual disability, language delay, hyperactivity, dysmorphic facies and vertebral and/or craniofacial abnormalities [219].

Additionally, a variety of homozygous or compound heterozygous mutations, including missense, nonsense, frameshift, splicing and exon deletions in POR, the CYP26 obligate electron donor give rise to abnormal steroidal profiles with and without Antley-Bixler skeletal phenotypes [220-222].

Missense mutations in CYP26C1 which reduce enzymatic metabolism of RA act as modifiers of missense SHOX mutations conferring the more severe skeletal phenotype of short stature and limb defects (shortening and bowing of the radius together with distal hypoplasia of the ulna and mesomelia) compared to phenotypically normal/mild short stature in family members carrying only the SHOX mutation [223]. It has since been shown that missense mutations and splice variants of CYP26C1 causing reduced enzymatic activity [224]. Homozygote $7 \mathrm{bp}$ duplications leading to a frameshift and a premature stop c.844_851dupCCATGCA p.Glu284fsX128 and/or compound heterozygote mutations of the duplication with an inactivating missense mutation c.1433G $>$ A p.Arg478His give rise to focal facial dermal dysplasia, where an abnormal epidermis and replacement of the dermis by connective tissue and loss of subcutaneous tissues gives rise to skin lesions at the sites of facial fusion during development [225]. Thus, in humans disease-causing variations in the Cyp26 genes give rise to variety of conditions including neural tube, cardiac and skeletal defects amongst others. This correlates with the phenotypes generated from null and conditional mutations of the Cyp26 genes in animal models as discussed in more detail below.

\section{Function of CYP26 Enzymes during Development}

\subsection{Deletion of All Three Cyp26 Genes/Por}

In mutant mice lacking all three Cyp26 genes, Nodal expression is ectopically activated in the entire epiblast during gastrulation, via an RARE in the Nodal autoregulatory enhancer. This ectopic activation results body axis duplication in approximately half the embryos and severe patterning defects in the brain in the remaining embryos, similar to those seen in Cyp26a1/c1 null embryos. About $25 \%$ of $C y p 26 a 1 / \mathrm{c}^{-/}$embryos also displayed duplication of the primitive streak whereas Cyp $26 a 1 / b 1^{-/-}$ mutants did not, suggesting that Cyp26a1 extra-embryonic expression is the main Cyp26 gene in early development, acting non-cell autonomously to keep the epiblast RA-free. However, since Cyp26a1 null mutants have no gastrulation defects, the other two genes must be able to compensate for its loss. Increased dietary RA was able to increase the frequency of severe phenotypes in triple and double homozygous mutants. These defects could be induced by very high levels of added RA in wild-type diets. This suggests that mutant phenotypic variation may be due to varying maternal RA levels and again highlights the importance of CYP26s in development, as under normal conditions the embryo should be protected against levels of variation of dietary maternal RA [226].

Studies in the chick embryo using the CYP26 inhibitor R115866 bypassed gastrulation stages to look at the effects of CYP26 inhibition when R115866 was added in ovo at stage 10 (10 somite) and stage 14 (22 somite E9.0) and examined following 24/48 $\mathrm{h}$ further incubation. Embryos given 
relatively high doses of R115866 displayed phenotypes similar to higher doses of RA and did not survive past E5 at the very latest. Defects included decreased head mesenchyme, smaller otic vesicles and loss of anterior tissues such as the forebrain. Pharyngeal defects included loss of caudal pharyngeal arches/arch arteries, pharyngeal endodermal pouch segmentation and reduced pharyngeal arch artery vascular smooth muscle, plus loss of migrating neural crest and mis-patterned cranial ganglia. Heart defects comprised shorter outflow tracts, abnormal looping and pericardial oedema. Embryos given lower doses of R115866 survived up to E8 and displayed mature cardiovascular defects resulting from abnormal pharyngeal arch artery development including common arterial trunk, double outlet right ventricle and ventricular septal defects. Upregulated retinoic acid levels were confirmed by anterior ectopic shifts of Hoxb1. These defects strongly phenocopy those seen in Tbx1 mutant mouse models for human 22q11 Deletion Syndrome which display dysregulated retinoic acid levels, likely driven by upregulated Raldh2 and downregulated Cyp26 expression [65,69,126,127,227].

Knockout mice for cytochrome 450 oxidoreductase (Por), which is the obligate electron donor for the CYP26 enzymes and necessary for their function, display very severe phenotypes. These included growth retardation, axial rotation defects abnormal head and caudal development, open neural tubes, pharyngeal and cardiovascular defects, which are lethal by E10.5. These embryos exhibit ectopic RA-signalling and can be partially rescued by genetic down-regulation of RA using the Raldh2 null allele [228-230], thus displaying the importance of CYP26 function during development.

\subsection{Loss-of Function Cyp26a1 Models}

Targeted disruption of Cyp26a1 and Cyp26b1 leads to phenotypes that are similar to the application of exogenous RA. Two separate knock-out mice for Cyp26a1 have been found to have a phenotype which includes posterior truncations and sirenomelia, abnormal development of the posterior gut and urogenital system, homeotic posterior transformations of the vertebrae and hindbrain and cranial nerve patterning defects $[179,231]$. These anomalies are accompanied by an increase in RA signalling which has been linked to the mis-patterning of the brain and vertebrae and caudal truncation associated with down-regulation of Brachyury and Wnt3a [103,232-235].

Caudal truncation malformations appear to be mediated by inappropriate activation of Rarg (retinoic acid receptor gamma). Loss of Rarg confers resistance to the caudal abnormalities induced by teratogenic RA doses and rescues $\mathrm{Cyp} 26 \mathrm{Ca}^{-/-}$caudal regression/lethality by restoring normal expression of tail bud genes including Wnt3a, Brachyury and $F g f 8[81,103,236]$. In the wild-type state it seems Cyp26a1 function is to protect against the effects of excess environmental RA, particularly since RA can induce Cyp26a1 expression via RARE sites in its promoter, although this system is not sufficient to degrade teratogenic doses of exogenous RA [103,142,183,237].

In some embryos developmentally arrested between E8.5 and 9.5 pericardial oedema, cardiac looping and dilation defects were also observed. As described above, forebrain defects of varying severity could be induced in Cyp26a1 $1^{-/}$embryos when given subteratogenic doses of RA that do not result in defects in wild-type embryos. The severity of the defect varied in dose and time-dependent fashion: an earlier period of administration at a low dose of RA (E6.5-7.5 20ugRA/g food) led to E9.5 lethality, a phenotype possibly linked to the gastrulation defects observed in triple-deleted at Cyp26a1/c1 $1^{-/}$embryos. Later RA-supplementation (E7.5-8.5) led to anterior truncations which could affect all rostral brain regions at E9.5 (high dose) to lesser truncations affecting only more anterior regions (lower dose). Blood vessel endothelium of the yolk sac and within the embryo was also affected with much lesser plexus development observed [238].

Similar phenotypes are also observed in the zebrafish cyp26a1 null mutant, giraffe [239]. Cyp26c1 knockouts alone seem to have no discernible embryological defects. This may be due to functional redundancy with Cyp26a1 with which it is expressed in an overlapping pattern and is found on the same chromosome $[161,240]$. In addition to the subset with gastrulation axis defects described above, double homozygous mutants for Cyp26a1/c1 display a more severe RA embryopathy phenotype than either mutant alone, with lethality by E11.0. This includes CNS patterning abnormalities, a reduced size of 
the head, eye, frontonasal region and an open neural tube between the fore and hindbrain, hypoplastic PA1 and 2 and abnormal NCC migration. The NCC defects can be rescued in the context of a Raldh2-/genetic background, again suggesting that CYP26s have a protective role against inappropriate RA exposure during development. This idea is supported by the studies described above where Cyp26a1 $1^{-/}$ RA-supplemented embryos exhibit more severe phenotypes when exposed to maternally administered subteratogenic doses of RA that do not result in defects in wild-type embryos $[226,240,241]$.

\subsection{Loss-of Function Cyp26b1 Models}

Cyp26b1 null mutants have been reported to have severe meromelia-like limb defects with oligodactyly, micronathia and lethality immediately after birth as a result of respiratory distress. Abnormal limbs undergo increased apoptosis and become proximilized and ectopic distal RARE-lacZ expression was observed. The apoptotic defect appeared to be mediated via Rarg but not the proximo-distal patterning anomalies [242-245]. These defects are discussed in more detail in the sections below.

Two cyp26b1 mutants in the zebrafish, stocksteif and dolphin exhibit a reduction in midline cartilage of the neurocranium and pharyngeal arches and severe over-ossification of the axial skeleton and craniofacial bones leading to fusion of the vertebrae, which can be phenocopied in mouse embryos by treatment with CYP26 inhibitor R115866. As discussed above, CYP26B1 mutations in humans also confer skeletal defects [202,203].

Craniofacial defects are also reported in the mouse, including cleft palate, reduced or absent incisor development, micrognathia and absent posterior nasopharynx [246]. Further investigation of the cleft palate defect revealed that Cyp 2661 null embryos have a $100 \%$ penetrant cleft palate defect, arising from reduced proliferation in the bend region of the palatal shelves [246,247]. Craniofacial ossification is reported to be reduced, along with severe abnormalities in the craniofacial skeleton where many bones are missing or deformed with abnormal fusions. Similar malformations are observed in the trachea, larynx, auditory system and dental development. Molecular markers reveal hindbrain patterning to be relatively normal but disturbance of caudal neural crest migration and cranial nerve patterning is present [246], matching reports using a Cyp26b1 morpholino (MO) in which cranial nerve patterning and $D l x 2$ expression in the neural crest is down-regulated in zebrafish morphants [248].

These loss-of-function experiments reveal a wide range of important roles for the Cyp26 genes in regulating RA availability during development, from gastrulation to whole embryo anterior-posterior patterning to organogenesis. Further studies which focus on the role of the Cyp26s in specific tissues/organs have elucidated particular cellular mechanisms requiring regulation RA by Cyp26s during development and have explored the relative importance of these enzymes in acting to secure RA-negative cells/tissues versus their role in establishing RA gradients. These reports are discussed in detail below for several developing orgains/tissues.

\section{Forebrain}

Studies in avian and mouse embryos indicate RA synthesis and signalling are required for forebrain development. Loss of RA causes increased apoptosis and decreased in anterior tissues which has been linked to dysregulation of signalling molecules including FGF8, WNT and SHH. It is tempting to speculate that these molecules, in conjunction with RA levels mediated by RALDH2 and CYP26A1, act in similar fashion in the forebrain as in the hindbrain (see below) to contribute to anterior patterning.

In mouse mutants, deletion of Cyp26a1 alone does not produce significant anterior defects. However, this is likely to be the result of redundancy with Cyp26c1, as double homozygote knockout embryos display severe anterior defects early in development [226]. Anterior truncations are also seen in Cyp26a1 mutants when dosed with exogenous RA in concentrations which are aphenotypic in wildtype embryos [238]. Studies in zebrafish and chick give similar results. Forebrain a/hypoplasia is seen in chick embryos treated at the 10-somite stage with CYP26 inhibitor R115866. In zebrafish cyp26a1 mutants, posteriorisation of the entire neural plate is seen in response to non-teratogenic doses 
of RA and smaller heads are seen in cyp26a1/c1 double morphants and giraffe (cyp26a1) mutant embryos injected with cyp $26 c 1$ morpholino. Moreover, expression of cyp $26 a 1$ in the anterior neural plate seems to be both RA dependent and independent. Regions of lower cyp26a1 expression upregulate this expression via RAREs when exposed to RA. However, high levels of cyp26a1 can also be induced in an RA-independent fashion [180,249-251]. An RA-independent SOX: OCT-binding motif in the cyp26a1 promoter was found to drive cyp26a1 expression in the anterior neural plate of the zebrafish and cyp26a1 expression was lost in sox2/3/19a/19b quadruple morphants. Finally, ChIP experiments were positive for SOX at the cyp $26 a 1$ promoter indicating a direct interaction $[252,253]$. Transcription factors tgif and zic1 are also reported to be involved in the initiation and maintenance of anterior neuroectodermal cyp26a1 expression. Zic1 knockdown caused severe forebrain and midline defects. These morphants displayed increased levels of RA resulting from decreased cyp $26 a 1$ expression in the forebrain (but not the hindbrain) and repression of dorsal bmp signalling [254].

Tgif is a TALE class homeobox transcription factor. Tgif loss of function produces severe anterior neural tube and midline defects in human [255-261], zebrafish and some mouse mutants [262-266]. TGIFs can bind to RXR/RAR complexes and in the zebrafish loss of tgif results in reduced anterior cyp26a1 and raldh2 expression at gastrulation [262,266,267]. Loss of tgif function phenocopies those of cyp26a1 mutants/morphants and ectopic tgif expression is sufficient to induce cyp26a1 [266]. Raldh2-/mice also exhibit severe forebrain hypoplasia phenotypes, and the severity of these anterior defects increases with the additional removal of Raldh3. Together, the Cyp26a1 and Raldh2/3 data indicate control of RA availability is crucial for proper forebrain development [268-270].

A later role for RA signalling exquisitely regulated by enzymatic control of RA availability has been demonstrated in the development of the chick dorsal forebrain. A central region of Raldh2-expressing dorsal mesenchyme overlying the forebrain roof-plate flanked by Cyp26a1/c1 expressing mesenchyme gives rise to a central region of anterior-posterior low-high RA activity with low proliferation in the dorsal forebrain. Experimental manipulation of these regions by electroporation of VP16 or dominant-negative RA receptor constructs suggested that Cyp26a1 expression was required to restrict RA-signalling which conferred dorsal forebrain identity and was required for invagination of Rathke's Pouch. Furthermore, degradation of RA by Cyp26a1 in the flanking regions to provide an RA-negative domain was necessary for the development of the choroid plexus [271].

\section{Hindbrain Patterning}

Retinoic acid signalling is known to be required for neuroectodermal anterior-posterior patterning as part of a complex signalling network also encompassing roles for FGF and WNT signalling. The role of RA in patterning the hindbrain into segments known as rhombomeres has received particular attention, especially with regard to the role of the Hox genes as direct RA targets genes. Each rhombomere has a specific anterior-posterior identity conferred by combinatorial transcription factors such as Hox gene expression and this identity is important in a number of further developmental events including brain and otic development and neural crest migration into pharyngeal arches (reviewed [272-281]).

The RALDH2 synthesising enzyme is expressed only in presomitic mesoderm/somites and not in the neuroepthelium, so atRA signalling in the developing neuroectoderm is of a paracrine nature. It can be hypothesised that RA gradients might be generated in the developing nervous system based on the distance RA must diffuse from generating RALDH2 tissues. This model can be amended to also consider CYP26 RA-degrading expression within the neuroectoderm.

CYP26s are expressed at high levels in very dynamic patterns during nervous system development. Cyp26a1 is expressed first and most anteriorly beginning with transient expression in $\mathrm{r} 2$ at E8.5 in mouse with a posterior $\mathrm{r} 2 / \mathrm{r} 3$ boundary which shifts posteriorly later to $\mathrm{r} 4 / \mathrm{r} 5$. Cyp26b1 is expressed strongly in $\mathrm{r} 5$ and more weakly in $\mathrm{r} 3$ at E8.0, but by E9.5 broader expression is seen, with strong expression at $\mathrm{r} 5 / \mathrm{r} 6$ and weaker expression domain extending up to $\mathrm{r} 2$. Cyp26c1 expression is initially in $\mathrm{r} 2$ and $\mathrm{r} 4$ and then restricted to $\mathrm{r} 2$. In zebrafish, cyp $26 a 1$ is first seen with a posterior boundary at $\mathrm{r} 3 / \mathrm{r} 4$ at $8.5 \mathrm{hpf}$ which then moves anteriorly to $\mathrm{r} 2 / \mathrm{r} 3$ by $10 \mathrm{hpf}$ and more anteriorly still at $11 \mathrm{hpf}$. Cyp $26 \mathrm{~b} 1$ 
expression begins later at $10 \mathrm{hpf}$ in $\mathrm{r} 3 / \mathrm{r} 4$ and then expands up to $\mathrm{r} 2$ by $15 \mathrm{hpf}$ as development proceeds, as for the mouse. Cyp26c1 expression overlaps with, but precedes, cyp26b1 expression at each stage.

Various types of loss-of-function models produce hindbrain patterning defects. In mouse embryos, loss of Cyp26a1 produces a partial $\mathrm{r} 3$ to $\mathrm{r} 4$ transformation accompanied by an enlargement or $\mathrm{r} 4[179,231]$. When both Cyp26a1/c1 are deleted, the presumptive $\mathrm{r} 1-\mathrm{r} 4$ region is posteriorised and loses segmentation $[226,246]$. Hindbrain abnormalities have not been reported for individual deleted alleles of Cyp26b1 and Cyp26c1.

In the zebrafish, cyp26a1 null embryo $\mathrm{r} 1-\mathrm{r} 3$ is slightly reduced in size and $\mathrm{r} 4$ slightly enlarged. Most caudal hindbrain region r7/r8 increases in length [239]. Alone, knock-down of cyp26b1 and cyp $26 c 1$ or both, has minimal phenotype beyond a very small shortening of the hindbrain. However, depletion of either cyp $26 b 1$ or cyp26c1 in a cyp $26 a 1$ null context strongly exacerbated the cyp26a1 phenotype. Cyp26a1/b1 depletion causes further expansion of $\mathrm{r} 4$ and there is a shift of the r6-r7 boundary towards $\mathrm{r} 5$ whereas depletion of cyp26a1/c1 leads to hypo or aplasia of $\mathrm{r} 3$, with expansion of $\mathrm{r} 4 \mathrm{up}$ to the presumptive cerebellar region. There is a similar shift of the $\mathrm{r} 6 / \mathrm{r} 7$ boundary towards a slightly reduced $\mathrm{r} 5$. When all three cyp 26 genes are removed $\mathrm{r} 3$ and $\mathrm{r} 5$ are lost completely and $\mathrm{r} 4$ lies next to the cerebellum, with $\mathrm{r} 5 / \mathrm{r} 6 / \mathrm{r} 7$ boundaries all shifted towards the cerebellum [250].

Differing experimental models in the zebrafish and mouse have led to differing interpretations of these possibilities for hindbrain patterning. A rare;yfp transgenic zebrafish demonstrated an RA-response gradient at the hindbrain-spinal cord junction with little RA signalling evident anteriorly, increasing to obvious expression in the posterior hindbrain and spinal cord. Loss of RA production led to loss of the rare-driven signal, which could be restored by re-establishing zones of RA-production in the somatic mesoderm [180]. More recently, genetically coded probes for RA (GEPRAs) have been used to confirm RA gradients consistent with this previous work in zebrafish [282]. Another zebrafish study suggested that this RA gradient grows increasingly steeper with time, leading to concentration-dependent anterior to posterior specification of rhombomere identity, with RA concentrations necessary to establish posterior identity being reached later in development [283]. Experiments in the mouse linked expression of RA-responsive gene Hoxb1 expression in $\mathrm{r} 4$ to that of Cyp26 genes suggesting that Cyp26 expression was linked to establishment of rhombomeric boundaries. Posterior Cyp 26 boundaries specify the anterior boundaries of genes conferring rhombomere identity. In this model, length of time of RA exposure rather than concentration drive hindbrain segmental fate [284]. Similar results from a third investigation in the zebrafish proposed that distinct regions of CYP26-driven degradation of RA over time, combined with changing RA sensitivity, specified increasingly posterior boundaries of RA dependent gene transcription necessary for rhombomere segmentation in a step-wise manner [250].

Finally, a mechanism which combined both RA gradient and CYP26 RA degradation in the patterning of the hindbrain was proposed on the basis of bead implantation experiments, and mathematical modelling. This requires FGF and RA to act together in parallel in the neural ectoderm to control cyp26a1 expression (RA induces and FGF inhibits cyp26a1) to generate a robust RA gradient which gives rise to rhombomere positional identity. Raldh2 in the somatic mesoderm produces RA which diffuses through the neural ectoderm. RA is degraded by Cyp26 enzymes at differing rates giving rise to a gradient across the hindbrain which confers rhombomere identity. Thus, FGF and RA act together to regulate cyp26 expression leading to the production of a stable yet flexible RA gradient which grows along with the embryonic axis [159,180,249,285-287] (Figure 4).

Identity switching and cell intermingling takes place during rhombomere segmentation to establish and maintain homogeneous identity and sharp rhombomere boundaries during hindbrain development. Morphogen (RA) signalling fluctuation initially established rough boundaries of gene expression requiring mutual repression of hoxb1 and egr 2 to restrict expression to $\mathrm{r} 4$ and $\mathrm{r} 3 / 5$ respectively $[288,289]$ whereas Eph-Ephrin driven signalling sharpens borders by preventing intermingling (reviewed by [290,291]). A recent paper has added further insight in to the processes that fine tune identity switching during the hindbrain segmentation process via the community effect. Transplantation 
experiments showed that cells which intermingle during boundary formation switch their identity to match that of their neighbours, a process mediated by feedback between segment identity as specified by expression of egr2 (krox 20) and cyp26b1 and cyp26c1. Lower expression of cyp26b1/c1 in r3 and r5 is regulated by repression by egr 2 . Cells in neighbouring $\mathrm{r} 2 / \mathrm{r} 4 / \mathrm{r} 6$ do not express egr 2 and have higher expression of cyp $26 b 1 / c 1$. Thus, RA levels are higher in $\mathrm{r} 3 / \mathrm{r} 5$ than in other rhombomeres leading to repression of hoxb1. Egr2 directly autoregulates itself, further repressing hoxb1. Higher expression of cyp26b1/c1 in segments not expressing egr2 (e.g., r4) leads to lower levels of RA thus allowing expression of hoxb1. Autoregulation of hoxb1 expression in turn represses expression of egr 2 in these segments. If cells from $\mathrm{r} 3 / \mathrm{r} 5$ intermingle into $\mathrm{r} 4$, they are surrounded by cells expressing cyp $26 b 1 / \mathrm{c} 1$ at higher levels which leads to a reduction of RA within the intruding cell as only paracrine non-cell autonomous RA signalling is active in the neuroectoderm. Lower concentrations of RA then repress egr 2 expression within ectopic $\mathrm{r} 3$ cells via the stimulation of hoxb1 expression which represses egr 2 . This then causes the $\mathrm{r} 3$ cell to change identity to match that of its $\mathrm{r} 4$ neighbours. When the ability to regulate cyp26b1/c1 levels is removed by experimental knockdown, this entire mechanistic chain is prevented [292-294] (Figure 4).

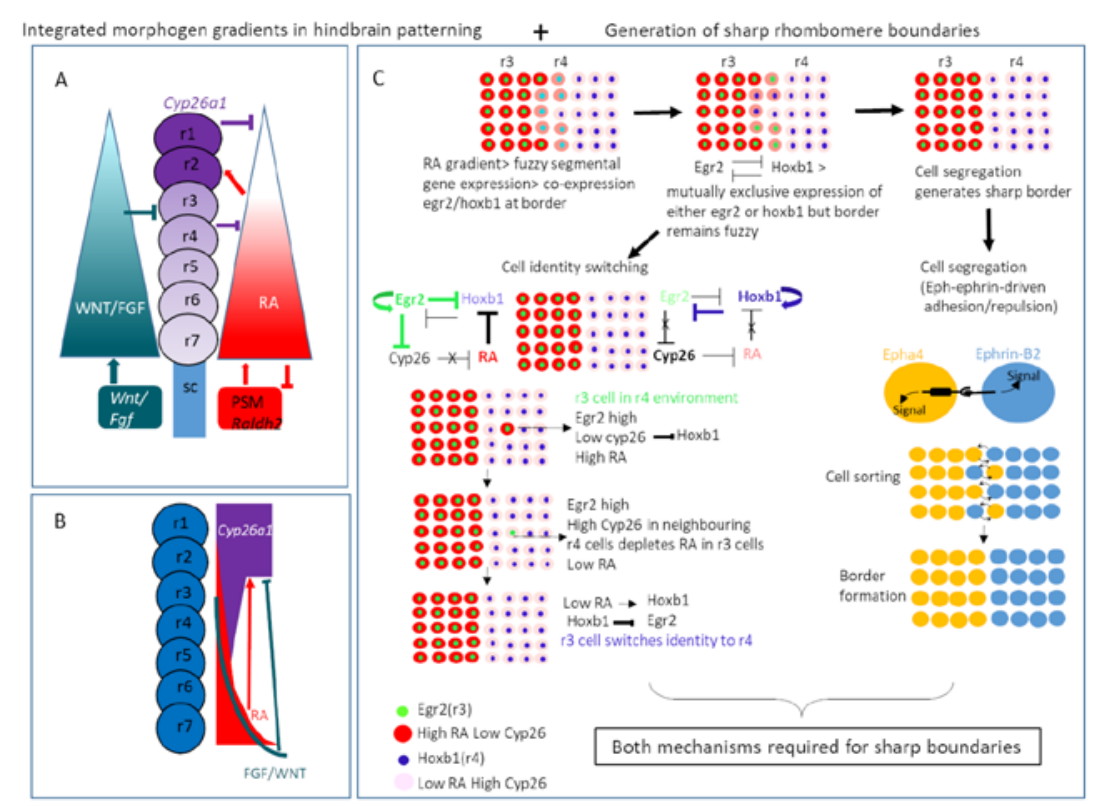

Figure 4. Regulation of RA availability by CYP26 enzymes in morphogen patterning of the hindbrain and generation of sharp rhombomere boundaries. (A) and (B). Integrated morphogen gradients in hindbrain patterning. Domains of RA synthesising enzyme Raldh2 in the pre-somitic mesoderm at the posterior of the hindbrain and high RA-degrading enzyme Cyp26a1 in the anterior neuroectoderm of the hindbrain plus lower Cyp26a1/c1 in more posterior hindbrain combined with inhibitory signals from an FGF/WNT signal gradient establish an RA gradient which is robust to RA fluctuation and adapts as the hindbrain grows larger (adapted from White et al. 2008 [159]). (C). Generation of sharp rhombomere boundaries requires Eph-Ephrin-mediated cell segregation and a cell identity switching mechanism driven by the RA status of the local environment. Cells of high egr2, low cyp26b1 and high RA specify $\mathrm{r} 3$ identity. If these cells are present in an $\mathrm{r} 4$ environment, high cyp $26 b 1$ in surrounding $\mathrm{r} 4$ cells leads to depletion of RA in the $\mathrm{r} 3$ cell, this induces hoxb1 expression which represses egr 2 leading to a switch to 4 identity of high cyp26b1, low RA, high hoxb1. Hoxb1 and egr2 reciprocally repress each-others' expression maintaining identity in each rhombomeric segment (adapted from Addison et al. 2018 [293], Wilkinson 2018 [294] and Kitazawa and Rijli 2018 [292]).

\section{Neuromesodermal Progenitors (NMPs) and Axis Extension}

Axis elongation in the developing embryo is driven by the generation of trunk mesoderm and spinal cord neurectodermal tissue. Previously, the generation of opposing RA/FGF-WNT gradients 
has been linked to the formation and patterning of caudal mesoderm/somitogenesis and spinal cord (reviewed [11,295,296]). As part of this process, Cyp26a1 expression from gastrulation onwards degrades RA from the most posterior regions, allowing expression of FGF/WNT in a posterior to anterior gradient. An opposing gradient of RA generated by expression of Raldh2 in somites and anterior presomitic mesoderm and transiently in the node and primitive streak inhibits FGF-driven mesoderm production and allows the drive towards a neural fate, thus maintaining a balance between caudal mesoderm and neural plate. SHH signalling is also implicated in this process, with RA negatively regulating Gli2, which is required to promote SHH signalling. Furthermore, loss of Cyp26a1 and increased RA signalling are apparent in the Shh LOF mutants along with caudal truncations similar to those seen in Cyp26a1 ${ }^{-/}$embryos, implying posterior Cyp26a1 expression may also promote GLI2-mediated processing of SHH signalling [229,297,298].

It has been shown that these tissues are generated in a progressively more posterior fashion by proliferation and subsequent differentiation of neuromesodermal progenitors (NMPs) found at the caudal end of the embryo. To ensure the embryo reaches the correct length, careful regulation of number of progenitors induced, rate of self-maintenance/renewal and differentiation towards neural or mesodermal fates is necessary [299-303].

NMPs are located in regions expressing WNT and FGF ligands including the border of the node/primitive streak, the caudolateral epiblast and the chordoneural hinge region. Caudal truncations result from interference with either of these signalling pathways as a result of NMP depletion [304-309]. Similar truncations/reduced size of caudal structures are reported when RA signalling is deregulated by either deletion of Cyp26a1 [179,231,239] or Raldh2 [11,60,229,310].

Both FGF and WNT are linked to roles in progenitor maintenance and act as posteriorising signals via $C d x$ genes, which in turn regulate more posterior Hox gene expression. Studies in mouse and zebrafish show that WNT signalling is also coupled to mesodermal differentiation of NMPs via an autoregulatory loop, which maintains a mesodermal progenitor niche in which T-box gene Brachyury directly regulates expression of Cyp26a1 in the caudal tail bud, generating a low RA region which allows the expression of Wnt3a and Fgf8 that is inhibited by high levels of RA [232,233,311-313]. Furthermore, this autoregulatory loop is regulated by the expression of $C d x$ genes [314-316]. Complex interaction and regulation of transcription factors such as T/Brachyury, Cdx, Sox2, Msgn1 and Tbx6 with signalling pathways WNT, FGF and RA seem to regulate induction and maintenance of NMPs, mesodermal or neurectoderm fate and embryonic axis elongation [302,308,309,317-325].

The complexity of the interacting events with overlapping functions and multiple feedback loops of the pathways involved has made it difficult to assess exactly which functions are mediated by which molecules. Recently, investigators have taken advantage of the iPSC/ESC model where NMPs can be generated outside the complex environment of the embryo [326-329] to attempt to build a definitive model for these events. This approach combined with RNA-Seq single cell analysis has confirmed much of what had been elucidated from embryonic studies, to wit, a transcriptional network comprised of the $C d x, T / B r a, S o x 2, M s g n 1$ and Tbx 6 which integrates signals from WNT and RA to control the NMP state. Tight control of RA via Raldh2/Cyp26a1 expression is important, firstly for NMP induction via Sox 2 and secondly to increase RA levels to drive neural differentiation. $C d x$ genes maintain $T / B r a$ expression and thus allow RA degradation via Cyp26a1 and mesoderm induction as well as acting to posteriorise expressing cells. Cell-autonomous repression of T/Bra and Sox 2 by Tbx6 and Msgn1 control time and fate of NMP differentiation, promoting mesodermal differentiation and Raldh2 expression and thus RA signalling. This leads to elevated levels of RA which signal in paracrine fashion to drive neural differentiation, thus balancing neural versus mesodermal fates [330-332] (Figure 5). 


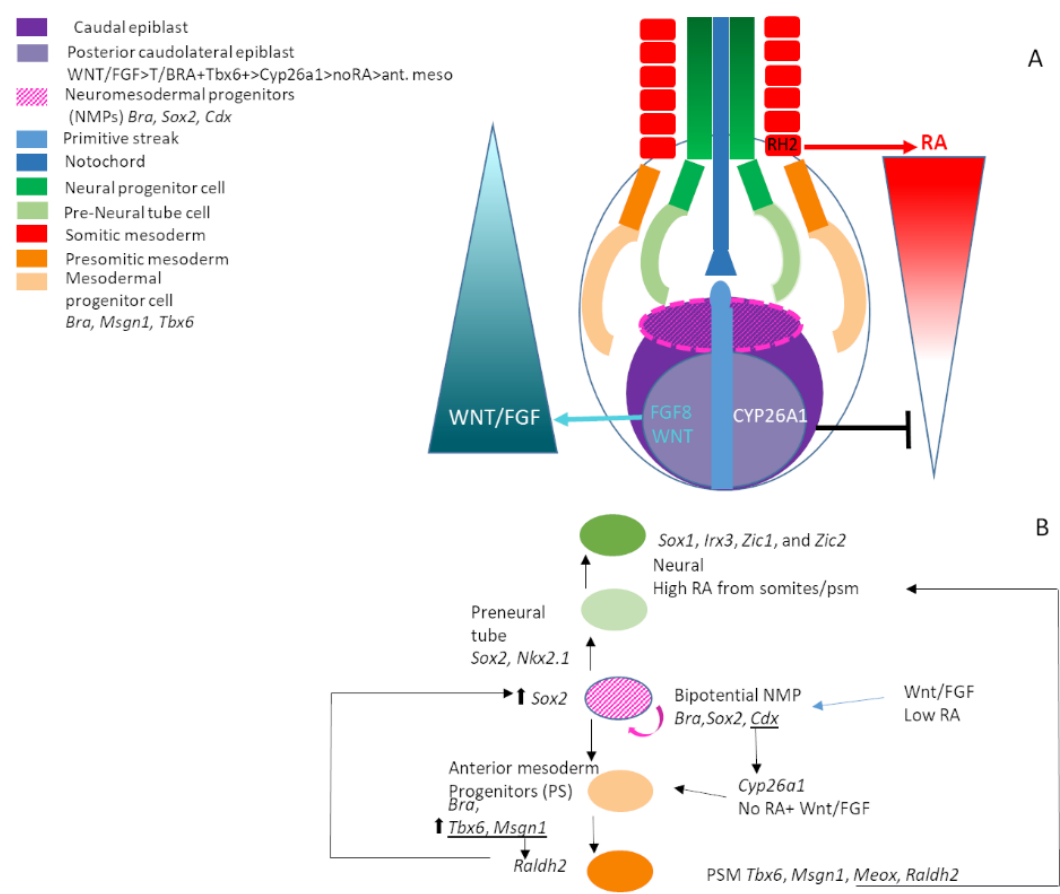

Figure 5. CYP26 enzyme function in neuromesodermal progenitor and axial elongation during development. (A) Schematic of posterior axial development, neuromesodermal progenitors and morphogen gradients. Expression of Cyp26a1 in the posterior caudolateral epiblast in combination with FGF/WNT signalling and RA synthesis by Raldh2 in the somatic mesoderm and epiblast establishes a posterior RA gradient required to promote caudal axial elongation. Axial elongation requires the establishment and maintenance of a neuromesodermal progenitor pool in the caudal epiblast at the anterior end of the regressing primitive streak. Bipotential NMPs can differentiate either to neural or mesodermal specifications and a balance between these fates is required for normal axial development. (B) Schematic of the molecular signals governing bipotential NMP fate specification towards either neural or mesodermal tissue. Posteriorly, CYP26A1-mediated inhibition of RA plus FGF/WNT signalling induces Bra/Tbx6-positive mesodermal tissue from NMPs. Anteriorly high RA promotes induction of Sox2/Nkx2.1 pre-neural fates from NMPs. NMPs themselves (Bra/Sox2-positive) require low levels of RA for induction and maintenance. In this model, the relative levels of mutually antagonistic RA and WNT signalling control T/Bra and Sox2 expression and regulate the switch between mesodermal and neural differentiation and therefore the proportion of the two cell fates. Adapted from Niederreither and Dolle 2008 [10] and Gouti et al. 2017 [330].

Embryonic data including Raldh2, Cyp26a1 and $R A R \gamma$ expression and loss-of-function data suggested an early role for RA signalling in NMP induction and anterior-posterior axis elongation but were confounded by a possible maternal contribution of Raldh2 [60,72,78,79,81,103,179,182,229,231,236, 284,333]. Data from single cell analyses confirmed RAR $\gamma$ NMP expression in vivo and in vitro, and showed Cyp26a1 was expressed at E9.5 but not E8.5. Upregulation of Cyp26a1 at E9.0 is thought to degrade RA levels to allow NMP maintenance. NMP identity was lost in vitro if RA was removed at differentiation day 0 , along with loss of Sox 2 and increased expression of mesodermal genes. On the other hand, exposure to high levels of RA in differentiating NMPs led to gain of pre-neural tube fate at the expense of mesoderm [330] (Figure 5).

Combined with embryonic studies, this suggests a model of the posterior of the elongating embryo where an anterior-posterior gradient of RA is established from RA-synthesis in the caudolateral epiblast plus paracrine RA from more anterior mesoderm counterbalanced by CYP26A1-mediated RA degradation in the posterior tailbud. This gradient controls the birth and anterior-posterior position of different trunk progenitor cells. Posteriorly, CYP26A1-mediated inhibition of RA plus FGF/WNT signalling induces Bra/Tbx6-positive mesodermal tissue from NMPs. Loss of Cyp26a1 expression causes 
loss of Sox2, loss of NMP identity and upregulation of mesodermal specific genes. Anteriorly high RA promotes induction of Sox2/Nkx2.1 pre-neural fates from NMPs. NMPs themselves (Bra/Sox2-positive) require low levels of RA for induction and maintenance [307,330] (Figure 5).

Thus, in this model, the relative levels of mutually antagonistic RA and WNT signalling control $\mathrm{T} / \mathrm{Bra}$ and Sox2 expression and regulate the switch between mesodermal and neural differentiation and therefore the proportion of the two cell fates. Experimentally altering RA/WNT levels in differentiating NMPs can alter the relative proportions of mesodermal (Tbx6+) and neural (Sox2+) cells produced. Moreover, this model allows an RA-driven feedback loop to maintain the proper balance between mesoderm and neural fates. RA signalling from differentiated mesoderm induces Sox2 in undifferentiated NMPs, thus promoting neural differentiation. Alternatively, reduced formation of mesoderm plus Cyp26a1 expression reduces RA thus decreasing Sox2 expression in NMPs inducing a switch towards mesoderm production. This establishes an equilibrium in the direction of differentiation towards neural or mesodermal tissue in the bipotential NMP progenitors which expedites correct axis elongation [330] (Figure 5).

\section{Skeletal Tissues: Craniofacial, Axis and Limb}

Deletion of Cyp26b1 revealed a very severe limb defect in line with its expression at the distal ectoderm and pre-cartilaginous blastemal of the limb bud. Both fore and hind limbs were affected, displaying abnormal proximodistal patterning of all skeletal elements up to the level of the ilium/scapula which were normal. Precartilage condensation staining minimal separation of the three proximodistal segments from each other. The stylopod (humerus/femur) and zeugopod (ulna/radius or tibia/fibia) had a single primordium plus a poorly formed autopod (digits) region. This led to fusion of the stylopod and zeugopod with a thicker proximal region and no joint formation. Only 2-3 digits were formed with poorly distinguished carpal bones. A similar phenotype was seen in embryos treated with R115866. Increased RA availability in the absence of Cyp26b1 led to loss of proximodistal patterning by the three distal Hox genes (Hox12, a13 and d13) and expansion of Meis 1 and 2 expression. Mesenchyme labelling experiments showed this led to presumptive autopod distal mesenchyme acquiring a more proximal identity thus contributing more to proximal (thickened) regions of the limb at the expense of the autopod in mutant limbs. The limb truncation phenotype was explained by greatly increased cell death and reduced chondrocyte maturation in the stylopod and zeugopod. Gene expression in the apical ectodermal ridge and zone of polarising activity was normal. [243,245].

Analysis of Shh loss-of-function mouse limb buds showed increased distal expansion of proximally located RA-dependent target genes alongside reduced distal Cyp26b1 expression. Bead grafting experiments with FGF and FGF-inhibitor and AER-conditional mutant $F g f$ limbs showed Cyp26b1 expression was dependent on FGF signals. This indicates that SHH-dependent AER-FGF signals likely control Cyp26b1 expression to create an RA-free area in the distal limb. Mathematical modelling confirmed by RA-bead grafting experiments suggested an antagonistic AER-FGF-CYP26B1-RA signal linked to the SHH/GREM/AER/FGF feedback loop which enables SHH to promote distal limb development via CYP26B1-mediated RA degradation [244]. Combined with studies from the chick which implicate RA as a proximalising signal and AER-FGF as an antagonistic distalising signal upon limb mesenchyme fates, this led to the proposition of the "two-signal model" in which these signals control proximodistal limb development, together with WNT3 [204,334,335]. Further development of this model to better fit experimental results on PD patterning has led to addition of a cell-autonomous intrinsic timing element. Hoxa13 expression is timed in limb mesenchyme in addition to cell cycle and duration of exposure to the AER signals to specify the stylopod and zeugopod/autopod. Hoxa13 expression is controlled by Meis genes via CYP26B1 degradation of RA and also requires limb cells to become competent for Hoxa13 expression. Competence cannot be activated prematurely by experimental signalling methods. However, increased histone acetylation by inhibition of HDACs, making chromatin more accessible, did allow early expression of Hoxa13. This model integrates epigenetic regulation determining timed Hoxa13 activation with classical limb patterning signals of 
SHH, FGF and RA and elucidates an epigenetically-regulated delay in gene expression timing required for spatial patterning of the limb [204,335,336]. Interestingly, the limb chondrocyte defects seen in Cyp26b1 $1^{-/-}$mutants are compatible with this model. Deletion of $R A R \gamma$ in a Cyp26b1 null background rescued stylopod and some digit formation, but not the zeugopod. This $R A R \gamma$-mediated rescue of the apoptosis defect and chondrocyte differentiation improved limb mesenchyme survival but not proximodistal gene patterning disruption, uncoupling the chondrocyte defects from the patterning abnormalities [243] (Figure 6).

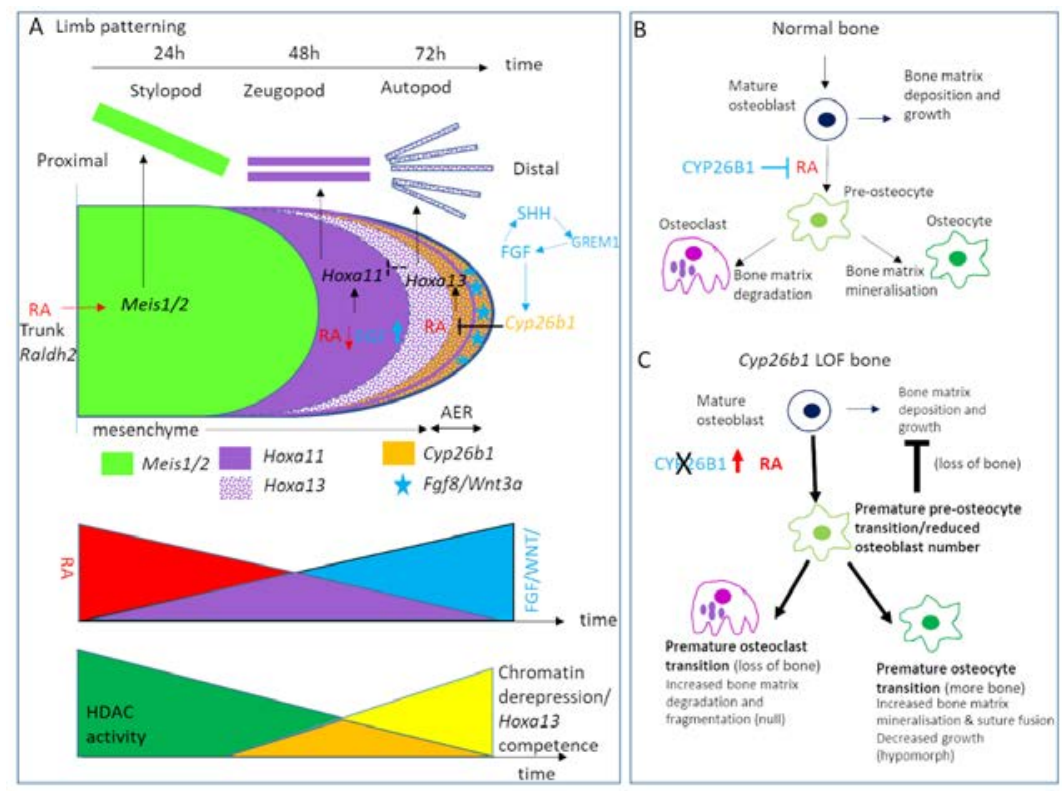

Figure 6. Roles for CYP26 enzymes in limb patterning and chondrogenic development. (A). Expression of Cyp26b1 in the apical ectodermal ridge and underlying mesenchyme induced by FGF8 signalling is required to degrade RA synthesised by RALDH2 in the trunk of the embryo near the outgrowing limb bud. This establishes an opposing proximodistal (PD) RA gradient to the FGF/WNT PD gradient. High RA is required to specify the most proximal limb element the stylopod by inducing Meis1/2 expression. Reduced RA levels at a point along the PD gradient inhibit Meis expression and in conjunction with FGF signals, promote expression of distal Hox gene Hoxa11, necessary to specify the zeugopod. Further reduction of RA levels distally by CYP26B1 degradation permits more distal Hoxa13 expression, once time-dependent HDAC activity is sufficiently reduced to allow chromatin derepression. This mediates competence for Hoxa13 expression in the limb mesenchyme and thus specification of the most distal limb element, the autopod. Adapted from Rosello-Diez et al. 2014 [204] (B). Role of Cyp26b1 in regulating RA signalling to prevent premature transition from mature osteoblasts producing bone matrix to bone mineralising osteocysts and bone degrading osteoclasts. (C). Loss of RA degradation by CYP26B1 leads to a range of phenotypes resulting from premature osteocyte and osteoclast differentiation including loss of bone due to decreased osteoblasts producing bone matrix and increased numbers of bone degrading osteoclasts plus increased osteocytic bone mineralisation. Adapted from Laue et al. 2011 [202].

In addition to the limb defects other skeletal anomalies were observed in Cyp26b1 mutant embryos, correlating with complex expression in cranial, pharyngeal and axial skeletal tissues including precartilage condensations, perichondrial cells and osteoblasts. Generally, expression in more mature ossifying cells was weaker than in less mature surrounding cells. Defective phenotypes included loss/underossification of both endochondral and inter-membranous bones including defects of the maxilla and mandible, calvarial bones, hyoid, thyroid and Meckel's cartilage, fusion of the exocciptial and basioccipital bones, coronal synostosis and loss of the clavicle. Many of these structures are neural crest derived and reported caudal neural crest defects could contribute to this phenotype. However, 
mesodermally derived bones are also abnormal, suggesting that chondrocyte defect contributes to these phenotypes [202,246]. Further investigation in mice revealed genetic loss or chemical inhibition of Cyp26b1 cells in limb mesenchymal cells resulted in reduced chondroblast differentiation, with cells instead being maintained in a pre-chondrogenic state accompanied by small increases in chondrocyte hypertrophy. There also appeared to be a small switch in fate towards a tendon lineage. Thus, Cyp26b1 restricts chondrogenesis by limiting RA which promotes chondrocyte maturation and hypertrophy. Furthermore, R115866 treatment resulted in axial hyperossification and fusion of cervical vertebrae implying a role for Cyp26b1 in spatial and temporal ossification patterning [202,242,337].

Three ENU cyp26b1 loss-of-function mutations have been identified in zebrafish (dolphin and stocksteif) encompassing one splice-donor and two nonsense mutations. Phenotypes can be copied by morpholino injection and were similar to mouse and human mutant phenotypes. These defects included fusion/loss of the neurocranium and posterior pharyngeal arches. Hyperossification, premature osteoblast to osteocyte differentiation and excess mineralisation produced these phenotypes which could be phenocopied with exogenous RA and rescued by inhibition of RA signalling. This work revealed a role for cyp $26 b 1$ in early neurocranial and pharyngeal patterning possibly via a mediolateral RA gradient and in inhibiting osteoblast maturation/activity and ossification [202,203,337].

The phenotypes from the various Cyp26b1 mutants/chemical treatments described above were complex, varying with level of Cyp26b1 depletion/RA augmentation and in some cases appearing to have opposing effects upon the same cells. For example, in zebrafish, coronal craniosynostosis resulting from ectopic suture mineralisation was observed, whereas in humans smaller, very fragile calvarial bones were seen. Further studies using RA/CYP26 inhibitor treatments in zebrafish revealed the same RA-induced premature osteoblast to preosteocyte transition at different time points in suture formation gave rise to both phenotypes. Premature osteoblast to osteocyte transition before suture formation caused reduced bone matrix production thus giving rise to smaller thinner calvaria. Preosteoctyes act to increase osteoclast activity via RANKL/Spp signalling and thus increase mineralisation/hyperossification. Regions of calvarial fragmentation displayed ectopic osteoclast activation and fragmentation could not be induced where there were no osteoclasts, suggesting bone resorption involvement. These phenotypes were associated with complete loss of Cyp26b1 function acting before suture formation begins. In hypomorphic models, the effect of the premature osteoblast to osteocyte transition was felt after suture formation initiation, where increased mineralisation and thus premature suture mineralisation leading to suture was the result of decreased osteoblast offsetting of bone mineralisation by $\mathrm{Ca}^{2+}$ sequestration and increased mineralisation by osteocytes. Thus CYP26B1/cyp26b1 mutants can therefore display phenotypes consistent with both net gain and net loss of bone [338] (Figure 6).

A role for RA/CYP26B1 in notochord epithelial chordoblast cells was shown to underlie axial hyper-mineralisation and vertebral fusion phenotypes with a similar mechanism to osteoblasts, including differentiation from bone-matrix producing cells to bone mineralising cells. Cyp26b1 metameric expression in a subset of chordoblasts along the axis is required to prevent RA signalling in intervertebral spaces, restricting the establishment of biomineralising cells. If this RA repression is abrogated by loss of cyp $26 b 1$ in this chordoblast subset, they ectopically acquire characteristics similar to preosteocytes, reducing matrix production and increasing mineralisation. This CYP26B1-mediated regulation of RA in chordoblasts seems required for the generation of a segmented vertebral column [339].

Finally, null mutations for Cyp26a1 in the mouse also revealed a skeletal phenotype of variable expressivity. Skeletal abnormalities were frequent in Cyp26a1 ${ }^{-/}$mice. Posterior vertebrae (lumbar, sacral and caudal) were frequently missing, thoracic vertebrae were often deformed with fused ribs and cervical vertebrae (C1-7) exhibited variable posterior homeotic transformations. A small number of embryos (20\%) exhibited sirenomelia due to hindlimb fusion, whilst some others exhibited malpositioning of the hindlimbs, but otherwise limb development was normal. To date, investigation into the underlying causes of these defects has been much less thorough than for Cyp26b1 mutation 
skeletal phenotypes. However, it has been suggested that shifts in anterior and posterior RA gradients could underlie the Cyp26a1 skeletal defects $[179,231]$.

\section{Pharyngeal and Cardiovascular Systems}

Normal development of the pharyngeal system and the neural crest are important for cardiovascular development (reviewed by [340-343]). Retinoic acid signalling is necessary for this development to take place [12-14]. All three Cyp26 genes are expressed in differing pharyngeal tissues during mouse development. At E9.5 and 10.5, there is strong expression of Cyp26a1 in cervical and pharyngeal arch mesenchyme, including neural crest derived mesenchyme and the maxillo-mandibular cleft, whereas Cyp26b1 is expressed in the pharyngeal surface ectoderm and pharyngeal pouch mesoderm and both genes are likely expressed in the developing SHF/OFT. Cyp26c1 is seen in maxillary and mandibular tissues of pa1 including surface ectoderm, superficial arch mesenchyme and maxillo-mandibular cleft. Strong expression is also observed in epibranchial placodes as well as a domain encompassing the cervical mesenchyme of the head lateral and caudal to the otic vesicle and the caudal pharyngeal endoderm.

All three genes are down/dysregulated in these tissues in Tbx1 mutants which display loss of caudal pharyngeal arches/arteries/pouches and SHF/OFT defects, leading to cardiac defects affecting the great vessels and OFT. These defects are phenocopied in R115866-treated chick embryos and include interrupted aortic arch B, common arterial trunk, double outlet right ventricle and ventricular septal defects [126].

Cyp26a1/c1 double null mutants have been reported to display neural crest defects. Premigratory neural crests were deemed to form normally in the neural plate but failed to undergo epithelial-mesenchymal transition correctly, particularly in more cranial regions, leading to reduced head mesenchyme, abnormal cranial ganglia and reduced size of pharyngeal arches [226].

Cyp26b1 mutants have abnormal skeletogenesis, affecting head and neck as discussed above. These mutants have also been described with normal hindbrain patterning but disorganised neural crest streams affecting pharyngeal arches 3-6 and mild cranial nerve defects, although in mice Cyp26b1 is not highly expressed in migrating neural crest, suggesting a possible non-cell autonomous effect from increased RA resulting from loss of Cyp26b1 in neighbouring tissues such as the pharyngeal endoderm/ectoderm [246]. Knockdown of cyp26b1 in the zebrafish also affects cranial nerves, particularly the vagus, in addition to jaw and gill neural-crest derived cartilages [248]. Expression of zebrafish cyp26b1 is also required in non-tendon neural crest cells separating two scxr-positive tenoblast populations to allow tenoblast to tendon condensation and thus normal musculoskeletal patterning of pharyngeal arch 1 and 2 tendon and muscle attachments. In the absence of cyp $26 b 1$ movement of tenoblasts into mature tendons is disrupted leading to ectopic muscle projection, which finally associate with areas of ectopic tendon marker expression. Thus, a non-cell autonomous role for cyp $26 b 1$ in neural crest regulates pharyngeal tendon development [344]. Cyp26b1 is also important in tongue muscle and palate formation in the mouse. In Cyp26b1 $1^{-/}$embryos, palatal shelves fail to elevate and have reduced expression of genes associated with proliferation ( $F g f 10, T b x 1, B m p 2)$ and reduced proliferation in the region of the palatal bend. Tongue muscles were a/hypoplastic likely affecting tongue withdrawal necessary for palatal closure. Ectopic RA signalling was observed in neural-crest derived mesenchyme surrounding affected tongue muscles, which form part of the pharyngeal arch 1 and 2 derived musculature [247]. SHH signalling is also implicated in palatal development, with Cyp26a1 and Cyp26b1 expression decreased and a concomitant increase in RA signals in Shh LOF mutants displaying cleft palate phenotypes [298]. The same mechanism in the tongue epithelium of Shh LOF mutants led to change in cell fate specification causing the formation of ectopic salivary glands and increased size taste-buds. Thus, Shh-mediated activation of Cyp26a1/c1 acts to control RA availability in these tissues [345].

Regulation of RA in the pharyngeal endoderm is necessary for thymus development $[68,107]$. Cyp26b1 mutants present with ectoptic and small/missing thymus at mid-gestation, a phenotype 
also seen in Tbx1 mutant mice [118,246,346] (C. Roberts unpublished data). Furthermore, Cyp26b1 RA-regulation seems to be required for regulation of RA-driven signalling in activated T-cells in gut-related lymphoid tissues [195].

As described above, loss-of-function phenotypes for the CYP26 enzymes individually and together can result in phenotypes affecting pharyngeal development, the neural crest and the cardiovascular system. The initial papers describing deletion phenotypes do not describe the defects affecting these developmental systems in great detail. For Cyp26a1 in the mouse this comprises only the information that some embryos were developmentally arrested between E8.5 and 9.5 and showed cardiac looping and dilation defects $[179,231]$.

However, further studies in the zebrafish have revealed important roles in cardiac lineage commitments within the early anterior lateral plate mesoderm (APLM) and requirements for ventricular cardiomyocyte contributions from both first and second heart field sources [251,347].

Knock-down of cyp $26 a 1$ or cyp $26 c 1$ individually does not reveal a significant cardiac defect but depletion of both produces a number of anomalies affecting cardiac development and upregulated expression of RARE-reporters indicating increased RA levels. Both genes are expressed in the APLM at 8 somites with a significant overlap of expression with vascular progenitor (VP) marker etv2, but a minimal overlap of the posterior expression boundary with the anterior limit of $n k x 2.5$ marking cardiac progenitor (CP) cells. In double-deficient cyp26a1/c1 $1^{-/-}$embryos at 36hpf atrial cardiomyocyte number was increased in manner reminiscent to that seen with moderate RA treatment [251,348-350]. At 8 somites, ventricular and markers of atrial and ventricular progenitor markers ( $n k x 2.5 / h a n d 2)$ (no atrial specific markers are yet identified for this stage) were shifted anteriorly in a fashion suggesting a possible expansion of atrial CPs.

RA-responsive $d h r s 3 a$ is expressed posterior to CP markers in the APLM [44] and in cyp26a1/c1 LOF embryos is expanded with a forward shift of the anterior boundary whilst the overall size of the APLM was unchanged. These changes in the patterning of the APLM could be restored by moderate inhibition of RA signalling. Lineage tracing revealed that in wild types anterior APLM gave rise to endothelial/endocardial cells whereas more posterior APLM produced myocardial cells. In cyp26a1/c1-deficient embryos labelled cells fated to become endothelial cells were significantly less frequent and endothelial/endocardial progenitors were not found posteriorly. In contrast, the origins of chamber myocardial progenitors expanded to include much more anterior APLM and the frequency of labelled atrial progenitors increased whereas that of ventricular progenitors was similar to controls. Cranial endothelial and endocardial cell contribution was greatly reduced and displayed abnormal morphology. Together, these data suggested expansion of atrial specification at the expense of the vascular lineage. Finally, transplantation experiments revealed that cyp26a1/c1 regulation of RA-mediated APLM patterning is non-cell autonomous [251].

Analysis of these cyp26a1/c1-deficient embryos and CYP26-inhibitor (ketacozanole) treated embryos at later stages (48-2hpf) identified reduced numbers of ventricular cardiomyocytes and markers of cardiac differentiation, despite previous data suggesting that specification of ventricular cardiomyocytes was relatively unchanged. These ventricular defects were independent of the increased atrial specification anomalies described above and could be produced with lower MO concentrations than required for the early APLM patterning defects, therefore suggesting that this abnormality arose after formation of the linear first heart field-derived heart tube. Instead, photo-conversion studies showed the addition of second heart field (SHF) cells to the arterial pole where they contribute to the ventricle and outflow tract was disrupted. SHF patterning was normal in double-deficient embryos but undifferentiated SHF-progenitors accumulated abnormally outside the heart tube. This aberrant migration then led to failure to contribute to OFT and ventricle, with SHF cells instead participating in pharyngeal arch artery $3 / 4$ endothelium formation. Furthermore, reduced proliferation and expression of FGF8 was observed in cyp26a1/c1 knockdown embryos. This SHF-driven part of the ventricular loss could be partially rescued by restoring expression of FGF8 which is required for SHF progenitor proliferation [347]. 
However, this SHF-defect alone was not sufficient to account for the total loss of ventricular cells that were observed, nor were changes in apoptosis seen. Instead, ectopic cardiomyocytes, likely arising from the FHF, were seen outside the heart. Time-lapse imaging showed that these cells were extruded from the differentiated heart tube in around half of the cyp26a1/c1-deficient embryos. These ectopic clusters then underwent apoptosis, thus contributing to the overall loss of ventricular cardiomyocytes. This phenomenon may be regulated by aberrant polarity and adhesion with cyp26a1/c1-LOF ventricular cells appearing rounder with mis-expressed ZO1 and B-CATENIN. This extrusion defect was not repaired by restoring FGF8 expression. Interestingly, MMP9 was found to be increased in cyp26a1/c1-deficient hearts. Treatment of wild-type embryos induced a small number to display ventricular phenotypes similar to loss of cyp26a1/c1. Moreover, when cyp26a1/c1-deficient embryos were treated with an MMP inhibitor, both SHF and cardiomyocyte extrusion phenotypes were found to be reduced without any amelioration of loss of FGF8 expression, suggesting that these molecules act in parallel in this context [347].

Recent studies have shown RA can specify atrial cardiomyocyte fate in human PSCs [351,352]. Embryoid bodies generated from hPSC cells treated with RA can generate both atrial and ventricular cardiomyocyte fates from different mesodermal precursors. Ventricular cells seemed to arise from CD235-positive mesodermal precursors which express high levels of CYP26A1 on day 3 of differentiation, with low levels of $R A L D H 2$ expression. Atrial cardiomyocytes arose from mesoderm expressing high levels of $R A L D H 2$ but no CYP26A1 from day 2-3 of differentiation. These cells responded to retinol via autocrine signals to produce atrial cardiomyocytes, apparently at the expense of ventricular fate. In summary, inhibition of RA signalling by CYP26A1 is required for CD235+ mesodermal precursors to give rise to ventricular fates whereas atrial induction is mediated via autocrine RA signalling in $R A L D H 2+$ mesoderm. Thus, the balance between atrial versus ventricular fate induction is, in part, mediated by balance between RA synthesis $(R A L D H 2+)$ and degradation expression (CYP26A1+) in two mesodermal precursor populations in a similar fashion to that exhibited in embryos [251,353], reviewed [354].

Cardiac development was reported as normal in Cyp26b1 mutants by Maclean et al. 2009 [246]. However, this report may be the result of mouse strain genetic background/deletion allele used, as unpublished data using the Cyp26b1 deletion allele published by Yashiro et al. 2004 [245], show a variety of cardiac defects, affecting the arterial pole, atrioventricular septation and epicardial/coronary vessel development (C. Roberts unpublished data, K. Yashiro pers.comm).

\section{Other Systems}

Foregut endoderm caudal to the pharyngeal endoderm is patterned by RA generated in the adjacent dorsal mesoderm to give rise to normal pancreas development. In zebrafish, expression of cyp $26 a 1$ is necessary to define the normal anterior limit of the pancreatic field by a feedback loop regulating expression of RA within the endoderm. The posterior limit is set by $C d x 4$ expression. Loss of cyp26a1 leads to anterior expansion of the pancreatic anlagen at the expense of more anterior (pharyngeal) endoderm derivatives [181,355]. In the developing zebrafish kidney, a similar mechanism specifies the dorsoventral axis. RA on the dorsal side of the embryo specifies anterior kidney fates, whereas expression of cyp26a1 ventrally is necessary to inhibit RA signalling allowing the induction of ventral kidney progenitors [356]. Moreover, the $c d x 1 a$ and $c d x 4$ regulate the posterior boundaries of expression of raldh 2 and cyp $26 a 1$ in the anterior paraxial mesoderm to correctly position the zebrafish pronephros along the anterior-posterior axis [357].

Patterning within the splanchnic mesoderm by Pbx1-Tlx1 (Hox11) gives rise to the splenic progenitor cells [358]. Tlx1 regulates proliferation of the splenic mesenchyme. It has both repressor and activator functions and in Tlx 1 mutants RA signalling pathway genes such as Raldh1, RA nuclear receptors and Vitamin A/RA transporters are up-regulated, whilst RA-degrading Cyp26b1 was down-regulated. In Cyp26b1 mutants, the splenic primordium mesenchyme is greatly reduced in size, suggesting that regulation of RA availability by Cyp 2661 is essential for spleen precursor cell proliferation and 
maintenance, particularly as in Tlx1 mutants, excess RA led to premature differentiation of this population [359].

Oedema and haemorrhage characterise the external phenotype of the Cyp26b1 mutant mouse. Whilst cardiac defects may contribute to these phenotypes, a severe lymphatic defect is also clearly causative. Expansion of lymphatic endothelial cell (LEC) progenitors arising from cardinal veins is seen in E11.5 mutants likely as a result of the loss of Cyp26b1 in Prox1-positive LECs on the dorsal side of the cardinal vein. For both deep and superficial lymphatics (dermal and jugular), increased size of lymph sacs and lymphatic vasculature was seen with reduced branching. Subcutaneous oedema presented at later stages along with accumulation of blood in lymphatic vessels. This was ascribed to the expanded size and increased expression of FOXC2 within the lymphovenous valves which normally separate vascular and lymphatic networks. Gain-of-function Cyp26b1 embryos exhibited reverse phenotypes with hypoplastic development of the LEC progenitor pool and lymph sacs [360]. Thus, Cyp26b1 regulation of RA availability controls the number of LEC progenitors during development.

Cyp26b1 regulation of RA levels is also required for normal skin and hair development. Expression begins in the mesenchyme around hair follicles at E14.5 and is strongly expressed in the dermis but not the epidermis by the end of development. Loss of this expression leads to reduction of the cornified envelope layers (terminally differentiated keratinocytes) and arrest of hair follicle development at the germ stage and led to increased proliferation in the basal layer. Keratin19 is abnormally upregulated from zero in the epidermis in Cyp26b1 mutant embryos and RAR $\beta$ in dermis and epidermis. Genes associated with development of the cornified layers and known to be upregulated in cases of skin barrier disruption were upregulated and increased skin barrier permeability was demonstrated. Keratins associated with hair follicle development were down-regulated. Importantly, filaggrin expression was completely lost. However, conditional deletion of Cyp26b1 in the dermal layer alone, did not recapitulate the epidermal phenotype. Markers of the peridermis, which is normally removed via desquamation were strongly upregulated and shown to be both inducible by RA and to be linked to filaggrin downregulation, suggesting that the failure to form a proper epidermal barrier was linked to abnormal peridermal development. Effects on hair follicle development included decreased hair follicle density and markers of follicle differentiation were down-regulated and differential expression of factors linked to hair follicle development including the Wnt pathway, and Runx, Sox and Fox families was observed [361].

Retinoic acid is also essential for the process of haematopoiesis, where haematopietic stem cells (HSCs) are specified in the aorta-gonad-mesonephros, leading to the birth of HSCs from hemogenic/aortic endothelium, with WNT signalling blocking the inductive effects of RA [362]. So far, no evidence has been provided as to a developmental role for CYP26s in this process. However, in vitro, away from the stem cell niche, bone marrow-derived Raldh1-positive primitive haematopoietic cells have been shown to terminally differentiate rapidly, being unable to maintain their self-renewal. Inhibition of RA signalling restored the initial phenotype and enable self-renewal. It was shown that bone marrow stromal cell expression of Cyp26a1/Cyp26b1 mediated this RA inhibition driven phenotype. Therefore, prevention of intrinsic RA-driven HSC differentiation requires degradation by bone marrow CYP26 enzymes [363].

Extensive experiments suggest that RA from the developing mesonephros region is required to induce meiosis in adjacent embryonic germ cells. However, significant differences in the timing of meiosis onset are apparent between male and female gonads. In female mice, meiosis is initiated at E13.5 (mid-late gestation), whereas males do not enter meiosis until post-natal stages. Pan-RAR antagonists prevent expression of RA-dependent Stra6 expression in cultured ovaries, whereas exogenous RA could induce expression in cultured embryonic testes which normally remain Stra6-negative. Thus in ovaries RA can induce Stra6 expression but testes are protected from this RA-activity. Cyp26b1 is expressed in the developing male gonad but not in embryonic ovaries and was discovered to be the RA-protective agent in the developing testis. When CYP26 expression is inhibited by chemical blocked (ketacozanole and R115866), cultured testes express Stra6 within germ cells. This up-regulation is 
prevented by inclusion of RAR-antagonists, confirming that Stra6 expression is RAR-signal dependent. Cyp26b1 null mice displayed premature entry into meiosis, similar to that observed in normal female gonads [364-366].

Normal male germ cells do not begin meiosis, instead becoming quiescent until puberty by supressing mitotic proliferation. RA is known to act as a driver of both mitosis and meiosis, thus testicular germ cells need to be protected against both these functions of RA until the appropriate developmental time-point. Cyp26b1 is present in the somatic cells of the testis degrading paracrine RA signals from near-by tissues such as the mesonephros. Studies in double knock-out Cyp26b1/Stra6 mice revealed that this RA-metabolising function of testicular Cyp26b1 acts to prevent the initiation of Stra6-dependent meiosis by RA and also prevents the Stra6-independent activation of mitosis. This suppression of mitosis appears to require cyclin-dependent kinase inhibitors to arrest germ cells in the G0/G1 phase. Therefore, Cyp26b1 is required to regulate both RA-driven testicular meiosis and mitosis in male germ cells [366-368].

\section{Regeneration}

In addition to the roles regulating developmental progenitors, iPSC and HSC cells, Cyp26a1 and Cyp26b1 have been shown to play multiple roles during regeneration of the adult fin in zebrafish and lens in Xenopus. In the former, the cyp 26 genes are required to regulate both non and cell-autonomous signalling. Following fin amputation, regeneration requires the formation of a blastema composed of cycling progenitor cells at the injury site. The formation, proliferation and maintenance of the blastemal requires a huge increase in RA signalling from fibroblast cells which is induced by amputation. To replace the lost bone elements of the amputated fin mature non-proliferative osteoblasts transition by dedifferentiation to a preosteoblast profiferating state to form a progenitor pool within the blastema. Following several cycles of division, these preosteoblasts redifferentiate to produce new bone. However, this de and re-differentiation is inhibited by RA, thus the high RA levels necessary for the blastemal conflict with osteoblast regenerative mechanisms [369,370].

Analysis of cyp26b1 and raldh 2 expression in experimental situations where RA levels in both the uninjured and amputated fin were experimentally manipulated revealed that cyp $26 b 1$ is initially upregulated in stump osteoblasts during limb regeneration. This then allows osteoblast dedifferentiation. Cyp26b1 levels are then down-regulated to promote RA-driven proliferation of the newly formed preostoblasts. After several rounds of proliferation, the preosteoblasts redifferentiate in a proximal-to-distal direction to give rise to non-proliferative osteoblasts producing new bone. Within the blastemal fibroblasts, cyp $26 b 1$ and raldh 2 exhibit opposite gradients of expression: Raldh 2 is high distally and rapidly decreases proximally while Cyp26b1 is absent in distal fibroblasts but expressed widely proximally. Proximal cyp26b1-positive cells may therefore act as an RA sink to generate RA gradients. High RA distally promotes preosteoblast proliferation and inhibits redifferentiation in this region. Varying the proximodistal position of amputation changes the RA gradient produced and gave rise to distal limits of preosteoblast redifferentiation consistent with the idea that below a certain RA threshold proximally preosteoblasts cease proliferating and redifferentiatiate to mature bone-producing osteoblasts [371].

Expression of cyp $26 b 1$ in both stump osteoblasts and fibroblasts is key in protecting the osteoblasts from high RA levels generated by blastemal fibroblasts to allow bone regeneration. It has been shown that WNT/B-CATENIN signalling promotes proliferation towards the distal tip of the regenerating fin, whereas BMP expression in differentiating osteoblasts stimulates differentiation, partly by inhibiting WNT signalling. Markers for BMP and WNT-inhibitors are down-regulated shortly after exposure to RA treatment. This implies that RA may have a negative impact on BMP signalling and promote WNT signalling, thus inhibiting preosteoblast redifferentiation [371].

A similar precise regulation of RA levels along the regenerating fin may also be required for osteoclast function. Osteoclasts are required for bone resorption in normal fin development and are not present in the uninjured adult fin. However, they are present in the regenerating fin. RA has been 
shown to inhibit osteoclast differentiation and excess bone matrix has been observed in regenerates exposed to excess RA promoting the idea that excess RA inhibits osteoclast differentiation and thus bone resorption [371].

In summary, cyp26b1-mediated degradation of RA acts to regulate both non- and cell-autonomous RA signalling during fin regeneration. Opposing raldh2 and cyp26b1 expression within fibroblasts establishes an RA environmental gradient with high RA distally and low RA proximally. Transient cell-autonomous degradation in osteoblasts by cyp26b1 allows dedifferentiation to occur. Inactivation of RA controls the preosteoblast proliferation rate and the PD axis position where preosteoblasts redifferentiate into mature osteoblasts. In conclusion, regulation of RA signalling by cyp $26 b 1$ controls bone matrix synthesis by osteoblasts and resorption by osteoclasts and thus drives the regeneration of the amputated fin [371] (Figure 7).

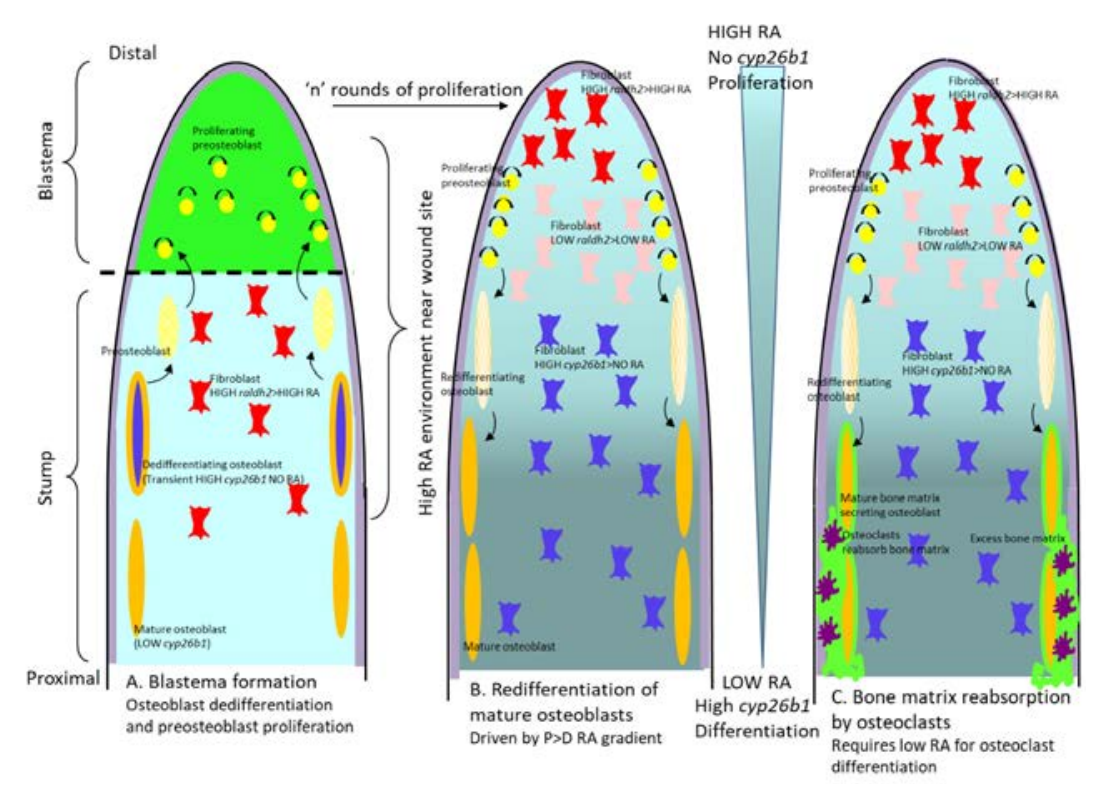

Figure 7. Cell autonomous and cell-non autonomous regulation of RA availability by CYP26 enzymes during zebrafish fin regeneration. (A). Blastema formation. A high RA environment produced by RALDH2 RA synthesis in stump fibroblasts near the amputation site is necessary to promote proliferation of preosteoblast cells forming the blastemal in response to the injury. However, dedifferentiation of mature osteoblasts is necessary to give rise to initial preosteoblasts and this requires a low RA environment. These two opposing requirements are met by a transient high level of Cyp26b1 expression in mature osteoblasts (cell autonomous function). This produces a low level of RA in osteoblasts allowing dedifferentiation to preosteoblasts, whilst maintaining the high RA environment necessary for preosteoblasts to proliferate. (B). After several rounds of preosteoblast proliferation, these cells need to initiate redifferentiation towards mature bone matrix producing osteoblasts if the amputated fin is to regenerate. This respecification requires the establishment of a proximal to distal RA gradient. This is generated by altering the expression of the enzymes controlling RA availability in the fibroblasts of the regenerating stump. Distally, fibroblasts maintain Raldh2 expression and thus synthesis of RA, allowing continued preosteoblast proliferation by maintaining a high RA environment. More proximally, fibroblasts express only low levels of Raldh2 leading to lower paracrine RA levels, thus allowing the redifferentiation of preosteoblasts towards mature osteoblasts to begin. Most proximally, fibroblasts express high levels of Cyp26b1 thus degrading RA, promoting an RA-free environment suitable for the maintenance of mature bone-matrix producing osteoblasts in the regenerating stump. (C). This low/negative RA environment is also required for the differentiation of osteoclasts from osteoblasts. Osteoclasts degrade excess bone matrix deposition, and seem required in the amputated fin to help mediate correct bone regeneration. Adapted from Blum and Begemann et al. 2015 [371]. 
In addition to controlling regenerative outgrowth of bone CYP26-mediated protection from RA signalling is also necessary to establish ray-interray organisation in the regenerating fin. In this scenario, cyp26a1 degradation of RA in the proximal basal epidermal layer is crucial for spatial restriction of osteoblasts. Cyp26a1 and shha are expressed within the basal epidermal layer next to pre and differentiating osteoblasts. With both exposure to exogenous RA and experimentally reduced CYP26 function shha and its receptor $p t c h 2$, are down-regulated, indicating that expression of these genes requires a low RA niche. In these regenerates, preosteoblasts migrate into the interray regions that they are normally excluded from, indicating a failure to align at the proximolateral blastema and disruption of ray-interray boundaries. Similar preosteoblast ectopic location in the interray leading to ray fusion can be produced by inducing cyp26a1 domains in abnormal proximity to each other, thus altering the patterning of RA-responsive/non-responsive regions within the fin.

Other blastemal cell types also spread ectopically into the interray regions and blood vessels also ignore the usual restrictions of regenerative patterning to form connections across interrays with adjacent rays. This leads to extensive disruption of ray-interray patterning including ectopic bone formation and a permanent repression of fin regeneration. Experiments altering exposure of pre/osteoblasts to shha signalling suggest that shha signals from cyp26a1-positive cells within the basal epidermis promote adjacent osteoblasts to proliferate. Furthermore FGF-dependent exclusion of sha from distal regions was found to be dependent upon inhibition of cyp26a1 expression. Therefore, cyp26a1 expression within specific domains of the basal epidermis creates regions protected from RA signalling thus allowing signalling required for the proper alignment of preosteoblasts in the developing blastema, which is important for correctly establishing ray-interray boundaries within the blastemal. Furthermore, cyp26a1-mediated RA degradation within the basal epidermis is necessary to allow shha-driven proliferation in neighbouring preosteoblasts during regeneration [372,373].

A role for CYP26 enzymes in the regeneration of the lens in Xenopus larvae and hair cells has also been documented. Following the loss of a lens, the epithelial cornea can become competent to regenerate the lens with FGF signalling from the neural retina playing a key role. In control and regenerating, corneal epithelium members of the Raldh and Cyp26 gene families are expressed. Interestingly, inhibition of CYP26 enzyme function, exogenous RA treatment and a synthetic retinoid not processed by CYP26 enzymes all repress lens regeneration, with CYP26 antagonism leading to reduced corneal proliferation and failure to form a lens. In addition, expression of cyp 26 genes may be important to maintain expression of key lens genes such as pax 6 and $f g f r 2$. The requirement for cyp 26 expression in lens regeneration is from 12 to $48 \mathrm{~h}$ post ablation, suggesting a possible role in establishing corneal competency to respond to lens inducing signals [374,375].

In zebrafish, inner ear raldh 3 is expressed in the anterior of the posterior macula sensory patches with cyp26b1 expressed in a complementary fashion, posteriorly. In the lateral crista, a similar complementary expression is seen, this time across a mediolateral axis. These complementary expression domains likely generate RA gradients across these tissues, with rar $\alpha$ expression seen equally across the region. Following laser ablation of hair cells the regenerative response in supporting cells includes upregulation of all genes in tissues already exhibiting expression and expansion of raldh3 expression into previously negative areas. In the regenerating lateral line upregulation of raldh3, rar $\beta$ and cyp $26 a 1$ followed by cyp $26 c 1$, is rapidly and transiently induced. Cyp26a1 expression restricted to two cells adjacent to the neuromasts and cyp $26 c 1$ is mostly seen in the dorsoventral poles of the neuromast. Suppression of $p 27^{k i p}$ and sox 2 expression is necessary following ablation to allow support cells to re-enter the cell cycle followed by subsequent differentiation to generate new hair and supporting cells. RA was shown to mediate this down-regulation and cyp 26 expression is limited to specific cells. However, the precise role of cyp 26 expression within specific cell populations during hair cell regeneration remains to be elucidated [376]. 


\section{Paradoxical Feedback Loops in RA Signalling}

Recent work in mouse and zebrafish has suggested the existence of feedback loops regulating retinoic acid signalling which can lead to apparently paradoxical phenotypes, whereby excess RA/RA signalling will produce both gain and loss of function phenotypes and vice versa.

Using the mouse kidney as a model, Lee et al. 2012 [377] showed that a teratogenic dose of RA at E9.0 led to a transient increase and ectopic location of the expression of RA-degrading CYP26A1 and CYP26B1 levels, concurrently with a longer-lasting reduction in the RA synthesising RALDH1-3 enzymes. HPLC quantification showed an initial rapid up-regulation of RA shortly after the RA insult followed by a longer-term overall reduction in RA levels. Supplementation with low doses of RA in the time period showing reduced RA following the initial high dose insult allowed rescue of the renal agenesis phenotype mediated by RA-driven reduction of $W t 1$. Development of other organs including the eye, ear, jaw, heart, and hindlimb were also improved by this subsequent low-dose RA rescue regimen although tail agenesis, palate defects and imperforate anus were not rescued. These results led to the conclusion that an excess RA insult leads to a feedback mechanism to reduce RA levels which eventually produces an RA deficiency. Thus, the defects observed are the result of early excess RA signalling in affected tissues compounded by prolonged RA deficiency induced by the mechanism to remove excess RA.

Interestingly, similar feedback mechanisms were observed in RAR-depleted and hyperactive RAR models in the zebrafish. Depletion of a novel conserved RAR-splice variant rarab1, thereby reducing RA signalling, led to increased heart size via increased specification of cardiomyocytes. This defect was driven via a positive feedback mechanism induced by loss of rarab1, which eventually gave rise to increased RA signalling via other RARs and up-regulation of RA-responsive genes including $h o x 5 b$, very similar to those observed with exogenous RA treatment. This increase in embryonic RA was confirmed by increased expression in an RA sensor transgenic line and was driven by increased expression of $r d h 10 a$ and $r d h 10 b$. Cyp26a1 as an RA-responsive gene was also upregulated to protect the rarab1-depeleted embryos from teratogenic RA-signalling. Therefore continuing reduction of rarab1 causes an over-active positive response from RA levels and RA signalling producing RA-driven teratogenic phenotypes [350,378].

The reverse experiment with gain-of-function of RA signalling was produced using a hyperactive RAR transgenic zebrafish line. Again, both gain and loss of function phenotypes were observed affecting anterior tissues such as the midbrain and more posterior organs including the heart. Similarly to the mouse exogenous RA experiment described above, gain-of-function phenotypes were due to the initial increase in RA signalling, with the loss-of-function defects arising from the subsequent fast induction of increased cyp26a1 in response to the increased RA signalling which led to an overall reduction in embryonic RA as shown by an RA-responsive transgenic reporter line. Transplantation experiments of the RA sensor line showed that that cyp26a1 can act as an RA sink with non-cell autonomous effects upon local RA levels and thus patterning gradients [378,379].

\section{Conclusions}

Retinoic acid signalling controls a variety of important processes during development and regeneration, including transcriptional patterning events, proliferation and differentiation necessary for the normal development of many organ systems. RA functions as a morphogen, with both non-cell and cell-autonomous roles, with complex regulatory feedback mechanisms. A growing understanding that regulating RA availability is key to regulating RA signalling has led to an increasing body of work in the last decade concerning the enzymes that synthesise and degrade RA. It is becoming increasingly apparent that RA synthesis and degradation are frequently coupled in opposing directions to pattern the developing embryo. This has produced a rising appreciation of the role of the CYP26 RA-degrading enzymes. As previously suggested, CYP26 enzymes do act as RA sinks and protect the developing embryo against excessive exposure to RA. However, their function extends well beyond this simple model. In multiple systems, complex dynamic expression of Raldh and Cyp26 genes allows subtle 
and often apparently contrary RA-signalling in both a cell and non-cell autonomous fashion across different cell types within the same and adjacent tissues. This provides mechanisms for a variety of processes including protection of specific cell types against a background of high environmental RA, creating RA gradients necessary to establish transcriptional pattern across developing organs, regulating equilibrium in bipotential progenitor cell fate and establishing and maintaining sharp developmental boundaries. Much remains to be understood as to the function of these enzymes in regulating RA availability in both development and regeneration, and also in terms of human health, with regard to congenital disease, understanding possible roles in cancer causation and cure and in possible future regenerative therapies.

Acknowledgments: This work was supported by British Heart Foundation grant PG/17/8/32840.

Conflicts of Interest: The author declares no conflict of interest

\section{References}

1. Mey, J.; McCaffery, P. Retinoic Acid Signaling in the Nervous System of Adult Vertebrates. Neuroscientist 2004, 10, 409-421. [CrossRef] [PubMed]

2. McCaffery, P.; Zhang, J.; Crandall, J.E. Retinoic acid signaling and function in the adult hippocampus. J. Neurobiol. 2006, 66, 780-791. [CrossRef]

3. Ransom, J.; Morgan, P.J.; McCaffery, P.J.; Stoney, P.N. The rhythm of retinoids in the brain. J. Neurochem. 2014, 129, 366-376. [CrossRef]

4. Kiser, P.D.; Palczewski, K. Retinoids and Retinal Diseases. Annu. Rev. Vis. Sci. 2016, 2, 197-234. [CrossRef] [PubMed]

5. Oliveira, L.d.M.; Teixeira, E.F.M.; Sato, M.N. Impact of Retinoic Acid on Immune Cells and Inflammatory Diseases. Mediat. Infllam. 2018, 2018, 17. [CrossRef] [PubMed]

6. Bonet, M.L.; Ribot, J.; Palou, A. Lipid metabolism in mammalian tissues and its control by retinoic acid. Biochim. Biophys. Acta 2012, 1821, 177-189. [CrossRef] [PubMed]

7. Williams, J.A.; Kondo, N.; Okabe, T.; Takeshita, N.; Pilchak, D.M.; Koyama, E.; Ochiai, T.; Jensen, D.; Chu, M.-L.; Kane, M.A.; et al. Retinoic acid receptors are required for skeletal growth, matrix homeostasis and growth plate function in postnatal mouse. Dev. Biol. 2009, 328, 315-327. [CrossRef]

8. Conaway, H.H.; Henning, P.; Lerner, U.H. Vitamin A Metabolism, Action, and Role in Skeletal Homeostasis. Endocr. Rev. 2013, 34, 766-797. [CrossRef]

9. Lammer, E.J.; Chen, D.T.; Hoar, R.M.; Agnish, N.D.; Benke, P.J.; Braun, J.T.; Curry, C.J.; Fernhoff, P.M.; Grix, A.W.; Lott, I.T., Jr.; et al. Retinoic acid embryopathy. N. Engl. J. Med. 1985, 313, 837-841. [CrossRef]

10. Niederreither, K.; Dolle, P. Retinoic acid in development: Towards an integrated view. Nat. Rev. Genet. 2008, 9, 541-553. [CrossRef]

11. Rhinn, M.; Dollé, P. Retinoic acid signalling during development. Development 2012, 139, 843-858. [CrossRef] [PubMed]

12. Stefanovic, S.; Zaffran, S. Mechanisms of retinoic acid signaling during cardiogenesis. Mech. Dev. 2017, 143, 9-19. [CrossRef]

13. Zaffran, S.; Niederreither, K. Retinoic Acid Signaling and Heart Development. The Retinoids: Biology, Biochemistry, and Disease; John Wiley \& Sons, Inc.: Hoboken, NJ, USA, 2015.

14. Zaffran, S.; Robrini, E.N.; Bertrand, N. Retinoids and Cardiac Development. J. Dev. Biol. 2014, 2, 50-71. [CrossRef]

15. Kam, R.K.T.; Deng, Y.; Chen, Y.; Zhao, H. Retinoic acid synthesis and functions in early embryonic development. Cell Biosci. 2012, 2, 11. [CrossRef]

16. Shannon, S.R.; Moise, A.R.; Trainor, P.A. New insights and changing paradigms in the regulation of vitamin A metabolism in development. Wiley Interdiscip. Rev. Dev. Biol. 2017, 6, e264. [CrossRef] [PubMed]

17. Simões-costa, M.S.; Azambuja, A.P.; Xavier-Neto, J. The search for non-chordate retinoic acid signaling: Lessons from chordates. J. Exp. Zool. Part Mol. Dev. Evol. 2008, 310, 54-72. [CrossRef] [PubMed] 
18. Pasutto, F.; Sticht, H.; Hammersen, G.; Gillessen-Kaesbach, G.; FitzPatrick, D.R.; Nürnberg, G.; Brasch, F.; Schirmer-Zimmermann, H.; Tolmie, J.L.; Chitayat, D.; et al. Mutations in STRA6 Cause a Broad Spectrum of Malformations Including Anophthalmia, Congenital Heart Defects, Diaphragmatic Hernia, Alveolar Capillary Dysplasia, Lung Hypoplasia, and Mental Retardation. Am. J. Hum. Genet. 2007, 80, 550-560. [CrossRef]

19. Deltour, L.; Foglio, M.H.; Duester, G. Metabolic Deficiencies in Alcohol Dehydrogenase Adh1,Adh3, and Adh4 Null Mutant Mice: Overlapping roles of adh1 and adh4 in ethanol clearance and metabolism of retinol to retinoic acid. J. Biol. Chem. 1999, 274, 16796-16801. [CrossRef]

20. Molotkov, A.; Fan, X.; Duester, G. Excessive vitamin A toxicity in mice genetically deficient in either alcohol dehydrogenase Adh1 or Adh3. Eur. J. Biochem. 2002, 269, 2607-2612. [CrossRef]

21. Molotkov, A.; Fan, X.; Deltour, L.; Foglio, M.H.; Martras, S.; Farrés, J.; Parés, X.; Duester, G. Stimulation of retinoic acid production and growth by ubiquitously expressed alcohol dehydrogenase Adh3. Proc. Natl. Acad. Sci. USA 2002, 99, 5337-5342. [CrossRef]

22. Molotkov, A.; Deltour, L.; Foglio, M.H.; Cuenca, A.E.; Duester, G. Distinct Retinoid Metabolic Functions for Alcohol Dehydrogenase Genes Adh1 and Adh4 in Protection against Vitamin A Toxicity or Deficiency Revealed in Double Null Mutant Mice. J. Biol. Chem. 2002, 277, 13804-13811. [CrossRef] [PubMed]

23. Deltour, L.; Foglio, M.H.; Duester, G. Impaired retinol utilization in Adh4 alcohol dehydrogenase mutant mice. Dev. Genet. 1999, 25, 1-10. [CrossRef]

24. Kumar, S.; Sandell, L.L.; Trainor, P.A.; Koentgen, F.; Duester, G. Alcohol and aldehyde dehydrogenases: Retinoid metabolic effects in mouse knockout models. Biochim. Biophys. Acta 2012, 1821, 198-205. [CrossRef] [PubMed]

25. Chambers, D.; Wilson, L.; Maden, M.; Lumsden, A. RALDH-independent generation of retinoic acid during vertebrate embryogenesis by CYP1B1. Development 2007, 134, 1369-1383. [CrossRef]

26. Dragin, N.; Shi, Z.; Madan, R.; Karp, C.L.; Sartor, M.A.; Chen, C.; Gonzalez, F.J.; Nebert, D.W. Phenotype of the Cyp1a1/1a2/1b1(-/-) Triple-Knockout Mouse. Mol. Pharmacol. 2008, 73, 1844-1856. [CrossRef]

27. Hollander, D.A.; Sarfarazi, M.; Stoilov, I.; Wood, I.S.; Fredrick, D.R.; Alvarado, J.A. Genotype and Phenotype Correlations in Congenital Glaucoma: CYP1B1 Mutations, Goniodysgenesis, and Clinical Characteristics. Am. J. Ophthalmol. 2006, 142, 993-1004. [CrossRef]

28. Vincent, A.; Billingsley, G.; Priston, M.; Williams-Lyn, D.; Sutherland, J.; Glaser, T.; Oliver, E.; Walte, M.A.; Heathcote, G.; Levin, A.; et al. Phenotypic heterogeneity of CYP1B1: Mutations in a patient with Peters' anomaly. J. Med Genet. 2001, 38, 324-326. [CrossRef]

29. Tanwar, M.; Dada, T.; Dada, R. Axenfeld-Rieger Syndrome Associated with Congenital Glaucoma and Cytochrome P4501B1 Gene Mutations. Case Rep. Med. 2010, 2010, 6. [CrossRef]

30. Millá, E.; Mañù, B.; Duch, S.; Hernan, I.; Borràs, E.; Planas, E.; de Sousa Dias, M.; Carballo, M.; Gamundi, M.J. Survey of familial glaucoma shows a high incidence of cytochrome P450, family 1, subfamily B, polypeptide 1 (CYP1B1) mutations in non-consanguineous congenital forms in a Spanish population. Mol. Vis. 2013, 19, 1707-1722.

31. Maeda, A.; Maeda, T.; Sun, W.; Zhang, H.; Baehr, W.; Palczewski, K. Redundant and unique roles of retinol dehydrogenases in the mouse retina. Proc. Natl. Acad. Sci. USA 2007, 104, 19565-19570. [CrossRef]

32. Maeda, A.; Maeda, T.; Golczak, M.; Palczewski, K. Retinopathy in Mice Induced by Disrupted All-trans-retinal Clearance. J. Biol. Chem. 2008, 283, 26684-26693. [CrossRef] [PubMed]

33. Sarkar, H.; Moosajee, M. Retinol dehydrogenase 12 (RDH12): Role in vision, retinal disease and future perspectives. Exp. Eye Res. 2019, 188, 107793. [CrossRef] [PubMed]

34. Lhor, M.; Salesse, C. Retinol dehydrogenases: Membrane-bound enzymes for the visual function. Biochem. Cell Biol. 2014, 92, 510-523. [CrossRef] [PubMed]

35. Wang, H.; Cui, X.; Gu, Q.; Chen, Y.; Zhou, J.; Kuang, Y.; Wang, Z.; Xu, X. Retinol dehydrogenase 13 protects the mouse retina from acute light damage. Mol. Vis. 2012, 18, 1021-1030.

36. Cui, X.; Ma, B.; Wang, Y.; Chen, Y.; Shen, C.; Kuang, Y.; Fei, J.; Lu, L.; Wang, Z. Rdh13 deficiency weakens carbon tetrachloride-induced liver injury by regulating Spot14 and Cyp2e1 expression levels. Front. Med. 2019, 13, 104-111. [CrossRef]

37. Cui, X.; Dang, S.; Wang, Y.; Chen, Y.; Zhou, J.; Shen, C.; Kuang, Y.; Fei, J.; Lu, L.; Wang, Z. Retinol dehydrogenase 13 deficiency diminishes carbon tetrachloride-induced liver fibrosis in mice. Toxicol. Lett. 2017, 265, 17-22. [CrossRef] 
38. Wu, L.; Belyaeva, O.V.; Adams, M.K.; Klyuyeva, A.; Lee, S.-A.; Goggans, K.R.; Kesterson, R.A.; Popov, K.M.; Kedishvili, N.Y. Mice lacking the epidermal retinol dehydrogenases SDR16C5 and SDR16C6 display accelerated hair growth and enlarged meibomian glands. J. Biol. Chem. 2019, 294, 17060-17074. [CrossRef]

39. Farjo, K.M.; Moiseyev, G.; Nikolaeva, O.; Sandell, L.L.; Trainor, P.A.; Ma, J.-X. RDH10 is the primary enzyme responsible for the first step of embryonic Vitamin A metabolism and retinoic acid synthesis. Dev. Biol. 2011, 357, 347-355.

40. Rhinn, M.; Schuhbaur, B.; Niederreither, K.; Dollé, P. Involvement of retinol dehydrogenase 10 in embryonic patterning and rescue of its loss of function by maternal retinaldehyde treatment. Proc. Natl. Acad. Sci. USA 2011, 108, 16687-16692. [CrossRef]

41. Sandell, L.L.; Sanderson, B.W.; Moiseyev, G.; Johnson, T.; Mushegian, A.; Young, K.; Rey, J.-P.; Ma, J.-X.; Staehling-Hampton, K.; Trainor, P.A. RDH10 is essential for synthesis of embryonic retinoic acid and is required for limb, craniofacial, and organ development. Genes Dev. 2007, 21, 1113-1124. [CrossRef]

42. Sandell, L.L.; Lynn, M.L.; Inman, K.E.; McDowell, W.; Trainor, P.A. RDH10 Oxidation of Vitamin A Is a Critical Control. Step in Synthesis of Retinoic Acid during Mouse Embryogenesis. PLoS ONE 2012, 7, e30698.

43. Strate, I.; Min, T.H.; Iliev, D.; Pera, E.M. Retinol dehydrogenase 10 is a feedback regulator of retinoic acid signalling during axis formation and patterning of the central nervous system. Development 2009, 136, 461-472. [CrossRef] [PubMed]

44. Feng, L.; Hernandez, R.E.; Waxman, J.S.; Yelon, D.; Moens, C.B. Dhrs3a regulates retinoic acid biosynthesis through a feedback inhibition mechanism. Dev. Biol. 2010, 338, 1-14. [CrossRef] [PubMed]

45. Billings, S.E.; Pierzchalski, K.; Tjaden, N.E.B.; Pang, X.-Y.; Trainor, P.A.; Kane, M.A.; Moise, A.R. The retinaldehyde reductase DHRS3 is essential for preventing the formation of excess retinoic acid during embryonic development. FASWB J. 2013, 27, 4877-4889. [CrossRef] [PubMed]

46. Adams, M.K.; Belyaeva, O.V.; Wu, L.; Kedishvili, N.Y. The Retinaldehyde Reductase Activity of DHRS3 Is Reciprocally Activated by Retinol Dehydrogenase 10 to Control. Retinoid Homeostasis. J. Biol. Chem. 2014, 289, 14868-14880. [CrossRef]

47. Belyaeva, O.V.; Adams, M.K.; Wu, L.; Kedishvili, N.Y. The Antagonistically Bifunctional Retinoid Oxidoreductase Complex. Is Required for Maintenance of All-trans-retinoic Acid Homeostasis. J. Biol. Chem. 2017, 292, 5884-5897. [CrossRef] [PubMed]

48. Ang, H.L.; Duester, G. Stimulation of premature retinoic acid synthesis in Xenopus embryos following premature expression of aldehyde dehydrogenase ALDH1. FEBS J. 1999, 260, 227-234. [CrossRef]

49. Duester, G. Involvement of alcohol dehydrogenase, short-chain dehydrogenase/reductase, aldehyde dehydrogenase, and cytochrome P450 in the control of retinoid signaling by activation of retinoic acid synthesis. Biochemistry 1996, 35, 12221-12227. [CrossRef]

50. Mic, F.A.; Haselbeck, R.J.; Cuenca, A.E.; Duester, G. Novel retinoic acid generating activities in the neural tube and heart identified by conditional rescue of Raldh2 null mutant mice. Development 2002, 129, 2271-2282.

51. Li, H.; Wagner, E.; McCaffery, P.; Smith, D.; Andreadis, A.; Dräger, U.C. A retinoic acid synthesizing enzyme in ventral retina and telencephalon of the embryonic mouse. Mech. Dev. 2000, 95, 283-289. [CrossRef]

52. Mic, F.A.; Molotkov, A.; Fan, X.; Cuenca, A.E.; Duester, G. RALDH3, a retinaldehyde dehydrogenase that generates retinoic acid, is expressed in the ventral retina, otic vesicle and olfactory pit during mouse development. Mech. Dev. 2000, 97, 227-230. [CrossRef]

53. Niederreither, K.; McCaffery, P.; Dräger, U.C.; Chambon, P.; Dollé, P. Restricted expression and retinoic acid-induced downregulation of the retinaldehyde dehydrogenase type 2 (RALDH-2) gene during mouse development. Mech. Dev. 1997, 62, 67-78. [CrossRef]

54. Chatzi, C.; Brade, T.; Duester, G. Retinoic Acid Functions as a Key GABAergic Differentiation Signal. in the Basal Ganglia. PLoS Biol. 2011, 9, e1000609. [CrossRef] [PubMed]

55. Dupe, V.; Matt, N.; Garnier, J.M.; Chambon, P.; Mark, M.; Ghyselinck, N.B. A newborn lethal defect due to inactivation of retinaldehyde dehydrogenase type 3 is prevented by maternal retinoic acid treatment. Proc. Natl. Acad. Sci. USA 2003, 100, 14036-14041. [CrossRef] [PubMed]

56. Fan, X.; Molotkov, A.; Manabe, S.I.; Donmoyer, C.M.; Deltour, L.; Foglio, M.H.; Cuenca, A.E.; Blaner, W.S.; Lipton, S.A.; Duester, G. Targeted Disruption of Aldh1a1 (Raldh1) Provides Evidence for a Complex. Mechanism of Retinoic Acid Synthesis in the Developing Retina. Mol. Cell. Biol. 2003, 23, 4637-4648. [PubMed] 
57. Matt, N.; Dupé, V.; Garnier, J.-M.; Dennefeld, C.; Chambon, P.; Mark, M.; Ghyselinck, N.B. Retinoic acid-dependent eye morphogenesis is orchestrated by neural crest cells. Development 2005, 132, 4789-4800. [CrossRef] [PubMed]

58. Begemann, G.; Schilling, T.F.; Rauch, G.J.; Geisler, R.; Ingham, P.W. The zebrafish neckless mutation reveals a requirement for raldh2 in mesodermal signals that pattern the hindbrain. Development 2001, 128, 3081-3094.

59. Hochgreb, T.; Linhares, V.L.; Menezes, D.C.; Sampaio, A.C.; Yan, C.Y.I.; Cardoso, W.V.; Rosentha, N.; Xavier-Neto, J. A caudorostral wave of RALDH2 conveys anteroposterior information to the cardiac field. Development 2003, 130, 5363-5374. [CrossRef]

60. Niederreither, K.; Subbarayan, V.; Dolle, P.; Chambon, P. Embryonic retinoic acid synthesis is essential for early mouse post-implantation development. Nat. Genet. 1999, 21, 444-448. [CrossRef]

61. Niederreither, K.; Vermot, J.; Schuhbaur, B.; Chambon, P.; Dollé, P. Embryonic retinoic acid synthesis is required for forelimb growth and anteroposterior patterning in the mouse. Development 2002, 129, 3563-3574.

62. Niederreither, K.; Vermot, J.; Schuhbaur, B.; Chambon, P.; Dolle, P. Retinoic acid synthesis and hindbrain patterning in the mouse embryo. Development 2000, 127, 75-85.

63. Niederreither, K.; Vermot, J.; Roux, I.L.; Schuhbaur, B.; Chambon, P.; Dollé, P. The regional pattern of retinoic acid synthesis by RALDH2 is essential for the development of posterior pharyngeal arches and the enteric nervous system. Development 2003, 130, 2525-2534. [CrossRef]

64. Niederreither, K.; Vermot, J.; Messaddeq, N.; Schuhbaur, B.; Chambon, P.; Dolle, P. Embryonic retinoic acid synthesis is essential for heart morphogenesis in the mouse. Development 2001, 128, 1019-1031. [PubMed]

65. Ryckebusch, L.; Wang, Z.; Bertrand, N.; Lin, S.C.; Chi, X.; Schwartz, R.; Zaffran, S.; Niederreither, K. Retinoic acid deficiency alters second heart field formation. Proc. Natl. Acad. Sci. USA 2008, 105, 2913-2918. [CrossRef] [PubMed]

66. Vermot, J.; Llamas, J.G.; Fraulob, V.; Niederreither, K.; Chambon, P.; Dolle, P. Retinoic Acid Controls the Bilateral Symmetry of Somite Formation in the Mouse Embryo. Science 2005, 308, 563-566. [CrossRef] [PubMed]

67. Vermot, J.; Pourquie, O. Retinoic acid coordinates somitogenesis and left-right patterning in vertebrate embryos. Nature 2005, 435, 215-220. [CrossRef] [PubMed]

68. Vermot, J.; Niederreither, K.; Garnier, J.-M.; Chambon, P.; Dollé, P. Decreased embryonic retinoic acid synthesis results in a DiGeorge syndrome phenotype in newborn mice. Proc. Natl. Acad. Sci. USA 2003, 100, 1763-1768. [CrossRef]

69. Ryckebusch, L.; Bertrand, N.; Mesbah, K.; Bajolle, F.; Niederreither, K.; Kelly, R.G.; Zaffran, S. Decreased Levels of Embryonic Retinoic Acid Synthesis Accelerate Recovery From Arterial Growth Delay in a Mouse Model of DiGeorge Syndrome. Circ. Res. 2010, 106, 686-694. [CrossRef]

70. Chambon, P. A decade of molecular biology of retinoic acid receptors. FASEB J. 1996, 10, 940-954. [CrossRef]

71. Dollé, P. Developmental expression of retinoic acid receptors (RARs). Nucl. Recept. Signal. 2009, 7, nrs-07006. [CrossRef]

72. Mark, M.; Ghyselinck, N.B.; Chambon, P. Function of retinoic acid receptors during embryonic development. Nucl. Recept. Signal. 2009, 7, nrs-07002. [CrossRef] [PubMed]

73. Lyn, S.; Giguère, V. Localization of CRABP-I and CRABP-II mRNA in the early mouse embryo by whole-mount in situ hybridization: Implications for teratogenesis and neural development. Dev. Dyn. 1994, 199, 280-291. [CrossRef] [PubMed]

74. Cai, A.Q.; Radtke, K.; Linville, A.; Lander, A.D.; Nie, Q.; Schilling, T.F. Cellular retinoic acid-binding proteins are essential for hindbrain patterning and signal robustness in zebrafish. Development 2012, 139, 2150-2155. [CrossRef] [PubMed]

75. Mic, F.A.; Molotkov, A.; Benbrook, D.M.; Duester, G. Retinoid activation of retinoic acid receptor but not retinoid $\mathrm{X}$ receptor is sufficient to rescue lethal defect in retinoic acid synthesis. Proc. Natl. Acad. Sci. USA 2003, 100, 7135-7140. [CrossRef]

76. Kastner, P.; Mark, M.; Ghyselinck, N.; Krezel, W.; Dupe, V.; Grondona, J.M.; Chambon, P. Genetic evidence that the retinoid signal is transduced by heterodimeric RXR/RAR functional units during mouse development. Development 1997, 124, 313-326.

77. Ghyselinck, N.B.; Wendling, O.; Messaddeq, N.; Dierich, A.; Lampron, C.; Decimo, D.; Viville, S.; Chambon, P.; Mark, M. Contribution of retinoic acid receptor beta isoforms to the formation of the conotruncal septum of the embryonic heart. Dev. Biol. 1998, 198, 303-318. [CrossRef] 
78. Mendelsohn, C.; Lohnes, D.; Decimo, D.; Lufkin, T.; LeMeur, M.; Chambon, P.; Mark, M. Function of the retinoic acid receptors (RARs) during development (II). Multiple abnormalities at various stages of organogenesis in RAR double mutants. Development 1994, 120, 2749-2771.

79. Lohnes, D.; Mark, M.; Mendelsohn, C.; Dolle, P.; Dierich, A.; Gorry, P.; Gansmuller, A.; Chambon, P. Function of the retinoic acid receptors (RARs) during development (I). Craniofacial and skeletal abnormalities in RAR double mutants. Development 1994, 120, 2723-2748.

80. Wendling, O.; Dennefeld, C.; Chambon, P.; Mark, M. Retinoid signaling is essential for patterning the endoderm of the third and fourth pharyngeal arches. Development 2000, 127, 1553-1562.

81. Lohnes, D.; Kastner, P.; Dierich, A.; Mark, M.; LeMeur, M.; Chambon, P. Function of retinoic acid receptor $\gamma$ in the mouse. Cell 1993, 73, 643-658. [CrossRef]

82. Iulianella, A.; Lohnes, D. Contribution of retinoic acid receptor gamma to retinoid-induced craniofacial and axial defects. Dev. Dyn. 1997, 209, 92-104. [CrossRef]

83. Gudas, L.J.; Wagner, J.A. Retinoids regulate stem cell differentiation. J. Cell. Physiol. 2011, 226, $322-330$. [CrossRef] [PubMed]

84. Mark, M.; Ghyselinck, N.B.; Chambon, P. Retinoic acid signalling in the development of branchial arches. Curr. Opin. Genet. Dev. 2004, 14, 591-598. [CrossRef] [PubMed]

85. Zile, M.H. Vitamin A Requirement for Early Cardiovascular Morphogenesis Specification in the Vertebrate Embryo: Insights from the Avian Embryo. Exp. Biol. Med. 2004, 229, 598-606. [CrossRef]

86. Maden, M.; Gale, E.; Kostetskii, I.; Zile, M. Vitamin A-deficient quail embryos have half a hindbrain and other neural defects. Curr. Biol. 1996, 6, 417-426. [CrossRef]

87. Sockanathan, S.; Jessell, T.M. Motor Neuron-Derived Retinoid Signaling Specifies the Subtype Identity of Spinal Motor Neurons. Cell 1998, 94, 503-514. [CrossRef]

88. Malpel, S.; Mendelsohn, C.; Cardoso, W.V. Regulation of retinoic acid signaling during lung morphogenesis. Development 2000, 127, 3057-3067.

89. Stratford, T.; Logan, C.; Zile, M.; Maden, M. Abnormal anteroposterior and dorsoventral patterning of the limb bud in the absence of retinoids. Mech. Dev. 1999, 81, 115-125. [CrossRef]

90. Stratford, T.; Horton, C.; Maden, M. Retinoic acid is required for the initiation of outgrowth in the chick limb bud. Curr. Biol. 1996, 6, 1124-1133. [CrossRef]

91. Batourina, E.; Gim, S.; Bello, N.; Shy, M.; Clagett-Dame, M.; Srinivas, S.; Costantini, F.; Mendelsohn, C. Vitamin A controls epithelial/mesenchymal interactions through Ret expression. Nat. Genet. 2001, 27, 74-78. [CrossRef]

92. Mendelsohn, C.; Batourina, E.; Fung, S.; Gilbert, T.; Dodd, J. Stromal cells mediate retinoid-dependent functions essential for renal development. Development 1999, 126, 1139-1148. [PubMed]

93. Wagner, E.; McCaffery, P.; Drager, U.C. Retinoic Acid in the Formation of the Dorsoventral Retina and Its Central Projections. Dev. Biol. 2000, 222, 460-470. [CrossRef] [PubMed]

94. Fantel, A.G.; Shepard, T.H.; Newell-Morris, L.L.; Moffett, B.C. Teratogenic effects of retinoic acid in pigtail monkeys (Macaca nemestrina). I. General features. Teratology 1977, 15, 65-71. [CrossRef] [PubMed]

95. Gale, E.; Zile, M.; Maden, M. Hindbrain respecification in the retinoid-deficient quail. Mech. Dev. 1999, 89, 43-54. [CrossRef]

96. Happle, R.; Traupe, H.; Bounameaux, Y.; Fisch, T. Teratogenic effects of etretinate in humans. Dtsch. Med. Wochenschr. 1984, 109, 1476-1480. [CrossRef] [PubMed]

97. Kalter, H.; Warkany, J. Experimental production of congenital malformations in strains of inbred mice by maternal treatment with hypervitaminosis A. Am. J. Pathol. 1961, 38, 1-21.

98. Kalter, $\mathrm{H}$. The teratogenic effects of hypervitaminosis A upon the face and mouth of inbred mice. Ann. N. Y. Acad. Sci. 1960, 85, 42-55. [CrossRef]

99. Kistler, A. Teratogenesis of retinoic acid in rats: Susceptible stages and suppression of retinoic acid-induced limb malformations by cycloheximide. Teratology 1981, 23, 25-31. [CrossRef]

100. Kochhar, D.M.; Johnson, E.M. Morphological and autoradiographic studies of cleft palate induced in rat embryos by maternal hypervitaminosis A. J. Embryol. Exp. Morphol. 1965, 14, 223-238.

101. Rosa, F.W.; Wilk, A.L.; Kelsey, F.O. Teratogen update: Vitamin A congeners. Teratology 1986, 33, 355-364. [CrossRef]

102. Shenefelt, R.E. Gross congenital malformations. Animal model: Treatment of various species with a large dose of vitamin A at known stages in pregnancy. Am. J. Pathol. 1972, 66, 589-592. [PubMed] 
103. Iulianella, A.; Beckett, B.; Petkovich, M.; Lohnes, D. A Molecular Basis for Retinoic Acid-Induced Axial Truncation. Dev. Biol. 1999, 205, 33-48. [CrossRef]

104. Durston, A.J.; Timmermans, J.P.M.; Hage, W.J.; Hendriks, H.F.J.; de Vries, N.J.; Heideveld, M.; Nieuwkoop, P.D. Retinoic acid causes an anteroposterior transformation in the developing central nervous system. Nature 1989, 340, 140-144. [CrossRef] [PubMed]

105. Dupe, V.; Ghyselinck, N.B.; Wendling, O.; Chambon, P.; Mark, M. Key roles of retinoic acid receptors alpha and beta in the patterning of the caudal hindbrain, pharyngeal arches and otocyst in the mouse. Development 1999, 126, 5051-5059. [PubMed]

106. Matt, N.; Ghyselinck, N.B.; Wendling, O.; Chambon, P.; Mark, M. Retinoic acid-induced developmental defects are mediated by RARbeta/RXR heterodimers in the pharyngeal endoderm. Development 2003, 130, 2083-2093. [CrossRef] [PubMed]

107. Mulder, G.B.; Manley, N.; Maggio-Price, L. Retinoic acid-induced thymic abnormalities in the mouse are associated with altered pharyngeal morphology, thymocyte maturation defects, and altered expression of Hoxa3 and Pax1. Teratology 1998, 58, 263-275. [CrossRef]

108. Mulder, G.B.; Manley, N.; Grant, J.; Schmidt, K.; Zeng, W.; Eckhoff, C.; Maggio-Price, L. Effects of excess vitamin A on development of cranial neural crest-derived structures: A neonatal and embryologic study. Teratology 2000, 62, 214-226. [CrossRef]

109. Lee, Y.M.; Osumi-Yamashita, N.; Ninomiya, Y.; Moon, C.K.; Eriksson, U.; Eto, K. Retinoic acid stage-dependently alters the migration pattern and identity of hindbrain neural crest cells. Development 1995, 121,825 .

110. Williams, A.L.; Bohnsack, B.L. What's retinoic acid got to do with it? Retinoic acid regulation of the neural crest in craniofacial and ocular development. Genesis 2019, 57, e23308.

111. Arinami, T. Analyses of the associations between the genes of 22q11 deletion syndrome and schizophrenia. J. Hum. Genet. 2006, 51, 1037. [CrossRef]

112. Gao, S.; Li, X.; Amendt, B.A. Understanding the Role of Tbx1 as a Candidate Gene for 22q11.2 Deletion Syndrome. Curr. Allergy Asthma Rep. 2013, 13, 613-621. [CrossRef]

113. Papangeli, I.; Scambler, P. The 22q11 deletion: DiGeorge and velocardiofacial syndromes and the role of TBX1. Wiley Interdiscip. Rev. Dev. Biol. 2013, 2, 393-403. [CrossRef] [PubMed]

114. Scambler, P.J. The 22q11 deletion syndromes. Hum. Mol. Genet. 2000, 9, 2421-2426. [CrossRef] [PubMed]

115. McDonald-McGinn, D.M.; Sullivan, K.E.; Marino, B.; Philip, N.; Swillen, A.; Vorstman, J.A.S.; Zackai, E.H.; Emanuel, B.S.; Vermeesch, R.J.; Morrow, B.E.; et al. 22q11.2 deletion syndrome. Nat. Rev. Dis. Primers 2015, 1, 15071. [CrossRef] [PubMed]

116. Conley, M.; Beckwith, J.; Manceer, J.F.K.; Tenckhoff, L. The spectrum of the DiGeorge syndrome. J. Pediatrics 1979, 94, 883-890. [CrossRef]

117. Wilson, D.I.; Goodship, J.A.; Burn, J.; Cross, I.E.; Scambler, P.J. Deletions within chromosome 22q11 in familial congenital heart disease. Lancet 1992, 340, 573-575. [CrossRef]

118. Jerome, L.A.; Papaioannou, V.E. DiGeorge syndrome phenotype in mice mutant for the T-box gene, Tbx1. Nat. Genet. 2001, 27, 286-291. [CrossRef]

119. Lindsay, E.A.; Vitelli, F.; Su, H.; Morishima, M.; Huynh, T.; Pramparo, T.; Jurecic, V.; Ogunrinu, G.; Sutherland, H.F.; Scambler, P.J.; et al. T Tbx1 haploinsufficiency in the DiGeorge syndrome region causes aortic arch defects in mice. Nature 2001, 410, 97-101. [CrossRef]

120. Merscher, S.; Funke, B.; Epstein, J.A.; Heyer, J.; Puech, A.; Lu, M.M.; Xavier, R.J.; Demay, M.B.; Russell, R.G.; Factor, S.; et al. TBX1 Is Responsible for Cardiovascular Defects in Velo-Cardio-Facial/DiGeorge Syndrome. Cell 2001, 104, 619-629. [CrossRef]

121. Vitelli, F.; Morishima, M.; Taddei, I.; Lindsay, E.A.; Baldini, A. Tbx1 mutation causes multiple cardiovascular defects and disrupts neural crest and cranial nerve migratory pathways. Hum. Mol. Genet. 2002, 11, 915-922. [CrossRef]

122. Xu, H.; Morishima, M.; Wylie, J.N.; Schwartz, R.J.; Bruneau, B.G.; Lindsay, E.A.; Baldini, A. Tbx1 has a dual role in the morphogenesis of the cardiac outflow tract. Development 2004, 131, 3217-3227. [CrossRef] [PubMed]

123. Arnold, J.S.; Werling, U.; Braunstein, E.M.; Liao, J.; Nowotschin, S.; Edelmann, W.; Hebert, J.M.; Morrow, B.E. Inactivation of Tbx1 in the pharyngeal endoderm results in 22q11DS malformations. Development 2006, 133, 977-987. [CrossRef] [PubMed] 
124. Kochilas, L.K.; Potluri, V.; Gitler, A.; Balasubramanian, K.; Chin, A.J. Cloning and characterization of zebrafish tbx1. Gene Expr. Patterns 2003, 3, 645-651. [CrossRef]

125. Roberts, C.; Ivins, S.M.; James, C.T.; Scambler, P.J. Retinoic acid down-regulates Tbx1 expression in vivo and in vitro. Dev. Dyn. 2005, 232, 928-938. [CrossRef]

126. Roberts, C.; Ivins, S.; Cook, A.C.; Baldini, A.; Scambler, P.J. Cyp26 genes a1, b1 and c1 are down-regulated in Tbx1 null mice and inhibition of Cyp26 enzyme function produces a phenocopy of DiGeorge Syndrome in the chick. Hum. Mol. Genet. 2006, 15, 3394-3410. [CrossRef]

127. Guris, D.L.; Duester, G.; Papaioannou, V.E.; Imamoto, A. Dose-Dependent Interaction of Tbx1 and Crkl and Locally Aberrant RA Signaling in a Model of del22q11 Syndrome. Dev. Cell 2006, 10, 81-92. [CrossRef]

128. Okubo, T.; Kawamura, A.; Takahashi, J.; Yagi, H.; Morishima, M.; Matsuoka, R.; Takada, S. Ripply3, a Tbx1 repressor, is required for development of the pharyngeal apparatus and its derivatives in mice. Development 2011, 138, 339-348. [CrossRef]

129. De Bono, C.; Thellier, C.; Bertrand, N.; Sturny, R.; Jullian, E.; Cortes, C.; Stefanovic, S.; Zaffran, S.; Théveniau-Ruissy, M.; Kelly, R.G. T-box genes and retinoic acid signaling regulate the segregation of arterial and venous pole progenitor cells in the murine second heart fieldHuman Molecular Genetics. Hum. Mol. Genet. 2018, 27, 3747-3760. [CrossRef]

130. Piotrowski, T.; Ahn, D.G.; Schilling, T.F.; Nair, S.; Ruvinsky, I.; Geisler, R.; Rauch, G.J.; Haffter, P.; Zon, L.I.; Zhou, Y.; et al. The zebrafish van gogh mutation disrupts tbx1, which is involved in the DiGeorge deletion syndrome in humans. Development 2003, 130, 5043-5052. [CrossRef]

131. Williams, P.A.; Cosme, J.; Sridhar, V.; Johnson, E.F.; McRee, D.E. Mammalian Microsomal Cytochrome P450 Monooxygenase: Structural Adaptations for Membrane Binding and Functional Diversity. Mol. Cell 2000, 5, 121-131. [CrossRef]

132. Cosme, J.; Johnson, E.F. Engineering microsomal cytochrome P450 2C5 to be a soluble, monomeric enzyme: Mutations that alter aggregation, phospholipid dependence of catalysis, and membrane binding. J. Biol. Chem. 2000, 275, 2545-2553. [CrossRef] [PubMed]

133. Gotoh, O. Substrate recognition sites in cytochrome P450 family 2 (CYP2) proteins inferred from comparative analyses of amino acid and coding nucleotide sequences. J. Biol. Chem. 1992, 267, 83-90. [PubMed]

134. Graham, S.E.; Peterson, J.A. How Similar Are P450s and What Can. Their Differences Teach. Us? Arch. Biochem. Biophys. 1999, 369, 24-29. [CrossRef] [PubMed]

135. Gilardi, G.; Di Nardo, G. Heme iron centers in cytochrome P450: Structure and catalytic activity. Rend. Lincei 2017, 28, 159-167. [CrossRef]

136. Werck-Reichhart, D.; Feyereisen, R. Cytochromes P450: A success story. Genome Biol. 2000, 1, reviews3003-1. [CrossRef]

137. Thatcher, J.E.; Isoherranen, N. The role of CYP26 enzymes in retinoic acid clearance. Expert Opin. Drug Metab. Toxicol. 2009, 5, 875-886. [CrossRef]

138. Thatcher, J.E.; Zelter, A.; Isoherranen, N. The relative importance of CYP26A1 in hepatic clearance of all-trans retinoic acid. Biochem. Pharmacol. 2010, 80, 903-912. [CrossRef]

139. Isoherranen, N.; Zhong, N. Biochemical and physiological importance of the CYP26 retinoic acid hydroxylases. Pharmacol. Ther. 2019, 107400. [CrossRef]

140. Lutz, J.D.; Dixit, V.; Yeung, C.K.; Dickmann, L.J.; Zelter, A.; Thatcher, J.E.; Nelson, W.L.; Isoherranen, N. Expression and functional characterization of cytochrome P450 26A1, a retinoic acid hydroxylase. Biochem. Pharmacol. 2009, 77, 258-268. [CrossRef]

141. Taimi, M.; Helvig, C.; Wisniewski, J.; Ramshaw, H.; White, J.; Korczak, B.; Petkovich, M. A Novel Human Cytochrome P450, CYP26C1, Involved in Metabolism of 9-cis and All-trans Isomers of Retinoic Acid. J. Biol. Chem. 2004, 279, 77-85. [CrossRef]

142. White, J.A.; Guo, Y.D.; Baetz, K.; Beckett-Jones, B.; Bonasoro, J.; Hsu, K.E.; Dilworth, F.J.; Jones, G.; Petkovich, M. Identification of the Retinoic Acid-inducible All-trans-retinoic Acid 4-Hydroxylase. J. Biol. Chem. 1996, 271, 29922-29927. [CrossRef] [PubMed]

143. Fujii, H.; Sato, T.; Kaneko, S.; Gotoh, O.; Fujii-Kuriyama, Y.; Osawa, K.; Kato, S.; Hamada, H. Metabolic Metabolic inactivation of retinoic acid by a novel $\mathrm{P} 450$ differentially expressed in developing mouse embryos. EMBO J. 1997, 16, 4163-4173. [CrossRef] [PubMed]

144. Ross, A.C.; Zolfaghari, R. Cytochrome P450s in the Regulation of Cellular Retinoic Acid Metabolism. Annu. Rev. Nutr. 2011, 31, 65-87. [CrossRef] [PubMed] 
145. Qian, L.; Zolfaghari, R.; Ross, A.C. Liver-specific cytochrome P450 CYP2C22 is a direct target of retinoic acid and a retinoic acid-metabolizing enzyme in rat liver. J. Lipid Res. 2010, 51, 1781-1792. [CrossRef]

146. White, J.A.; Ramshaw, H.; Taimi, M.; Stangle, W.; Zhang, A.; Everingham, S.; Creighton, S.; Tam, S.P.; Jones, G.; Petkovich, M. Identification of the human cytochrome P450, P450RAI-2, which is predominantly expressed in the adult cerebellum and is responsible for all-trans-retinoic acid metabolism. Proc. Natl. Acad. Sci. USA 2000, 97, 6403-6408. [CrossRef]

147. Topletz, A.R.; Tripathy, S.; Foti, R.S.; Shimshoni, J.A.; Nelson, W.L.; Isoherranen, N. Induction of CYP26A1 by metabolites of retinoic acid: Evidence that CYP26A1 is an important enzyme in the elimination of active retinoids. Mol. Pharmacol. 2015, 87, 430-441. [CrossRef]

148. Topletz, A.R.; Thatcher, J.E.; Zelter, A.; Lutz, J.D.; Tay, S.; Nelson, W.L.; Isoherranen, N. Comparison of the function and expression of CYP26A1 and CYP26B1, the two retinoic acid hydroxylases. Biochem. Pharmacol. 2012, 83, 149-163. [CrossRef]

149. Stevison, F.; Jing, J.; Tripathy, S.; Isoherranen, N. Chapter Eleven-Role of Retinoic Acid-Metabolizing Cytochrome P450s, CYP26, in Inflammation and Cancer. In Advances in Pharmacology; Hardwick, J.P., Ed.; Academic Press: Cambridge, MA, USA, 2015; pp. 373-412.

150. Zhong, G.; Ortiz, D.; Zelter, A.; Nath, A.; Isoherranen, N. CYP26C1 Is a Hydroxylase of Multiple Active Retinoids and Interacts with Cellular Retinoic Acid Binding Proteins. Mol. Pharmacol. 2018, 93, 489-503. [CrossRef]

151. Chithalen, J.V.; Luu, L.; Petkovich, M.; Jones, G. HPLC-MS/MS analysis of the products generated from all-trans-retinoic acid using recombinant human CYP26A. J. Lipid Res. 2002, 43, 1133-1142. [CrossRef]

152. Samokyszyn, V.M.; Gall, W.E.; Zawada, G.; Freyaldenhoven, M.A.; Chen, G.; Mackenzie, P.I.; Tephly, T.R.; Radominska-Pandya, A. 4-Hydroxyretinoic Acid, a Novel Substrate for Human Liver Microsomal UDP-glucuronosyltransferase(s) and Recombinant UGT2B7. J. Biol. Chem. 2000, 275, 6908-6914. [CrossRef]

153. Reijntjes, S.; Blentic, A.; Gale, E.; Maden, M. The control of morphogen signalling: Regulation of the synthesis and catabolism of retinoic acid in the developing embryo. Dev. Biol. 2005, 285, 224-237. [CrossRef] [PubMed]

154. Pijnappel, W.W.M.; Hendriks, H.F.J.; Folkers, G.E.; van den Brink, C.E.; Dekker, E.J.; Edelenbosch, C.; van der Saag, P.T.; Durston, A.J. The retinoid ligand 4-oxo-retinoic acid is a highly active modulator of positional specification. Nature 1993, 366, 340-344. [CrossRef] [PubMed]

155. Herrmann, K. Teratogenic effects of retinoic acid and related substances on the early development of the zebrafish (Brachydanio rerio) as assessed by a novel scoring system. Toxicol. Vitr. 1995, 9, 267-283. [CrossRef]

156. Niederreither, K.; Abu-Abed, S.; Schuhbaur, B.; Petkovich, M.; Chambon, P.; Dolle, P. Genetic evidence that oxidative derivatives of retinoic acid are not involved in retinoid signaling during mouse development. Nat. Genet. 2002, 31, 84-88. [CrossRef] [PubMed]

157. Carvalho, J.E.; Theodosiou, M.; Chen, J.; Chevret, P.; Alvarez, S.; de Lera, A.R.; Laudet, V.; Croce, J.C.; Schubert, M. Lineage-specific duplication of amphioxus retinoic acid degrading enzymes (CYP26) resulted in sub-functionalization of patterning and homeostatic roles. BMC Evol. Biol. 2017, 17, 24. [CrossRef] [PubMed]

158. Carvalho, J.E.; Lahaye, F.; Croce, C.J.; Schubert, M. CYP26 function is required for the tissue-specific modulation of retinoic acid signaling during amphioxus development. Int. J. Dev. Biol. 2017, 61, 733-747. [CrossRef]

159. White, R.J.; Schilling, T.F. How degrading: Cyp26s in hindbrain development. Dev. Dyn. 2008, 237, $2775-2790$. [CrossRef]

160. MacLean, G.; Abu-Abed, S.; Dolle, P.; Tahayatoc, A.; Chambonb, P.; Petkovich, M. Cloning of a novel retinoic-acid metabolizing cytochrome P450, Cyp26B1, and comparative expression analysis with Cyp26A1 during early murine development. Mech. Dev. 2001, 107, 195-201. [CrossRef]

161. Tahayato, A.; Dolle, P.; Petkovich, M. Cyp26C1 encodes a novel retinoic acid-metabolizing enzyme expressed in the hindbrain, inner ear, first branchial arch and tooth buds during murine development. Gene Expr. Patterns 2003, 3, 449-454. [CrossRef]

162. White, J.A.; Beckett-Jones, B.; Guo, Y.-D.; Dilworth, F.J.; Bonasoro, J.; Jones, G.; Petkovich, M. cDNA Cloning of Human Retinoic Acid-metabolizing Enzyme (hP450RAI) Identifies a Novel Family of Cytochromes P450 (CYP26). J. Biol. Chem. 1997, 272, 18538-18541. [CrossRef]

163. Zhao, Q.; Dobbs-McAuliffe, B.; Linney, E. Expression of cyp26b1 during zebrafish early development. Gene Expr. Patterns 2005, 5, 363-369. [CrossRef] [PubMed] 
164. Fujiwara, S.; Kawamura, K. Acquisition of Retinoic Acid Signaling Pathway and Innovation of the Chordate Body Plan. Zool. Sci. 2003, 20, 809-818. [CrossRef] [PubMed]

165. Blentic, A.; Gale, E.; Maden, M. Retinoic acid signalling centres in the avian embryo identified by sites of expression of synthesising and catabolising enzymes. Dev. Dyn. 2003, 227, 114-127. [CrossRef] [PubMed]

166. De Roos, K.; Sonneveld, E.; Compaan, B.; Berge, D.T.; Durston, A.J.; van der Saag, P.T. Expression of retinoic acid 4-hydroxylase (CYP26) during mouse and Xenopus laevis embryogenesis. Mech. Dev. 1999, 82, $205-211$. [CrossRef]

167. Reijntjes, S.; Gale, E.; Maden, M. Expression of the retinoic acid catabolising enzyme CYP26B1 in the chick embryo and its regulation by retinoic acid. Gene Expr. Patterns 2003, 3, 621-627. [CrossRef]

168. Reijntjes, S.; Gale, E.; Maden, M. Generating gradients of retinoic acid in the chick embryo: Cyp26C1 expression and a comparative analysis of the Cyp26 enzymes. Dev. Dyn. 2004, 230, 509-517. [CrossRef]

169. Swindell, E.C.; Thaller, C.; Sockanathan, S.; Petkovich, M.; Jessell, T.M.; Eichele, G. Complementary Domains of Retinoic Acid Production and Degradation in the Early Chick Embryo. Dev. Biol. 1999, 216, 282-296. [CrossRef]

170. McCaffery, P.; Wagner, O.N.J.; Petkovich, M.; Drager, U. Dorsal and ventral retinal territories defined by retinoic acid synthesis, break-down and nuclear receptor expression. Mech. Dev. 1999, 82, 119-130. [CrossRef]

171. Pennimpede, T.; Cameron, D.A.; MacLean, G.A.; Li, H.; Abu-Abed, S.; Petkovich, M. The role of CYP26 enzymes in defining appropriate retinoic acid exposure during embryogenesis. Birth Defects Res. Part Clin. Mol. Teratol. 2010, 88, 883-894. [CrossRef]

172. Romand, R.; Kondo, T.; Fraulob, V.; Petkovich, M.; Dollé, P.; Hashino, E. Dynamic expression of retinoic acid-synthesizing and -metabolizing enzymes in the developing mouse inner ear. J. Comp. Neurol. 2006, 496, 643-654. [CrossRef]

173. Stoney, P.N.; Fragoso, Y.D.; Saeed, R.B.; Ashton, A.; Goodman, T.; Simons, C.; Gomaa, M.S. Expression of the retinoic acid catabolic enzyme CYP26B1 in the human brain to maintain signaling homeostasis. Brain Struct. Funct. 2016, 221, 3315-3326. [CrossRef] [PubMed]

174. Cifelli, C.J.; Ross, A.C. Chronic Vitamin A Status and Acute Repletion with Retinyl Palmitate Are Determinants of the Distribution and Catabolism of all-trans-Retinoic Acid in Rats. J. Nutr. 2007, 137, 63-70. [CrossRef] [PubMed]

175. Yamamoto, Y.; Zolfaghari, R.; Ross, A.C. Regulation of CYP26 (cytochrome P450RAI) mRNA expression and retinoic acid metabolism by retinoids and dietary vitamin A in liver of mice and rats. FASEB J. 2000, 14, 2119-2127. [CrossRef] [PubMed]

176. Chapman, J.S.; Weiss, K.L.; Curley, R.W.; Highland, M.A.; Clagett-Dame, M. Hydrolysis of 4-HPR to atRA occurs in vivo but is not required for retinamide-induced apoptosis. Arch. Biochem. Biophys. 2003, 419, 234-243. [CrossRef]

177. Wang, Y.; Zolfaghari, R.; Catharine Ross, A. Cloning of rat cytochrome P450RAI (CYP26) cDNA and regulation of its gene expression by all-trans-retinoic acid in vivo. Arch. Biochem. Biophys. 2002, 401, 235-243. [CrossRef]

178. Zhang, Y.; Zolfaghari, R.; Ross, A.C. Multiple retinoic acid response elements cooperate to enhance the inducibility of CYP26A1 gene expression in liver. Gene 2010, 464, 32-43. [CrossRef] [PubMed]

179. Sakai, Y.; Meno, C.; Fujii, H.; Nishino, J.; Shiratori, H.; Saijoh, Y.; Rossant, J.; Hamada, H. The retinoic acid-inactivating enzyme CYP26 is essential for establishing an uneven distribution of retinoic acid along the anterio-posterior axis within the mouse embryo. Genes Dev. 2001, 15, 213-225. [CrossRef]

180. White, R.J.; Nie, Q.; Lander, A.D.; Schilling, T.F. Complex. Regulation of cyp26a1 Creates a Robust Retinoic Acid Gradient in the Zebrafish Embryo. PLoS Biol. 2007, 5, e304. [CrossRef]

181. Kinkel, M.D.; Sefton, E.M.; Kikuchi, Y.; Mizoguchi, T.; Ward, A.B.; Prince, V.E. Cyp26 enzymes function in endoderm to regulate pancreatic field size. Proc. Natl. Acad. Sci. USA 2009, 106, 7864-7869. [CrossRef] [PubMed]

182. Janesick, A.; Tang, W.; Shioda, T.; Blumberg, B. RAR $\gamma$ is required for mesodermal gene expression prior to gastrulation in Xenopus. Development 2018, 145, dev147769. [CrossRef]

183. Loudig, O.; Maclean, G.A.; Dore, N.L.; Luu, L.; Petkovich, M. Transcriptional co-operativity between distant retinoic acid response elements in regulation of Cyp26A1 inducibility. Biochem. J. 2005, 392, 241-248. [CrossRef] [PubMed] 
184. Loudig, O.; Babichuk, C.; White, J.; Abu-Abed, S.; Mueller, C.; Petkovich, M. Cytochrome P450RAI(CYP26) Promoter: A Distinct Composite Retinoic Acid Response Element Underlies the Complex. Regulation of Retinoic Acid Metabolism. Mol. Endocrinol. 2000, 14, 1483-1497. [CrossRef] [PubMed]

185. Hu, P.; Tian, M.; Bao, J.; Xing, G.; Gu, X.; Gao, X.; Linney, E.; Zhao, Q. Retinoid regulation of the zebrafish cyp26a1 promoter. Dev. Dyn. 2008, 237, 3798-3808. [CrossRef] [PubMed]

186. Lalevee, S.; Anno, Y.N.; Chatagnon, A.; Samarut, E.; Poch, O.; Laudet, V.; Benoit, G.; Lecompte, O.; Rochette-Egly, C. Genome-wide in silico identification of new conserved and functional retinoic acid receptors response elements (directs repeats separated by 5bp). J. Biol. Chem. 2011, 286, 33322-33334. [CrossRef] [PubMed]

187. Quere, R.; Baudet, A.; Cassinat, B.; Bertrand, G.; Marti, J.; Manchon, L.; Piquemal, D.; Chomienne, C.; Commes, T. Pharmacogenomic analysis of acute promyelocytic leukemia cells highlights CYP26 cytochrome metabolism in differential all-trans retinoic acid sensitivity. Blood 2007, 109, 4450-4460. [CrossRef] [PubMed]

188. Pozzi, S.; Rossetti, S.; Bistulfi, G.; Sacchi, N. RAR-mediated epigenetic control of the cytochrome P450 Cyp26a1 in embryocarcinoma cells. Oncogene 2006, 25, 1400-1407. [CrossRef]

189. Kashyap, V.; Gudas, L.J. Epigenetic Regulatory Mechanisms Distinguish Retinoic Acid-mediated Transcriptional Responses in Stem Cells and Fibroblasts. J. Biol. Chem. 2010, 285, 14534-14548. [CrossRef]

190. Delacroix, L.; Moutier, E.; Altobelli, G.; Legras, S.; Poch, O.; Choukrallah, M.-A.; Bertin, I.; Jost, B.; Davidson, I. Cell-Specific Interaction of Retinoic Acid Receptors with Target. Genes in Mouse Embryonic Fibroblasts and Embryonic Stem Cells. Mol. Cell. Biol. 2010, 30, 231-244. [CrossRef]

191. Urvalek, A.M.; Gudas, L.J. Retinoic Acid and Histone Deacetylases Regulate Epigenetic Changes in Embryonic Stem Cells. J. Biol. Chem. 2014, 289, 19519-19530. [CrossRef]

192. Zolfaghari, R.; Cifelli, C.J.; Lieu, S.O.; Chen, Q.; Li, N.-Q.; Ross, A.C. Lipopolysaccharide opposes the induction of CYP26A1 and CYP26B1 gene expression by retinoic acid in the rat liver in vivo. Am. J. Physiol. Gastrointest. Liver Physiol. 2007, 292, G1029-G1036. [CrossRef]

193. Wu, L.; Ross, A.C. Acidic retinoids synergize with vitamin A to enhance retinol uptake and STRA6, LRAT, and CYP26B1 expression in neonatal lung. J. Lipid Res. 2010, 51, 378-387. [CrossRef] [PubMed]

194. Ocaya, P.A.; Elmabsout, A.A.; Olofsson, P.S.; Törmä, H.; Gidlöf, A.C.; Sirsjö, A. CYP26B1 Plays a Major Role in the Regulation of All-trans-Retinoic Acid Metabolism and Signaling in Human Aortic Smooth Muscle Cells. J. Vasc. Res. 2011, 48, 23-30. [CrossRef] [PubMed]

195. Takeuchi, H.; Yokota, A.; Ohoka, Y.; Iwata, M. Cyp26b1 regulates retinoic acid-dependent signals in T cells and its expression is inhibited by transforming growth factor- $\beta$. PLoS ONE 2011, 6, e16089. [CrossRef] [PubMed]

196. Cambray, S.; Arber, C.; Little, G.; Dougalis, A.G.; de Paola, V.; Ungless, M.A.; Li, M.; Rodríguez, T.A. Activin induces cortical interneuron identity and differentiation in embryonic stem cell-derived telencephalic neural precursors. Nat. Commun. 2012, 3, 841. [CrossRef] [PubMed]

197. Kipp, J.L.; Golebiowski, A.; Rodriguez, G.; Demczuk, M.; Kilen, S.M.; Mayo, K.E. Gene Expression Profiling Reveals Cyp26b1 to Be an Activin Regulated Gene Involved in Ovarian Granulosa Cell Proliferation. Endocrinology 2011, 152, 303-312. [CrossRef] [PubMed]

198. Kashimada, K.; Svingen, T.; Feng, C.-W.; Pelosi, E.; Bagheri-Fam, S.; Harley, V.R.; Schlessinger, D.; Bowles, J.; Koopman, P. Antagonistic regulation of Cyp26b1 by transcription factors SOX9/SF1 and FOXL2 during gonadal development in mice. FASEB J. 2011, 25, 3561-3569. [CrossRef]

199. Tay, S.; Dickmann, L.; Dixit, V.; Isoherranen, N. A Comparison of the Roles of Peroxisome Proliferator-Activated Receptor and Retinoic Acid Receptor on CYP26 Regulation. Mol. Pharmacol. 2010, 77, 218-227. [CrossRef]

200. Stoppie, P.; Borgers, M.; Borghgraef, P.; Dillen, L.; Goossens, J.; Sanz, G.; Szel, H.; van Hove, C.; van Nyen, G.; Nobels, G.; et al. R115866 Inhibits All-trans-Retinoic Acid Metabolism and Exerts Retinoidal Effects in Rodents. J. Pharmacol. Exp. Ther. 2000, 293, 304-312.

201. Thatcher, J.E.; Buttrick, B.; Shaffer, S.A.; Shimshoni, J.A.; Goodlett, D.R.; Nelson, W.L.; Isoherranen, N. Substrate Specificity and Ligand Interactions of CYP26A1, the Human Liver Retinoic Acid Hydroxylase. Mol. Pharmacol. 2011, 80, 228-239. [CrossRef] 
202. Laue, K.; Pogoda, H.M.; Daniel, P.-á.; van-áHaeringen, A.; Alanay, Y.; von-áAmeln, S.; Rachwalsk, M.; Morgan, T.; Gray, M.-á.; Breuning, M.-á.; et al. Craniosynostosis and Multiple Skeletal Anomalies in Humans and Zebrafish Result from a Defect in the Localized Degradation of Retinoic Acid. Am. J. Hum. Genet. 2011, 89, 595-606. [CrossRef]

203. Poorendonk, K.M.; Peterson-Maduro, J.; Renn, J.; Trowe, T.; Kranenbarg, S.; Winkler, C.; Schulte-Merker, S. Retinoic acid and Cyp26b1 are critical regulators of osteogenesis in the axial skeleton. Development 2008, 135, 3765-3774. [CrossRef] [PubMed]

204. Roselló-Díez, A.; Arques, C.G.; Delgado, I.; Giovinazzo, G.; Torres, M. Diffusible signals and epigenetic timing cooperate in late proximo-distal limb patterning. Development 2014, 141, 1534-1543. [CrossRef] [PubMed]

205. Nelson, C.H.; Buttrick, B.R.; Isoherranen, N. Therapeutic Potential of the Inhibition of the Retinoic Acid Hydroxylases CYP26A1 and CYP26B1 by Xenobiotics. Curr. Top Med. Chem. 2013, 13, 1402-1428. [CrossRef] [PubMed]

206. Lee, S.-J.; Perera, L.; Coulter, S.J.; Mohrenweiser, H.W.; Jetten, A.; Goldstein, J.A. The discovery of new coding alleles of human CYP26A1 that are potentially defective in the metabolism of all-trans retinoic acid and their assessment in a recombinant cDNA expression system. Pharm. Genom. 2007, 17, 169-180. [CrossRef]

207. Li, H.; Zhang, J.; Chen, S.; Wang, F.; Zhang, T.; Niswander, L. Genetic contribution of retinoid-related genes to neural tube defects. Hum. Mutat. 2018, 39, 550-562. [CrossRef]

208. Rat, E.; Billaut-Laden, I.; Allorge, D.; Lo-Guidice, J.-M.; Tellier, M.; Cauffiez, C.; Jonckheere, N.; van Seuningen, I.; Lhermitte, M.; Romano, A.; et al. Evidence for a functional genetic polymorphism of the human retinoic acid-metabolizing enzyme CYP26A1, an enzyme that may be involved in spina bifida. Birth Defects Res. Part Clin. Mol. Teratol. 2006, 76, 491-498. [CrossRef]

209. Wu, S.-J.; Chen, Y.-J.; Shieh, T.-Y.; Chen, C.-M.; Wang, Y.-Y.; Lee, K.-T.; Lin, Y.-M.; Chien, P.-H.; Chen, P.-H. Association Study between Novel CYP26 Polymorphisms and the Risk of Betel Quid-Related Malignant Oral Disorders. Sci. World J. 2015, 2015, 9. [CrossRef]

210. Chen, P.-H.; Lee, K.-W.; Chen, C.-H.; Shieh, T.-Y.; Ho, P.-S.; Wang, S.-J.; Lee, C.-H.; Yang, S.-F.; Chen, M.-K.; Chiang, S.-L.; et al. CYP26B1 is a novel candidate gene for betel quid-related oral squamous cell carcinoma. Oral Oncol. 2011, 47, 594-600. [CrossRef]

211. Chen, P.-H.; Lee, K.-W.; Hsu, C.-C.; Chen, J.Y.-F.; Wang, Y.-H.; Chen, K.-K.; Wang, H.-M.D.; Huang, H.-W.; Huang, B. Expression of a splice variant of CYP26B1 in betel quid-related oral cancer. Sci. World J. 2014, 2014, 810561. [CrossRef]

212. Chang, J.; Zhong, R.; Tian, J.; Li, J.; Zhai, K.; Ke, J.; Lou, J.; Chen, W.; Zhu, B.; Shen, N.; et al. Exome-wide analyses identify low-frequency variant in CYP26B1 and additional coding variants associated with esophageal squamous cell carcinoma. Nat. Genet. 2018, 50, 338-343. [CrossRef]

213. Meire, F.; Delpierre, I.; Brachet, C.; Roulez, F.; van Nechel, C.; Depasse, F.; Christophe, C.; Menten, B.; de Baere, E. Nonsyndromic bilateral and unilateral optic nerve aplasia: First familial occurrence and potential implication of CYP26A1 and CYP26C1 genes. Mol. Vis. 2011, 17, 2072-2079. [PubMed]

214. Nilsson, O.; Isoherranen, N.; Guo, M.H.; Lui, J.C.; Jee, Y.H.; Guttmann-Bauman, I.; Acerini, C.; Lee, W.; Allikmets, R.; Yanovski, J.A.; et al. Accelerated Skeletal Maturation in Disorders of Retinoic Acid Metabolism: A Case Report and Focused Review of the Literature. Horm. Metab. Res. 2016, 48, 737-744. [CrossRef] [PubMed]

215. Elmabsout, A.A.; Kumawat, A.; Saenz-Méndez, P.; Krivospitskaya, O.; Sävenstrand, H.; Olofsson, P.S.; Eriksson, L.A.; Strid, Å.; Valen, G.; Törmä, H.; et al. Cloning and Functional Studies of a Splice Variant of CYP26B1 Expressed in Vascular Cells. PLoS ONE 2012, 7, e36839. [CrossRef] [PubMed]

216. Krivospitskaya, O.; Elmabsout, A.A.; Sundman, E.; Söderström, Å.L.; Ovchinnikova, O.; Gidlöf, C.A.; Scherbak, N.; Norata, G.D.; Samnegård, A.; Törmä, H.; et al. A CYP26B1 Polymorphism Enhances Retinoic Acid Catabolism and May Aggravate Atherosclerosis. Mol. Med. 2012, 18, 712-718. [CrossRef] [PubMed]

217. Fransén, K.; Franzén, P.; Magnuson, A.; Elmabsout, A.A.; Nyhlin, N.; Wickbom, A.; Curman, B.; Törkvist, L.; D'Amato, M.; Bohr, J.; et al. Polymorphism in the Retinoic Acid Metabolizing Enzyme CYP26B1 and the Development of Crohn's Disease. PLoS ONE 2013, 8, e72739. [CrossRef] [PubMed]

218. Morton, J.E.V.; Frentz, S.; Morgan, T.; Sutherland-Smith, A.J.; Robertson, S.P. Biallelic mutations in CYP26B1: A differential diagnosis for Pfeiffer and Antley-Bixler syndromes. Am. J. Med. Genet. Part 2016, 170, 2706-2710. [CrossRef] [PubMed] 
219. Wen, J.; Lopes, F.; Soares, G.; Farrell, S.A.; Nelson, C.; Qiao, Y.; Martel, S.; Badukke, C.; Bessa, C.; Ylstra, B.; et al. Phenotypic and functional consequences of haploinsufficiency of genes from exocyst and retinoic acid pathway due to a recurrent microdeletion of 2p13.2. Orphanet J. Rare Dis. 2013, 8, 100. [CrossRef]

220. Adachi, M.; Tachibana, K.; Asakura, Y.; Yamamoto, T.; Hanaki, K.; Oka, A. Compound heterozygous mutations of cytochrome P450 oxidoreductase gene (POR) in two patients with Antley-Bixler syndrome. Am. J. Med. Genet. Part 2004, 128, 333-339. [CrossRef]

221. Flück, C.E.; Tajima, T.; Pandey, A.V.; Arlt, W.; Okuhara, K.; Verge, C.F.; Jabs, E.W.; Mendonça, B.B.; Fujieda, K.; Miller, W.L. Mutant P450 oxidoreductase causes disordered steroidogenesis with and without Antley-Bixler syndrome. Nat. Genet. 2004, 36, 228-230. [CrossRef]

222. Fukami, M.; Ogata, T. Cytochrome P450 oxidoreductase deficiency: Rare congenital disorder leading to skeletal malformations and steroidogenic defects. Pediatrics Int. 2014, 56, 805-808. [CrossRef]

223. Montalbano, A.; Juergensen, L.; Roeth, R.; Weiss, B.; Fukami, M.; Fricke-Otto, S.; Binder, G.; Ogata, T.; Decker, E.; Nuernberg, G.; et al. Retinoic acid catabolizing enzyme CYP26C1 is a genetic modifier in SHOX deficiency. EMBO Mol. Med. 2016, 8, 1455-1469. [CrossRef] [PubMed]

224. Montalbano, A.; Juergensen, L.; Fukami, M.; Thiel, C.T.; Hauer, N.H.; Roeth, R.; Weiss, B.; Naiki, Y.; Ogata, T.; Hassel, D.; et al. Functional missense and splicing variants in the retinoic acid catabolizing enzyme CYP26C1 in idiopathic short stature. Eur. J. Hum. Genet. 2018, 26, 1113-1120. [CrossRef] [PubMed]

225. Slavotinek, A.M.; Mehrotra, P.; Nazarenko, I.; Tang, P.L.-F.; Lao, R.; Cameron, D.; Li, B.; Chu, C.; Chou, C.; Marqueling, A.L.; et al. Focal facial dermal dysplasia, type IV, is caused by mutations in CYP26C1. Hum. Mol. Genet. 2012, 22, 696-703. [CrossRef] [PubMed]

226. Uehara, M.; Yashiro, K.; Takaoka, K.; Yamamoto, M.; Hamada, H. Removal of maternal retinoic acid by embryonic CYP26 is required for correct Nodal expression during early embryonic patterning. Genes Dev. 2009, 23, 1689-1698. [CrossRef] [PubMed]

227. Ivins, S.; Lammerts van Beuren, K.; Roberts, C.; James, C.; Lindsay, E.; Baldini, A.; Ataliotis, P.; Scambler, P.J. Microarray analysis detects differentially expressed genes in the pharyngeal region of mice lacking Tbx1. Dev. Biol. 2005, 285, 554-569. [CrossRef] [PubMed]

228. Otto, D.M.E.; Henderson, C.J.; Carrie, D.; Davey, M.; Gundersen, T.E.; Blomhoff, R.; Adams, R.H.; Tickle, C.; Wolf, C.R. Identification of Novel Roles of the Cytochrome P450 System in Early Embryogenesis: Effects on Vasculogenesis and Retinoic Acid Homeostasis. Mol. Cell. Biol. 2003, 23, 6103-6116. [CrossRef]

229. Ribes, V.; le Roux, I.; Rhinn, M.; Schuhbaur, B.; Dolle, P. Early mouse caudal development relies on crosstalk between retinoic acid, Shh and Fgf signalling pathways. Development 2009, 136, 665-676. [CrossRef]

230. Shen, A.L.; O'Leary, K.A.; Kasper, C.B. Association of Multiple Developmental Defects and Embryonic Lethality with Loss of Microsomal NADPH-Cytochrome P450 Oxidoreductase. J. Biol. Chem. 2002, 277, 6536-6541. [CrossRef]

231. Abu-Abed, S.; Dolle, P.; Metzger, D.; Beckett, B.; Chambon, P.; Petkovich, M. The retinoic acid-metabolizing enzyme, CYP26A1, is essential for normal hindbrain patterning, vertebral identity, and development of posterior structures. Genes Dev. 2001, 15, 226-240. [CrossRef]

232. Yoshikawa, Y.; Fujimori, T.; McMahon, A.P.; Takada, S. Evidence That Absence ofWnt-3aSignaling Promotes Neuralization Instead of Paraxial Mesoderm Development in the Mouse. Dev. Biol. 1997, 183, $234-242$. [CrossRef]

233. Yamaguchi, T.P.; Takada, S.; Yoshikawa, Y.; Wu, N.; McMahon, A.P. T (Brachyury) is a direct target of Wnt3a during paraxial mesoderm specification. Genes Dev. 1999, 13, 3185-3190. [CrossRef] [PubMed]

234. Takada, S.; Stark, K.L.; Shea, M.J.; Vassileva, G.; McMahon, J.A.; McMahon, A.P. Wnt-3a regulates somite and tailbud formation in the mouse embryo. Genes Dev. 1994, 8, 174-189. [CrossRef] [PubMed]

235. Wilkinson, D.G.; Bhatt, S.; Herrmann, B.G. Expression pattern of the mouse T gene and its role in mesoderm formation. Nature 1990, 343, 657-659. [CrossRef] [PubMed]

236. Abu-Abed, S.; Dollé, P.; Metzger, D.; Wood, C.; MacLean, G.; Chambon, P.; Petkovich, M. Developing with lethal RA levels: Genetic ablation of Rarg can restore the viability of mice lacking Cyp26a1. Development 2003, 130, 1449-1459. [CrossRef]

237. Abu-Abed, S.S.; Beckett, B.R.; Chiba, H.; Chithalen, J.V.; Jones, G.; Metzger, D.; Chambon, P.; Petkovich, M. Mouse P450RAI (CYP26) Expression and Retinoic Acid-inducible Retinoic Acid Metabolism in F9 Cells Are Regulated by Retinoic Acid Receptor $\gamma$ and Retinoid X Receptor $\alpha$. J. Biol. Chem. 1998, 273, 2409-2415. [CrossRef] 
238. Ribes, V.; Fraulob, V.; Petkovich, M.; Dollé, P. The oxidizing enzyme CYP26a1 tightly regulates the availability of retinoic acid in the gastrulating mouse embryo to ensure proper head development and vasculogenesis. Dev. Dyn. 2007, 236, 644-653. [CrossRef] [PubMed]

239. Emoto, Y.; Wada, H.; Okamoto, H.; Kudo, A.; Imai, Y. Retinoic acid-metabolizing enzyme Cyp26a1 is essential for determining territories of hindbrain and spinal cord in zebrafish. Dev. Biol. 2005, 278, 415-427. [CrossRef] [PubMed]

240. Uehara, M.; Yashiro, K.; Mamiya, S.; Nishino, J.; Chambon, P.; Dolle, P.; Sakai, Y. CYP26A1 and CYP26C1 cooperatively regulate anterior-posterior patterning of the developing brain and the production of migratory cranial neural crest cells in the mouse. Dev. Biol. 2007, 302, 399-411. [CrossRef]

241. Ribes, V.; Otto, D.M.E.; Dickmann, L.; Schmidt, K.; Schuhbaur, B.; Henderson, C.; Blomhoff, R.; Wolf, C.R.; Tickle, C.; Dollé, P. Rescue of cytochrome P450 oxidoreductase (Por) mouse mutants reveals functions in vasculogenesis, brain and limb patterning linked to retinoic acid homeostasis. Dev. Biol. 2007, 303, 66-81. [CrossRef]

242. Dranse, H.J.; Sampaio, A.V.; Petkovich, M.; Underhill, T.M. Genetic deletion of Cyp26b1 negatively impacts limb skeletogenesis by inhibiting chondrogenesis. J. Cell Sci. 2011, 124, 2723-2734. [CrossRef] [PubMed]

243. Pennimpede, T.; Cameron, D.A.; MacLean, G.A.; Petkovich, M. Analysis of Cyp26b1/Rarg compound-null mice reveals two genetically separable effects of retinoic acid on limb outgrowth. Dev. Biol. 2010, 339, 179-186. [CrossRef]

244. Probst, S.; Kraemer, C.; Demougin, P.; Sheth, R.; Martin, G.R.; Shiratori, H.; Hamada, H.; Iber, D.; Zeller, R.; Zuniga, A.E. SHH propagates distal limb bud development by enhancing CYP26B1-mediated retinoic acid clearance via AER-FGF signalling. Development 2011, 138, 1913-1923. [CrossRef] [PubMed]

245. Yashiro, K.; Zhao, X.; Uehara, M.; Yamashita, K.; Nishijima, M.; Nishino, J.; Saijoh, Y.; Sakai, Y.; Hamada, H. Regulation of Retinoic Acid Distribution Is Required for Proximodistal Patterning and Outgrowth of the Developing Mouse Limb. Dev. Cell 2004, 6, 411-422. [CrossRef]

246. MacLean, G.; Doll, P.; Petkovich, M. Genetic disruption of CYP26B1 severely affects development of neural crest derived head structures, but does not compromise hindbrain patterning. Dev. Dyn. 2009, 238, 732-745. [CrossRef] [PubMed]

247. Okano, J.; Kimura, W.; Papaionnou, V.E.; Miura, N.; Yamada, G.; Shiota, K.; Sakai, Y. The regulation of endogenous retinoic acid level through CYP26B1 is required for elevation of palatal shelves. Dev. Dyn. 2012, 241, 1744-1756. [CrossRef] [PubMed]

248. Reijntjes, S.; Rodaway, A.; Maden, M. The retinoic acid metabolising gene, CYP26B1, patterns the cartilaginous cranial neural crest in zebrafish. Int. J. Dev. Biol. 2007, 51, 351-360. [CrossRef] [PubMed]

249. Kudoh, T.; Wilson, S.W.; Dawid, I.B. Distinct roles for Fgf, Wnt and retinoic acid in posteriorizing the neural ectoderm. Development 2002, 129, 4335-4346.

250. Hernandez, R.E.; Putzke, A.P.; Myers, J.P.; Margaretha, L.; Moens, C.B. Cyp26 enzymes generate the retinoic acid response pattern necessary for hindbrain development. Development 2007, 134, 177-187. [CrossRef]

251. Rydeen, A.B.; Waxman, J.S. Cyp26 enzymes are required to balance the cardiac and vascular lineages within the anterior lateral plate mesoderm. Development 2014, 141, 1638-1648. [CrossRef]

252. Okuda, Y.; Ogura, E.; Kondoh, H.; Kamachi, Y. B1 SOX Coordinate Cell Specification with Patterning and Morphogenesis in the Early Zebrafish Embryo. PLoS Genet. 2010, 6, e1000936. [CrossRef]

253. Chen, C.; Stedman, A.; Havis, E.; Anselme, I.; Onichtchouk, D.; Giudicelli, F.; Schneider-Maunoury, S. Initiation of cyp26a1 Expression in the Zebrafish Anterior Neural Plate by a Novel Cis-Acting Element. PLoS ONE 2016, 11, e0150639. [CrossRef] [PubMed]

254. Maurus, D.; Harris, W.A. Zic-associated holoprosencephaly: Zebrafish Zic1 controls midline formation and forebrain patterning by regulating Nodal, Hedgehog, and retinoic acid signaling. Genes Dev. 2009, 23, 1461-1473. [CrossRef] [PubMed]

255. El-Jaick, K.B.; Powers, S.E.; Bartholin, L.; Myers, K.R.; Hahn, J.; Orioli, I.M.; Ouspenskaia, M.; Lacbawan, F.; Roessler, E.; Wotton, D.; et al. Functional analysis of mutations in TGIF associated with holoprosencephaly. Mol. Genet. Metab. 2007, 90, 97-111. [CrossRef] [PubMed]

256. Gripp, K.W.; Wotton, D.; Edwards, M.C.; Roessler, E.; Ades, L.; Meinecke, P.; Richieri-Costa, A.; Zackai, E.H.; Massagué, J.; Muenke, M.; et al. Mutations in TGIF cause holoprosencephaly and link NODAL signalling to human neural axis determination. Nat. Genet. 2000, 25, 205-208. [CrossRef] 
257. Aguilella, C.; Dubourg, C.; Attia-Sobol, J.; Vigneron, J.; Blayau, M.; Pasquier, L.; Lazaro, L.; Odent, S.; David, V. Molecular screening of the TGIF gene in holoprosencephaly: Identification of two novel mutations. Hum. Genet. 2003, 112, 131-134. [CrossRef]

258. Kantaputra, P.N.; Limwongse, C.; Tochareontanaphol, C.; Mutirangura, A.; Mevatee, U.; Praphanphoj, V. Contiguous gene syndrome of holoprosencephaly and hypotrichosis simplex: Association with an 18p11.3 deletion. Am. J. Med. Genet. Part 2006, 140, 2598-2602. [CrossRef]

259. Chen, M.; Kuo, S.-J.; Liu, C.-S.; Chen, W.-L.; Ko, T.-M.; Chen, T.-H.; Chang, S.-P.; Huang, C.-H.; Chang, Y.-Y.; Wang, B.-T. A novel heterozygous missense mutation 377T $>$ C (V126A) of TGIF gene in a family segregated with holoprosencephaly and moyamoya disease. Prenat. Diagn. 2006, 26, 226-230. [CrossRef]

260. Wallis, D.; Muenke, M. Mutations in holoprosencephaly. Hum. Mutat. 2000, 16, 99-108. [CrossRef]

261. Ferrand, N.; Demange, C.; Prunier, C.; Seo, S.R.; Atfi, A. A mechanism for mutational inactivation of the homeodomain protein TGIF in holoprosencephaly. FASEB J. 2007, 21, 488-496. [CrossRef]

262. Bartholin, L.; Powers, S.E.; Melhuish, T.A.; Lasse, S.; Weinstein, M.; Wotton, D. TGIF Inhibits Retinoid Signaling. Mol. Cell. Biol. 2006, 26, 990-1001. [CrossRef]

263. Jin, J.-Z.; Gu, S.; McKinney, P.; Ding, J. Expression and functional analysis of Tgif during mouse midline development. Dev. Dyn. 2006, 235, 547-553. [CrossRef] [PubMed]

264. Shen, J.; Walsh, C.A. Targeted Disruption of Tgif, the Mouse Ortholog of a Human Holoprosencephaly Gene, Does Not. Result in Holoprosencephaly in Mice. Mol. Cell. Biol. 2005, 25, 3639-3647. [CrossRef] [PubMed]

265. Kuang, C.; Xiao, Y.; Yang, L.; Chen, Q.; Wang, Z.; Conway, S.J.; Chen, Y. Intragenic deletion of Tgif causes defectsin brain development. Hum. Mol. Genet. 2006, 15, 3508-3519. [CrossRef] [PubMed]

266. Gongal, P.A.; Waskiewicz, A.J. Zebrafish model of holoprosencephaly demonstrates a key role for TGIF in regulating retinoic acid metabolism. Hum. Mol. Genet. 2007, 17, 525-538. [CrossRef]

267. Bertolino, E.; Reimund, B.; Wildt-Perinic, D.; Clerc, R.G. A Novel Homeobox Protein Which Recognizes a TGT Core and Functionally Interferes with a Retinoid-responsive Motif. J. Biol. Chem. 1995, 270, 31178-31188. [CrossRef]

268. Ribes, V.; Wang, Z.; Dollé, P.; Niederreither, K. Retinaldehyde dehydrogenase 2 (RALDH2)-mediated retinoic acid synthesis regulates early mouse embryonic forebrain development by controlling FGF and sonic hedgehog signaling. Development 2006, 133, 351-361. [CrossRef]

269. Halilagic, A.; Ribes, V.; Ghyselinck, N.B.; Zile, M.H.; Dollé, P.; Studer, M. Retinoids control anterior and dorsal properties in the developing forebrain. Dev. Biol. 2007, 303, 362-375. [CrossRef]

270. Molotkova, N.; Molotkov, A.; Duester, G. Role of retinoic acid during forebrain development begins late when Raldh3 generates retinoic acid in the ventral subventricular zone. Dev. Biol. 2007, 303, 601-610. [CrossRef]

271. Gupta, S.; Sen, J. Retinoic acid signaling regulates development of the dorsal forebrain midline and the choroid plexus in the chick. Development 2015, 142, 1293-1298. [CrossRef]

272. Mallo, M. Reassessing the Role of Hox Genes during Vertebrate Development and Evolution. Trends Genet. 2018, 34, 209-217. [CrossRef]

273. Lescroat, F.; Zaffran, S. Hox and Tale transcription factors in heart development and disease. Int. J. Dev. Biol. 2018, 62, 837-846. [CrossRef] [PubMed]

274. Roux, M.; Zaffran, S. Hox Genes in Cardiovascular Development and Diseases. J. Dev. Biol. 2016, 4, 14. [CrossRef] [PubMed]

275. Parker, H.J.; Bronner, M.E.; Krumlauf, R. The vertebrate Hox gene regulatory network for hindbrain segmentation: Evolution and diversification. Bioessays 2016, 38, 526-538. [CrossRef] [PubMed]

276. Krumlauf, R. Chapter Thirty-Four-Hox Genes and the Hindbrain: A Study in Segments. In Current Topics in Developmental Biology; Wassarman, P.M., Ed.; Academic Press: Cambridge, MA, USA, 2016; pp. 581-596.

277. Parker, H.J.; Pushel, I.; Krumlauf, R. Coupling the roles of Hox genes to regulatory networks patterning cranial neural crest. Dev. Biol. 2018, 444, S67-S78. [CrossRef]

278. Parker, H.J.; Krumlauf, R. Segmental arithmetic: Summing up the Hox gene regulatory network for hindbrain development in chordates. Wiley Interdiscip. Rev. Dev. Biol. 2017, 6, e286. [CrossRef]

279. Alexander, T.; Nolte, C.; Krumlauf, R. Hox Genes and Segmentation of the Hindbrain and Axial Skeleton. Annu. Rev. Cell Dev. Biol. 2009, 25, 431-456. [CrossRef]

280. Tümpel, S.; Wiedemann, L.M.; Krumlauf, R. Chapter 8 Hox Genes and Segmentation of the Vertebrate Hindbrain. In Current Topics in Developmental Biology; Academic Press: Cambridge, MA, USA, 2019; pp. 103-137. 
281. Prin, F.; Serpente, P.; Itasaki, N.; Gould, A.P. Hox proteins drive cell segregation and non-autonomous apical remodelling during hindbrain segmentation. Development 2014, 141, 1492-1502. [CrossRef]

282. Shimozono, S.; Iimura, T.; Kitaguchi, T.; Higashijima, S.-I.; Miyawaki, A. Visualization of an endogenous retinoic acid gradient across embryonic development. Nature 2013, 496, 363. [CrossRef]

283. Maves, L.; Kimmel, C.B. Dynamic and sequential patterning of the zebrafish posterior hindbrain by retinoic acid. Dev. Biol. 2005, 285, 593-605. [CrossRef]

284. Sirbu, I.O.; Gresh, L.; Barra, J.; Duester, G. Shifting boundaries of retinoic acid activity control hindbrain segmental gene expression. Development 2005, 132, 2611-2622. [CrossRef]

285. Shiotsugu, J.; Katsuyama, Y.; Arima, K.; Baxter, A.; Koide, T.; Song, J.; Chandraratna, R.A.S.; Blumberg, B. Multiple points of interaction between retinoic acid and FGF signaling during embryonic axis formation. Development 2004, 131, 2653-2667. [CrossRef] [PubMed]

286. Schilling, T.F.; Sosnik, J.; Nie, Q. Visualizing retinoic acid morphogen gradients. Methods Cell Biol. 2016, 133, 139-163. [PubMed]

287. Schilling, T.F.; Nie, Q.; Lander, A.D. Dynamics and precision in retinoic acid morphogen gradients. Curr. Opin. Genet. Dev. 2012, 22, 562-569. [CrossRef]

288. Labalette, C.; Wassef, M.A.; Desmarquet-Trin, C.; Bouchoucha, Y.X.; Men, J.L.; Charnay, P.; Gilardi-Hebenstreit, P. Molecular dissection of segment formation in the developing hindbrain. Development 2015, 142, 185-195. [CrossRef] [PubMed]

289. Zhang, L.; Radtke, K.; Zheng, L.; Cai, A.Q.; Schilling, T.F.; Nie, Q. Noise drives sharpening of gene expression boundaries in the zebrafish hindbrain. Mol. Syst. Biol. 2012, 8, 613. [CrossRef] [PubMed]

290. Niethamer, T.K.; Bush, J.Q. Getting direction(s): The Eph/ephrin signaling system in cell positioning. Dev. Biol. 2019, 447, 42-57. [CrossRef]

291. Cayuso, J.; Xu, Q.; Wilkinson, D.G. Mechanisms of boundary formation by Eph receptor and ephrin signaling. Dev. Biol. 2015, 401, 122-131. [CrossRef]

292. Kitazawa, T.; Rijli, F.M. Integrating into the Rhombomere Community across the Border. Dev. Cell 2018, 45, 546-548. [CrossRef]

293. Addison, M.; Xu, Q.; Cayuso, J.; Wilkinson, D.G. Cell Identity Switching Regulated by Retinoic Acid Signaling Maintains Homogeneous Segments in the Hindbrain. Dev. Cell 2018, 45, 606-620. [CrossRef]

294. Wilkinson, D.G. Establishing sharp and homogeneous segments in the hindbrain. F1000Research $2018,7$. [CrossRef]

295. Pourquié, O. Vertebrate Segmentation: From Cyclic Gene Networks to Scoliosis. Cell 2011, 145, 650-663. [CrossRef] [PubMed]

296. Aulehla, A.; Pourquié, O. Signaling Gradients during Paraxial Mesoderm Development. Cold Spring Harb. Perspect. Biol. 2010, 2, a000869. [CrossRef] [PubMed]

297. Sirbu, I.O.; Duester, G. Retinoic-acid signalling in node ectoderm and posterior neural plate directs left-right patterning of somitic mesoderm. Nat. Cell Biol. 2006, 8, 271-277. [CrossRef] [PubMed]

298. El Shahawy, M.; Reibring, C.-G.; Hallberg, K.; Neben, C.L.; Marangoni, P.; Harfe, B.D.; Klein, O.D.; Linde, A.; Gritli-Linde, A. Sonic Hedgehog Signaling Is Required for Cyp26 Expression during Embryonic Development. Int. J. Mol. Sci. 2019, 20, 2275. [CrossRef]

299. Wilson, V.; Olivera-Martinez, I.; Storey, K.G. Stem cells, signals and vertebrate body axis extension. Development 2009, 136, 1591-1604. [CrossRef]

300. Tzouanacou, E.; Wegener, A.; Wymeersch, F.J.; Wilson, V.; Nicolas, J.-F. Redefining the Progression of Lineage Segregations during Mammalian Embryogenesis by Clonal Analysis. Dev. Cell 2009, 17, 365-376. [CrossRef]

301. Henrique, D.; Abranches, E.; Verrier, L.; Storey, K.G. Neuromesodermal progenitors and the making of the spinal cord. Development 2015, 142, 2864-2875. [CrossRef]

302. Kimelman, D. Chapter Twenty-Nine-Tales of Tails (and Trunks): Forming the Posterior Body in Vertebrate Embryos. In Current Topics in Developmental Biology; Wassarman, P.M., Ed.; Academic Press: Cambridge, MA, USA, 2016; pp. 517-536.

303. Attardi, A.; Fulton, T.; Florescu, M.; Shah, G.; Muresan, L.; Lenz, M.O.; Lancaster, C.; Huisken, J.; van Oudenaarden, A.; Steventon, B. Neuromesodermal progenitors are a conserved source of spinal cord with divergent growth dynamics. Development 2018, 145, dev166728. [CrossRef]

304. Cambray, N.; Wilson, V. Axial progenitors with extensive potency are localised to the mouse chordoneural hinge. Development 2002, 129, 4855-4866. 
305. Cambray, N.; Wilson, V. Two distinct sources for a population of maturing axial progenitors. Development 2007, 134, 2829-2840. [CrossRef]

306. Delfino-Machín, M.; Lunn, J.S.; Breitkreuz, D.N.; Akai, J.; Storey, K.G. Specification and maintenance of the spinal cord stem zone. Development 2005, 132, 4273-4283. [CrossRef] [PubMed]

307. Olivera-Martinez, I.; Harada, H.; Halley, P.A.; Storey, K.G. Loss of FGF-Dependent Mesoderm Identity and Rise of Endogenous Retinoid Signalling Determine Cessation of Body Axis Elongation. PLoS Biol. 2012, 10, e1001415. [CrossRef] [PubMed]

308. Kondoh, H.; Takemoto, T. Axial stem cells deriving both posterior neural and mesodermal tissues during gastrulation. Curr. Opin. Genet. Dev. 2012, 22, 374-380. [CrossRef] [PubMed]

309. Kondoh, H.; Takada, S.; Takemoto, T. Axial level-dependent molecular and cellular mechanisms underlying the genesis of the embryonic neural plate. Dev. Growth Differ. 2016, 58, 427-436. [CrossRef]

310. Del Corral, R.D.; Olivera-Martinez, I.; Goriely, A.; Gale, E.; Maden, M.; Storey, K. Opposing FGF and Retinoid Pathways Control. Ventral Neural Pattern, Neuronal Differentiation, and Segmentation during Body Axis Extension. Neuron 2003, 40, 65-79. [CrossRef]

311. Martin, B.L.; Kimelman, D. Brachyury establishes the embryonic mesodermal progenitor niche. Genes Dev. 2010, 24, 2778-2783. [CrossRef]

312. Martin, B.L.; Kimelman, D. Canonical Wnt Signaling Dynamically Controls Multiple Stem Cell Fate Decisions during Vertebrate Body Formation. Dev. Cell 2012, 22, 223-232. [CrossRef]

313. Garriock, R.J.; Chalamalasetty, R.B.; Kennedy, M.W.; Canizales, L.C.; Lewandoski, M.; Yamaguchi, T.P. Lineage tracing of neuromesodermal progenitors reveals novel Wnt-dependent roles in trunk progenitor cell maintenance and differentiation. Development 2015, 142, 1628-1638. [CrossRef]

314. Savory, J.G.A.; Bouchard, N.; Pierre, V.; Rijli, F.M.; de Repentigny, Y.; Kothary, R.; Lohnes, D. Cdx2 regulation of posterior development through non-Hox targets. Development 2009, 136, 4099-4110. [CrossRef]

315. Young, T.; Rowland, J.E.; van de Ven, C.; Bialecka, M.; Novoa, A.; Carapuco, M.; van Nes, J.; de Graaff, W.; Duluc, I.; Freund, J.-N.; et al. Cdx and Hox Genes Differentially Regulate Posterior Axial Growth in Mammalian Embryos. Dev. Cell 2009, 17, 516-526. [CrossRef]

316. Young, T.; Deschamps, J. Chapter 8 Hox, Cdx, and Anteroposterior Patterning in the Mouse Embryo. In Current Topics in Developmental Biology; Academic Press: Cambridge, MA, USA, 2009; pp. 235-255.

317. Koch, F.; Scholze, M.; Wittler, L.; Schifferl, D.; Sudheer, S.; Grote, P.; Timmermann, B.; Macura, K.; Herrmann, B.G. Antagonistic Activities of Sox2 and Brachyury Control. the Fate Choice of Neuro-Mesodermal Progenitors. Dev. Cell 2017, 42, 514-526. [CrossRef] [PubMed]

318. Cunningham, T.J.; Duester, G. Mechanisms of retinoic acid signalling and its roles in organ and limb development. Nat. Rev. Mol. Cell Biol. 2015, 16, 110-123. [CrossRef] [PubMed]

319. Cunningham, T.J.; Colas, A.; Duester, G. Early molecular events during retinoic acid induced differentiation of neuromesodermal progenitors. Biol. Open 2016, 5, 1821-1833. [CrossRef] [PubMed]

320. Goto, H.; Kimmey, S.C.; Row, R.H.; Matus, D.Q.; Martin, B.L. FGF and canonical Wnt signaling cooperate to induce paraxial mesoderm from tailbud neuromesodermal progenitors through regulation of a two-step epithelial to mesenchymal transition. Development 2017, 144, 1412-1424. [CrossRef] [PubMed]

321. Neijts, R.; Amin, S.; van Rooijen, C.; Deschamps, J. Cdx is crucial for the timing mechanism driving colinear Hox activation and defines a trunk segment in the Hox cluster topology. Dev. Biol. 2017, 422, 146-154. [CrossRef] [PubMed]

322. Martin, B.L. Factors that coordinate mesoderm specification from neuromesodermal progenitors with segmentation during vertebrate axial extension. Semin. Cell Dev. Biol. 2016, 49, 59-67. [CrossRef]

323. Steventon, B.; Martinez Arias, A. Evo-engineering and the cellular and molecular origins of the vertebrate spinal cord. Dev. Biol. 2017, 432, 3-13. [CrossRef]

324. Diez del Corral, R.; Morales, A.V. The Multiple Roles of FGF Signaling in the Developing Spinal Cord. Front. Cell Dev. Biol. 2017, 5, 58. [CrossRef]

325. Wymeersch, F.J.; Skylaki, S.; Huang, Y.; Watson, J.A.; Economou, C.; Marek-Johnston, C.; Tomlinson, S.R.; Wilson, V. Transcriptionally dynamic progenitor populations organised around a stable niche drive axial patterning. Development 2019, 146, dev168161. [CrossRef]

326. Gouti, M.; Tsakiridis, A.; Wymeersch, F.J.; Huang, Y.; Kleinjung, J.; Wilson, V.; Briscoe, J. In Vitro Generation of Neuromesodermal Progenitors Reveals Distinct Roles for Wnt Signalling in the Specification of Spinal Cord and Paraxial Mesoderm Identity. PLoS Biol. 2014, 12, e1001937. [CrossRef] 
327. Turner, D.A.; Hayward, P.C.; Baillie-Johnson, P.; Rué, P.; Broome, R.; Faunes, F.; Arias, A.M. Wnt/ $\beta$-catenin and FGF signalling direct the specification and maintenance of a neuromesodermal axial progenitor in ensembles of mouse embryonic stem cells. Development 2014, 141, 4243-4253. [CrossRef] [PubMed]

328. Tsakiridis, A.; Huang, Y.; Blin, G.; Skylaki, S.; Wymeersch, F.; Osorno, R.; Economou, C.; Karagianni, E.; Zhao, S.; Lowell, S.; et al. Distinct Wnt-driven primitive streak-like populations reflect in vivo lineage precursors. Development 2014, 141, 1209-1221. [CrossRef] [PubMed]

329. Lippmann, E.S.; Williams, C.E.; Ruhl, D.A.; Estevez-Silva, M.C.; Chapman, E.R.; Coon, J.J.; Ashton, S.R. Deterministic HOX patterning in human pluripotent stem cell-derived neuroectoderm. Stem Cell Rep. 2015, 4, 632-644. [CrossRef] [PubMed]

330. Gouti, M.; Delile, J.; Stamataki, D.; Wymeersch, F.J.; Huang, Y.; Kleinjung, J.; Wilson, V.; Briscoe, J. A Gene Regulatory Network Balances Neural and Mesoderm Specification during Vertebrate Trunk Development. Dev. Cell 2017, 41, 243-261. [CrossRef] [PubMed]

331. Edri, S.; Hayward, P.; Jawaid, W.; Arias, A.M. Neuro-mesodermal progenitors (NMPs): A comparative study between pluripotent stem cells and embryo-derived populations. Development 2019, 146, dev180190. [CrossRef] [PubMed]

332. Edri, S.; Hayward, P.; Baillie-Johnson, P.; Steventon, B.J.; Arias, A.M. An epiblast stem cell-derived multipotent progenitor population for axial extension. Development 2019, 146, dev168187. [CrossRef]

333. Janesick, A.; Nguyen, T.T.L.; Aisaki, K.-I.; Igarashi, K.; Kitajima, S.; Chandraratna, R.A.S.; Kanno, J.; Blumberg, B. Active repression by RAR $\gamma$ signaling is required for vertebrate axial elongation. Development 2014, 141, 2260-2270. [CrossRef]

334. Cooper, K.L.; Hu, J.K.-H.; Berge, D.T.; Fernandez-Teran, M.; Ros, M.A.; Tabin, C.J. Initiation of Proximal-Distal Patterning in the Vertebrate Limb by Signals and Growth. Science 2011, 332, 1083-1086. [CrossRef]

335. Zuniga, A. Next generation limb development and evolution: Old questions, new perspectives. Development 2015, 142, 3810-3820. [CrossRef]

336. Saiz-Lopez, P.; Chinnaiya, K.; Campa, V.M.; Delgado, I.; Ros, M.A.; Towers, M. An intrinsic timer specifies distal structures of the vertebrate limb. Nat. Commun. 2015, 6, 8108. [CrossRef]

337. Laue, K.; Janicke, M.; Plaster, N.; Sonntag, C.; Hammerschmidt, M. Restriction of retinoic acid activity by Cyp26b1 is required for proper timing and patterning of osteogenesis during zebrafish development. Development 2008, 135, 3775-3787. [CrossRef] [PubMed]

338. Jeradi, S.; Hammerschmidt, M. Retinoic acid-induced premature osteoblast-to-preosteocyte transitioning has multiple effects on calvarial development. Development 2016, 143, 1205-1216. [CrossRef] [PubMed]

339. Pogoda, H.-M.; Riedl-Quinkertz, I.; Löhr, H.; Waxman, J.S.; Dale, R.M.; Topczewski, J.; Schulte-Merker, S.; Hammerschmidt, M. Direct activation of chordoblasts by retinoic acid is required for segmented centra mineralization during zebrafish spine development. Development 2018, 145, dev159418. [CrossRef] [PubMed]

340. Hutson, M.R.; Kirby, M.L. Model systems for the study of heart development and disease: Cardiac neural crest and conotruncal malformations. Semin. Cell Dev. Biol. 2007, 18, 101-110. [CrossRef] [PubMed]

341. Plein, A.; Fantin, A.; Ruhrberg, C. Chapter Six-Neural Crest Cells in Cardiovascular Development. In Current Topics in Developmental Biology; Trainor, P.A., Ed.; Academic Press: Cambridge, MA, USA, 2015; pp. 183-200.

342. Diogo, R.; Kelly, R.G.; Christiaen, L.; Levine, M.; Ziermann, J.M.; Molnar, J.L.; Noden, D.M.; Tzahor, E. A new heart for a new head in vertebrate cardiopharyngeal evolution. Nature 2015, 520, 466. [CrossRef]

343. Kelly, R.G.; Buckingham, M.E.; Moorman, A.F. Heart Fields and Cardiac Morphogenesis. Cold Spring Harb. Perspect. Med. 2014, 4, a015750. [CrossRef]

344. McGurk, P.D.; Swartz, M.E.; Chen, J.W.; Galloway, J.L.; Eberhart, J.K. In vivo zebrafish morphogenesis shows Cyp26b1 promotes tendon condensation and musculoskeletal patterning in the embryonic jaw. PLoS Genet. 2017, 13, e1007112. [CrossRef]

345. El Shahawy, M.; Reibring, C.-G.; Neben, C.L.; Hallberg, K.; Marangoni, P.; Harfe, B.D.; Klein, O.D.; Linde, A.; Gritli-Linde, A. Cell fate specification in the lingual epithelium is controlled by antagonistic activities of Sonic hedgehog and retinoic acid. PLoS Genet. 2017, 13, e1006914. [CrossRef]

346. Hasten, E.; Morrow, B.E. Tbx1 and Foxi3 genetically interact in the pharyngeal pouch endoderm in a mouse model for 22q11.2 deletion syndrome. PLoS Genet. 2019, 15, e1008301. [CrossRef]

347. Rydeen, A.B.; Waxman, J.S. Cyp26 Enzymes Facilitate Second Heart Field Progenitor Addition and Maintenance of Ventricular Integrity. PLoS Biol. 2016, 14, e2000504. [CrossRef] 
348. Waxman, J.S.; Keegan, B.R.; Roberts, R.W.; Poss, K.D.; Yelon, D. Hoxb5b acts downstream of retinoic acid signaling in the forelimb field to restrict heart field potential in zebrafish. Dev. Biol. 2008, 319, 482. [CrossRef]

349. Waxman, J.S.; Yelon, D. Increased Hox activity mimics the teratogenic effects of excess retinoic acid signaling. Dev. Dyn. 2009, 238, 1207-1213. [CrossRef] [PubMed]

350. D'Aniello, E.; Rydeen, A.B.; Anderson, J.L.; Mandal, A.; Waxman, J.S. Depletion of Retinoic Acid Receptors Initiates a Novel Positive Feedback Mechanism that Promotes Teratogenic Increases in Retinoic Acid. PLoS Genet. 2013, 9, e1003689. [CrossRef] [PubMed]

351. Zhang, Q.; Jiang, J.; Han, P.; Yuan, Q.; Zhang, J.; Zhang, X.; Xu, Y.; Cao, H.; Meng, Q.; Chen, L.; et al. Direct differentiation of atrial and ventricular myocytes from human embryonic stem cells by alternating retinoid signals. Cell Res. 2010, 21, 579. [CrossRef]

352. Devalla, H.D.; Schwach, V.; Ford, J.W.; Milnes, J.T.; El-Haou, S.; Jackson, C.; Gkatzis, K.; Elliott, D.A.; Lopes, S.M.C.D.; Mummery, C.L.; et al. Atrial-like cardiomyocytes from human pluripotent stem cells are a robust preclinical model for assessing atrial-selective pharmacology. EMBO Mol. Med. 2015, 7, 394-410. [CrossRef]

353. Lee, J.H.; Protze, S.I.; Laksman, Z.; Backx, P.H.; Keller, G.M. Human Pluripotent Stem Cell-Derived Atrial and Ventricular Cardiomyocytes Develop from Distinct Mesoderm Populations. Cell Stem Cell 2017, 21, 179-194. [CrossRef]

354. Perl, E.; Waxman, J.S. Reiterative Mechanisms of Retinoic Acid Signaling during Vertebrate Heart Development. J. Dev. Biol. 2019, 7, 11. [CrossRef]

355. Kinkel, M.D.; Eames, S.C.; Alonzo, M.R.; Prince, V.E. Cdx4 is required in the endoderm to localize the pancreas and limit $\beta$-cell number. Development 2008, 135, 919-929. [CrossRef]

356. Naylor, R.W.; Skvarca, L.B.; Thisse, C.; Thisse, B.; Hukriede, N.A.; Davidson, A.J. BMP and retinoic acid regulate anterior-posterior patterning of the non-axial mesoderm across the dorsal-ventral axis. Nat. Commun. 2016, 7, 12197. [CrossRef]

357. Wingert, R.A.; Selleck, R.; Yu, J.; Song, H.-D.; Chen, Z.; Song, A.; Zhou, Y.; Thisse, B.; Thisse, C.; McMahon, A.P.; et al. The cdx Genes and Retinoic Acid Control. the Positioning and Segmentation of the Zebrafish Pronephros. PLoS Genet. 2007, 3, e189. [CrossRef]

358. Brendolan, A.; Ferretti, E.; Salsi, V.; Moses, K.; Quaggin, S.; Blasi, F.; Cleary, M.L.; Selleri, L. A Pbx1-dependent genetic and transcriptional network regulates spleen ontogeny. Development 2005, 132, 3113-3126. [CrossRef] [PubMed]

359. Lenti, E.; Farinello, D.; Yokoyama, K.K.; Penkov, D.; Castagnaro, L.; Lavorgna, G.; Wuputra, K.; Sandell, L.L.; Tjaden, N.E.B.; Bernassola, F.; et al. Transcription factor TLX1 controls retinoic acid signaling to ensure spleen development. J. Clin. Investig. 2016, 126, 2452-2464. [CrossRef] [PubMed]

360. Bowles, J.; Secker, G.; Nguyen, C.; Kazenwadel, J.; Truong, V.; Frampton, E.; Curtis, C.; Skoczylas, R.; Davidson, T.L.; Miura, N.; et al. Control. of retinoid levels by CYP26B1 is important for lymphatic vascular development in the mouse embryo. Dev. Biol. 2014, 386, 25-33. [CrossRef] [PubMed]

361. Okano, J.; Lichti, U.; Mamiya, S.; Aronova, M.; Zhang, G.; Yuspa, S.H.; Hamada, H.; Sakai, Y.; Morasso, M.I. Increased retinoic acid levels through ablation of Cyp26b1 determine the processes of embryonic skin barrier formation and peridermal development. J. Cell Sci. 2012, 125, 1827-1836. [CrossRef] [PubMed]

362. Chanda, B.; Ditadi, A.; Iscove, N.N.; Keller, G. Retinoic Acid Signaling Is Essential for Embryonic Hematopoietic Stem Cell Development. Cell 2013, 155, 215-227. [CrossRef]

363. Ghiaur, G.; Yegnasubramanian, S.; Perkins, B.; Gucwa, J.L.; Gerber, J.M.; Jones, R.J. Regulation of human hematopoietic stem cell self-renewal by the microenvironment's control of retinoic acid signaling. Proc. Natl. Acad. Sci. USA 2013, 110, 16121-16126. [CrossRef] [PubMed]

364. Bowles, J.; Knight, D.; Smith, C.; Wilhelm, D.; Richman, J.; Mamiya, S.; Yashiro, K.; Chawengsaksophak, K.; Wilson, M.J.; Rossant, J.; et al. Retinoid Signaling Determines Germ Cell Fate in Mice. Science 2006, 312, 596-600. [CrossRef]

365. Koubova, J.; Menke, D.B.; Zhou, Q.; Capel, B.; Griswold, M.D.; Page, D.C. Retinoic acid regulates sex-specific timing of meiotic initiation in mice. Proc. Natl. Acad. Sci. USA 2006, 103, 2474-2479. [CrossRef]

366. Yadu, N.; Kumar, P.G. Retinoic acid signaling in regulation of meiosis during embryonic development in mice. Genesis 2019, 57, e23327. [CrossRef]

367. Saba, R.; Wu, Q.; Saga, Y. CYP26B1 promotes male germ cell differentiation by suppressing STRA8-dependent meiotic and STRA8-independent mitotic pathways. Dev. Biol. 2014, 389, 173-181. [CrossRef] 
368. Bowles, J.; Feng, C.-W.; Ineson, J.; Miles, K.; Spiller, C.M.; Harley, V.R.; Sinclair, A.H.; Koopman, P. Retinoic Acid Antagonizes Testis Development in Mice. Cell Rep. 2018, 24, 1330-1341. [CrossRef] [PubMed]

369. Blum, N.; Begemann, G. Retinoic acid signaling controls the formation, proliferation and survival of the blastema during adult zebrafish fin regeneration. Development 2012, 139, 107-116. [CrossRef] [PubMed]

370. Blum, N.; Begemann, G. The roles of endogenous retinoid signaling in organ and appendage regeneration. Cell. Mol. Life Sci. 2013, 70, 3907-3927. [CrossRef] [PubMed]

371. Blum, N.; Begemann, G. Osteoblast de- and redifferentiation are controlled by a dynamic response to retinoic acid during zebrafish fin regeneration. Development 2015, 142, 2894-2903. [CrossRef]

372. Lee, Y.; Hami, D.; de Val, S.; Kagermeier-Schenk, B.; Wills, A.A.; Black, B.L.; Weidinger, G.; Poss, K.D. Maintenance of blastemal proliferation by functionally diverse epidermis in regenerating zebrafish fins. Dev. Biol. 2009, 331, 270-280. [CrossRef]

373. Blum, N.; Begemann, G. Retinoic acid signaling spatially restricts osteoblasts and controls ray-interray organization during zebrafish fin regeneration. Development 2015, 142, 2888-2893. [CrossRef]

374. Thomas, A.G.; Henry, J.J. Retinoic acid regulation by CYP26 in vertebrate lens regeneration. Dev. Biol. 2014, 386, 291-301. [CrossRef]

375. Thomas, A.G.; Adil, M.T.; Henry, J.J. Understanding the basis of CYP26 mediated regulation of lens regeneration using ex vivo eye cultures and 4-oxo-RA. bioRxiv 2019, 631994. [CrossRef]

376. Rubbini, D.; Robert-Moreno, À.; Hoijman, E.; Alsina, B. Retinoic Acid Signaling Mediates Hair Cell Regeneration by Repressing p27kip and sox2 in Supporting Cells. J. Neurosci. 2015, 35, 15752-15766. [CrossRef]

377. Lee, L.M.Y.; Leung, C.-Y.; Tang, W.W.C.; Choi, H.-L.; Leung, Y.-C.; McCaffery, P.J.; Wang, C.-C.; Woolf, A.S.; Shum, A.S.W. A paradoxical teratogenic mechanism for retinoic acid. Proc. Natl. Acad. Sci. USA 2012, 109, 13668-13673. [CrossRef]

378. D'Aniello, E.; Waxman, J.S. Input overload: Contributions of retinoic acid signaling feedback mechanisms to heart development and teratogenesis. Dev. Dyn. 2015, 244, 513-523. [CrossRef] [PubMed]

379. Rydeen, A.; Voisin, N.; D’Aniello, E.; Ravisankar, P.; Devignes, C.-S.; Waxman, J.S. Excessive feedback of Cyp26a1 promotes cell non-autonomous loss of retinoic acid signaling. Dev. Biol. 2015, 405, 47-55. [CrossRef] [PubMed]

(C) 2020 by the author. Licensee MDPI, Basel, Switzerland. This article is an open access article distributed under the terms and conditions of the Creative Commons Attribution (CC BY) license (http://creativecommons.org/licenses/by/4.0/). 